\title{
Use of Solid Hydride Fuel for Improved LWR Core Designs
}

\author{
NERI Award No. DE-FG07-02SF22615
}

FINAL SUMMARY REPORT

\author{
Lead organization/PI \\ Ehud Greenspan \\ University of California \\ Department of Nuclear Engineering \\ Berkeley, CA 94720
}

Teaming organizations/PI

Neil Todreas

Massachusetts Institute of Technology

Department of Nuclear Engineering

\author{
Bojan Petrovic \\ Westinghouse Electric Company \\ Science \& Technology Department
}

April 30, 2006 


\title{
Participating Organizations and Researchers
}

\author{
E. Greenspan (PI), M. Fratoni, F. Ganda, F. Ginex, D. Olander and Z. Shayer \\ Department of Nuclear Engineering \\ University of California \\ Berkeley, CA 94720 \\ gehud@nuc.berkeley.edu
}
N. Todreas (co-PI), P. Diller, P. Ferroni, J. Malen, A. Romano, C. Shuffler and J. Trant
Department of Nuclear Engineering
Massachusetts Institute of Technology
Cambridge, MA 02139
todreas@mit.edu

B. Petrovic' (co-PI) and H. Garkisch

Westinghouse Electric Company

Science \& Technology Department

1344 Beulah Rd.

Pittsburgh, PA 15235-5083

petrovb@westinghouse.com 


\section{ACKNOWLEDGMENT}

This report is based upon work supported by the U S. Department of Energy under Award No. DE-FG07-02SF22615.

\section{DISCLAIMER}

Any opinions, findings, and conclusions or recommendations expressed in this material are those of the author(s) and do not necessarily reflect the views of the Department of Energy. 


\section{Table of Contents}

$\begin{array}{ll}\text { Preface } & 1\end{array}$

Executive summary 3

1. Introduction 6

1.1 Incentives for hydride fuel 6

$\begin{array}{ll}1.2 \text { Hydride fuels considered } & 8\end{array}$

$\begin{array}{lll}1.3 \text { Scope of work } & 11\end{array}$

2. PWR - design approaches and methodology 13

$\begin{array}{lll}2.1 & \text { Reference reactor } & 13\end{array}$

$\begin{array}{lll}2.2 & \text { Design approaches } & 13\end{array}$

$\begin{array}{lll}2.3 & \text { Design variables } & 14\end{array}$

$\begin{array}{lll}2.4 \text { Neutronics } & 15\end{array}$

$\begin{array}{ll}2.5 \text { Thermal-hydraulics } & 16\end{array}$

$\begin{array}{lll}2.6 & \text { Fuel performance analysis } & 16\end{array}$

$\begin{array}{lll}2.7 & \text { Vibration analysis } & 18\end{array}$

2.8 Accident and transient analysis 20

$\begin{array}{lll}2.9 & \text { Economic analysis } & 21\end{array}$

3. PWR - results for square lattice designs 25

$\begin{array}{lll}3.1 \text { Neutronics } & 25\end{array}$

3.2 Thermal hydraulics accounting for vibration and wear 28

3.3 Clad integrity 32

3.4 Transient analysis $\quad 32$

3.5 Economics 35

$\begin{array}{lll}3.6 & \text { Discussion } & 46\end{array}$

4. PWR - hexagonal lattice designs 49

4.1 Introduction 49

4.2 Methodology - general 50

4.3 Methodology - neutronics 51

4.4 Methodology - thermal-hydraulics 51

4.5 Methodology - vibrations 53 
4.6 Methodology - clad integrity 54

4.7 Methodology - economics 54

4.8 Results - steady-state $\quad 54$

4.9 Results - transient analysis $\quad 56$

4.10 Results - burnup-limits $\quad 57$

$\begin{array}{ll}4.11 \text { Results - economics } & 60\end{array}$

4.12 Discussion $\quad 62$

5. PWR - inverted geometry designs 64

$\begin{array}{lll}5.1 \text { Introduction } & 64\end{array}$

5.2 Methodology 65

$\begin{array}{lll}5.3 & \text { Results } & 66\end{array}$

$\begin{array}{lll}5.4 \text { Discussion } & 69\end{array}$

6. PWR - plutonium containing designs $\quad 70$

$\begin{array}{lll}6.1 \text { Introduction } & 70\end{array}$

$\begin{array}{lll}6.2 & \text { Methodology } & 73\end{array}$

$\begin{array}{lll}6.3 \text { Results } & 74\end{array}$

$\begin{array}{lll}6.4 & \text { Alternate hydride fuels } & 79\end{array}$

$\begin{array}{lll}6.5 & \text { Discussion } & 81\end{array}$

7. BWR - design approaches and methodology 83

$\begin{array}{lll}7.1 \text { Introduction } & 83\end{array}$

$\begin{array}{lll}7.2 & \text { Reference reactor } & 86\end{array}$

$\begin{array}{lll}7.3 & \text { Neutronics } & 87\end{array}$

$\begin{array}{lll}7.4 & \text { Thermal-hydraulics } & 89\end{array}$

8. BWR - results 92

$\begin{array}{lll}8.1 \text { Neutronics } & 92\end{array}$

8.2 Thermal-hydraulics 96

$\begin{array}{lll}8.3 \text { Discussion } & 99\end{array}$

$\begin{array}{ll}\text { 9. Summary and recommendations } & 102\end{array}$

$\begin{array}{ll}\text { References } & 108\end{array}$

Appendix I - Papers for special issue of Nuclear Engineering \& Design 111

$\begin{array}{ll}\text { Appendix II - Conference papers } & 112\end{array}$ 


\section{PREFACE}

Summarized in this report is the DOE NERI program sponsored project NERI 02189 entitled "Use of Solid Hydride Fuel for Improved Long-Life LWR Core Designs" that lasted from September 15, 2002 through January 31, 2006. Collaborating on this project were the University of California at Berkeley Nuclear Engineering Department $(\mathrm{UCB})$ - in charge of overall project management (E. Greenspan - PI), neutronics (E. Greenspan) and material compatibility analysis (D. Olander - co-PI); Massachusetts Institute of Technology Nuclear Engineering Department (MIT) - in charge of ThermalHydraulics (T-H), safety, vibration and economic analysis (N. Todreas - co PI); and Westinghouse Electric Company Science \& Technology Division (W) - in charge of establishing data base, defining constraints and providing sanity checks (B. Petrovic - co PI).

A more comprehensive summary of the work performed under this DOE contract will be provided in a special issue of Nuclear Engineering and Design under preparation that will include eleven or twelve papers. The list of planned papers is given in Appendix I. Following a project overview paper (Greenspan et al., 2007), the scope of which will be similar to this summary, there will be a paper that describes the hydride fuels under consideration, reviews the experience accumulated with hydride fuel, summarizes their physical properties, defines their design constraints and discusses compatibility issues in LWR environment (Olander et al., 2007). The following five papers are related to hydride fueled PWR designs (Ganda et al., 2007a; Shuffler et al., 2007a; Diller et al., 2007; Romano et al., 2007; Shuffler et al.,2007b). Three design approaches were studied conventional square lattice fuel assemblies with grid-spacers support (Shuffler et al., 
2007a), hexagonal lattice fuel assemblies with wire-wrap support (Diller et al., 2007), and "inverted fuel" design in which the fuel assemblies are made of hexagonal prisms of hydride fuel that are penetrated by vertical coolant channels (Shuffler et al., 2007a). Only preliminary feasibility study is performed for the latter design approach. The next three papers are devoted to BWR designs (Fratoni et al., 2007; Ferroni et al., 2007; Ganda et al., 2007b). Only square lattice with grid spacers support are considered. The eleventh paper describes a preliminary study that compares the plutonium recycling ability of PWR designed with hydride fuel versus MOX (Ganda and Greenspan, 2007c). The last paper in this series summarizes optimal PWR and BWR core designs that use oxide fuel identified in this project (Todreas et al., 2007). Although the project focused on hydride fuel, it first searched for optimal oxide fuel using the same methodology developed to search for optimal hydride fuel core designs, so as to enable a consistent and fair comparison.

It is planned to submit all the 11 or 12 papers to the journal in the Fall of 2006. The special issue is likely to be published in 2007 and will provide a most comprehensive summary of the work done under this NERI project 


\section{EXECUTIVE SUMMARY}

The primary objective of this project was to assess the feasibility of improving the performance of PWR and BWR cores by using solid hydride fuels instead of the commonly used oxide fuel. The primary measure of performance considered is the busbar cost of electricity (COE). Additional performance measures considered are safety, fuel bundle design simplicity - in particular for BWR's, and plutonium incineration capability.

It was found that hydride fuel can safely operate in PWR's and BWR's without restricting the linear heat generation rate of these reactors relative to that attainable with oxide fuel. A couple of promising applications of hydride fuel in PWR's and BWR's were identified: (1) Eliminating dedicated water moderator volumes in BWR cores thus enabling to significantly increase the cooled fuel rods surface area as well as the coolant flow cross section area in a given volume fuel bundle while significantly reducing the heterogeneity of BWR fuel bundles thus achieving flatter pin-by-pin power distribution. The net result is a possibility to significantly increase the core power density - on the order of $30 \%$ and, possibly, more, while greatly simplifying the fuel bundle design. Implementation of the above modifications is, though, not straightforward; it requires a design of completely different control system that could probably be implemented only in newly designed plants. It also requires increasing the coolant pressure drop across the core. (2) Recycling plutonium in PWR's more effectively than is possible with oxide fuel by virtue of a couple of unique features of hydride fuel - reduced inventory of ${ }^{238} \mathrm{U}$ and increased inventory of hydrogen. As a result, the hydride fuelled core achieves nearly double the average discharge burnup and the fraction of the loaded Pu it incinerates in 
one pass is double that of the MOX fuel. The fissile fraction of the Pu in the discharged hydride fuel is only $\sim 2 / 3$ that of the MOX fuel and the discharged hydride fuel is more proliferation resistant. Preliminary feasibility assessment indicates that by replacing some of the $\mathrm{ZrH}_{1.6}$ by $\mathrm{ThH}_{2}$ it will be possible to further improve the plutonium incineration capability of PWR's. Other possibly promising applications of hydride fuel were identified but not evaluated in this work.

A number of promising oxide fueled PWR core designs were also found as spin-offs of this study: (1) The optimal oxide fueled PWR core design features smaller fuel rod diameter of $6.5 \mathrm{~mm}$ and a larger P/D ratio of 1.39 than presently practiced by industry $9.5 \mathrm{~mm}$ and 1.326 . This optimal design can provide a $30 \%$ increase in the power density and a $24 \%$ reduction in the cost of electricity (COE) provided the PWR could be designed to have the coolant pressure drop across the core increased from the reference 29 psia to 60 psia. (2) Using wire wrapped oxide fuel rods in hexagonal fuel assemblies it is possible to design PWR cores to operate at 54\% higher power density than the reference PWR design that uses grid spacers and a square lattice, provided 60 psia coolant pressure drop across the core could be accommodated. Uprating existing PWR's to use such cores could result in $40 \%$ reduction in the COE. The optimal lattice geometry is $\mathrm{D}=8.08 \mathrm{~mm}$ and $\mathrm{P} / \mathrm{D}=1.41$. The most notable advantages of wire wraps over grid spacers are their significant lower pressure drop, higher critical heat flux and improved vibrations characteristics.

U- $\mathrm{ZrH}_{1.6}$ fueled PWR cores were found to have positive coolant temperature coefficient of reactivity in the $\mathrm{D}-\mathrm{P}$ design range offering peak power. Three approaches that can turn over the CTC to be negative were identified: (a) Use of erbium burnable 
poison; (b) Replacement of some of the $\mathrm{ZrH}_{1.6}$ by $\mathrm{ThH}_{2}$; (c) Using plutonium rather than enriched uranium as the primary fissile material. Of the three, use of erbium is the least desirable as it penalizes the attainable discharge burnup, even if the erbium is enriched with the isotope ${ }^{167} \mathrm{Er}$. Replacement of some of the $\mathrm{Zr}$ hydride by Th hydride can, actually, somewhat increase the attainable discharge burnup. The use of plutonium is also effective but is practical only when Pu recycling is desirable.

The BOL prompt reactivity feedback due to fuel temperature increase is more negative when using $\mathrm{U}-\mathrm{ZrH}_{1.6}$ fuel than when using $\mathrm{UO}_{2}$ fuel due to a unique feature of hydride fuel - spectrum hardening due to fuel hydrogen temperature increase. This prompt spectrum hardening effect is superimposed on and enhances the Doppler effect. However, the EOL prompt reactivity feedback is not as negative as is the BOL feedback because of the buildup of ${ }^{239} \mathrm{Pu}$. The void reactivity feedback of hydride fueled BWR fuel assemblies is not as negative with hydride fuel as it is with oxide fuel. This is expected to have stability and safety benefits but the quantification of these benefits was out of the scope of this work.

Material compatibility issues could not be addressed in this work. The most important of these issues are the compatibility of hydride fuel with PWR and BWR coolants and clad. It is crucial to address these issues before a sound conclusion could be drawn on the desirability of developing hydride fuel for commercial LWR's. The conclusions of the design feasibility assessment reported in this set of papers justifies embarking upon an experimental investigation of material compatibility. 


\section{Introduction}

\subsection{Incentives for hydride fuel}

The general objective of this project was to assess the feasibility of improving the performance of PWR and BWR cores by using solid hydride fuels instead of the commonly used oxide fuel. The primary measure of performance considered is the busbar cost of electricity (COE). Other important performance measures are safety, fuel bundle design simplicity - in particular for BWR's, and plutonium incineration capability.

The primary hydride fuel considered is TRIGA type $\mathrm{U}-\mathrm{ZrH}_{1.6}$ fuel having $45 \mathrm{wt} \% \mathrm{U}$. Properties of this fuel and its compatibility with LWR's are briefly discussed in the following section and elaborated upon in a companion paper in this special issue (Olander et al., 2007). The concentration of hydrogen in the hydride fuel is comparable to that of hydrogen in the liquid water of LWR cores. The introduction of part of the hydrogen needed for neutron moderation within the fuel volume permits attainment of optimal neutron spectrum while using smaller water volume. This feature may enable the core to be designed to have optimal moderation, in terms of the attainable discharge burnup, and to have a higher power density than a LWR core that uses oxide fuel. This feature of hydride fuel could be of particular benefit to BWR's as it may enable to eliminate the water rods, partial length fuel rods and water channels by providing a relatively large hydrogen inventory in the core that is fixed and independent of the boiling conditions. Thus it is expected that hydride BWR fuel bundles could be designed to be significantly less heterogeneous and to have a significantly higher power density than oxide fueled bundles. The higher hydrogen concentration per unit core volume may 
also be of significant benefit for both BWR's and PWR's that are to be designed to incinerate plutonium and, possibly, minor actinides (MA).

Hydride fueled cores may be safer than oxide fueled cores by virtue of three unique features: smaller cold zero power to hot full power reactivity deficiency that may reduce power oscillations in BWR's, a prompt negative fuel temperature reactivity feedback mechanism and a delayed negative fuel temperature reactivity feedback mechanism. The prompt feedback is due to the reactivity effect of spectrum hardening induced by fuel hydrogen temperature increase that enhances thermal neutron upscattering. It is this negative reactivity feedback that enables operating TRIGA reactors in a pulsed power mode. The other reactivity feedback is due to hydrogen migration out from the fuel into the fuel rod gas plenum. This phenomenon is caused by fuel temperature increase. As the core is designed to be somewhat under-moderated, hydrogen release from the fuel has a negative reactivity feedback effect. This is a delayed effect. Hydrogen exchange between the gas phase and the solid hydride is a reversible process - upon cooling the hydrogen diffuses back and is absorbed in the fuel. As this process is very slow as compared with the delayed neutrons decay time, there will be no difficulty to compensate for the positive reactivity effect of hydrogen concentration increase in the fuel.

Whereas the uranium concentration in $\mathrm{U}-\mathrm{ZrH}_{1.6}$ fuel is only $\sim 45 \%$ that in uranium dioxide fuel, thorium hydride fuel, one of the hydride materials that are being considered (Olander et al., 2007), has a higher heavy metal (HM) density than oxide fuel. As a result of this higher HM concentration and larger fuel-to-water volume ratio, cores loaded with thorium hydride based fuel may be designed to have a higher energy generation per core loading and longer core life than the corresponding oxide fueled cores. 


\subsection{Hydride fuels considered}

The primary hydride fuel considering in this project is uranium-zirconium hydride similar to that developed by General Atomics (GA) for TRIGA reactors (Simnad, 1981). The U-Zr hydride composition used for the TRIGA fuel has, typically, 1.6 hydrogen atoms per $\mathrm{Zr}$ atom, i.e., it is $\mathrm{U}-\mathrm{ZrH}_{1.6}$. The Medium Enriched Uranium (MEU) fuel developed by General Atomics for TRIGA reactors contains $45 \mathrm{w} / \mathrm{o}$ uranium of up to $20 \mathrm{w} / \mathrm{o}$ ${ }^{235} \mathrm{U}$ (Simnad, 1981). This corresponds to $\mathrm{U} / \mathrm{Zr}$ atom ratio of 0.31 . The $\mathrm{U}-\mathrm{Zr}$ hydride fuel considered throughout this project has the same elemental composition. The uranium enrichment is a design variable. This fuel has been in use for more than 40 years in many reactors around the world both in constant power and pulsed power operating conditions. It has an impressive record of safety.

The design limits set for the high power TRIGA core (Iorgulis et al., 1998) are fuel temperatures of $750^{\circ} \mathrm{C}$ at steady-state and $1050^{\circ} \mathrm{C}$ under transients. Although these temperatures are significantly lower than the maximum permissible operating temperatures of $\mathrm{UO}_{2}$ fuel, the thermal conductivity of hydride fuel is $\sim 5$ times higher than that of oxide fuel. Consequently, $\mathrm{U}-\mathrm{ZrH}_{1.6}$ fuel can safely operate at linear heat rates that even exceed those of commercial LWR. TRIGA fuel burnup also significantly exceeds typical LWR oxide fuel burnup.

In high power TRIGA reactor (Iorgulis et al., 1998) the fuel-average linear heat generation rate (LHGR) is $37 \mathrm{~kW} / \mathrm{m}$ while the peak LHR is $74 \mathrm{~kW} / \mathrm{m}$. The corresponding peak steady-state fuel temperature is $550^{\circ} \mathrm{C}$. For comparison, the average LHGR of oxide fueled PWR is $19 \mathrm{~kW} / \mathrm{m}$. The TRIGA fuel discharge burnup is $\sim 120 \mathrm{GWD} / \mathrm{tHM}$ versus $<60 \mathrm{GWD} / \mathrm{tHM}$ of oxide fuel in PWR. The specific power of the TRIGA fuel is 76 
$\mathrm{W} / \mathrm{gHM}$ versus $\sim 36 \mathrm{~W} / \mathrm{gHM}$ of the PWR. The water in TRIGA reactors is at a significantly lower temperature than in LWR's. Hence, the LHGR hydride fuel could operate at in a PWR is significantly lower than in the TRIGA reactor. Nevertheless, careful analyses performed in this study established that $\mathrm{U}-\mathrm{ZrH}_{1.6}$ fuel can safely operate in both PWR and BWR cores at as high a LHGR as attainable with oxide fuel.

Relative to uranium dioxide fuel, $\mathrm{U}-\mathrm{ZrH}_{1.6}$ fuel has a number of possible drawbacks:

(a) The nominal specific density of $\mathrm{U}-\mathrm{ZrH}_{1.6}$ at room temperature is $8.256 \mathrm{~g} / \mathrm{cm}^{3}$ and the maximum practical $\mathrm{U}$ weight $\%$ is 45 . This makes the atomic density of uranium in $\mathrm{U}-\mathrm{ZrH}_{1.6}$ only about $40 \%$ that in $\mathrm{UO}_{2}$ fuel. For $\mathrm{Pu}$ and MA recycling, though, the relatively low $\mathrm{U}$ loading is likely to be an asset rather than a disadvantage - it reduces the inventory of $\mathrm{Pu}$ that needs to be loaded per core and increases the fraction of the $\mathrm{Pu}$ that is consumed in one cycle (Ganda et al., 2007c). Moreover, the nominal density of a U$\mathrm{ThH}_{2}$ fuel having $25 \mathrm{w} / \mathrm{O}$ is $10.865 \mathrm{~g} / \mathrm{cm}^{3}$ making the $\mathrm{HM}$ density in Th-hydride fuel nearly $12 \%$ higher than the $\mathrm{U}$ density in $\mathrm{UO}_{2}$ ! This might enable increasing the PWR cycle length beyond that attainable using oxide fuel using same loading of fissile material.

(b) Zircaloy may not be a compatible clad material for hydride fuel, as the hydrogen of the fuel may hydride it. Nevertheless, half-a- dozen of approaches have been proposed for protecting the Zy clad using a hydrogen permeation barrier (Olander et al., 2007) including the following: (i) Form a thin oxide layer $(\sim 40 \mu \mathrm{m})$ over the hydride fuel pellets; it may retain the hydrogen up to $800^{\circ} \mathrm{C}$ and will probably avoid fuel-cladding chemical reaction. (ii) Fill the fuel-clad gap with a liquid metal. In addition to providing a hydrogen permeation barrier, the LM will significantly reduce the gap-resistance to heat 
transfer and will enable to accommodate significant pellet swelling with burnup without

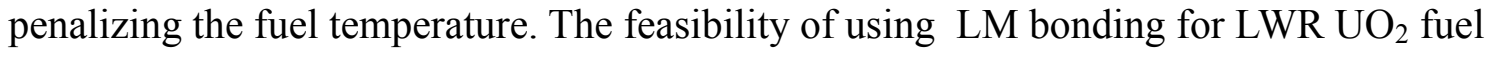
so as to improve the heat transfer from the fuel to the clad and thus reduce the peak fuel temperature, delay onset of fission gas release, avoids PCI and prevents Zy clad secondary hydriding due to clad failure has recently been established by Olander et al. (2007). The $\mathrm{LM}$ is a low melting temperature $\left(\sim 120^{\circ} \mathrm{C}\right)$ alloy of $\mathrm{Pb}, \mathrm{Sn}$ and $\mathrm{Bi}$ at 33 weight $\%$ each.

The feasibility of such barriers needs to be carefully studied. The "default" approach is to use SS clad. Experiments done at General Atomics with hydride fuel proved that (Simnad, 1981) "high-temperature strength and ductility of the stainless steel or Alloy 800 fuel cladding provides total clad integrity at temperatures as high as $950^{\circ} \mathrm{C} "$ Whereas for low enrichment uranium fuel use of SS clad will significantly penalize the neutron economy relative the $\mathrm{Zy}$ clad, the penalty for Pu bearing fuel is smaller, due to the higher absorption cross section of $\mathrm{Pu}$.

(c) If, due to a very severe accident, the hydride fuel temperature will significantly exceed $1000^{\circ} \mathrm{C}$ for a prolonged period of time, hydrogen could diffuse out from the fuel into the fission gas plenum. If the gas pressure buildup will be excessive, it may pose a safety hazard. Assessment of this hazard and its probability need yet to be performed.

(d) Hydride fuel may not be compatible with water coolant at PWR and/or BWR operating conditions. Experiments performed at GA showed that there was no chemical reaction when a very hot $\left(1200^{\circ} \mathrm{C}\right)$ pellet of $\mathrm{U}-\mathrm{ZrH}_{1.6}$ was dropped into a container of water. A safety concern may be steam - fuel interaction in case of a breach in the clad. Based on the experience with TRIGA fuel, steam -fuel interaction is not likely to be of 
safety concern. Nevertheless, due to the higher operating temperatures and pressures of LWR's, there may be a compatibility issue.

Several types of hydride fuels have been considered for this study in addition to U$\mathrm{ZrH}_{1.6}$; they are members of a family of a composite hydride fuel that can be denoted as $\mathrm{U}-\left(\mathrm{Th}_{\mathrm{n}} \mathrm{Pu}_{\mathrm{m}} \mathrm{Zr}_{\mathrm{j}}\right) \mathrm{H}_{\mathrm{x}}$; the subscripts $\mathrm{n}, \mathrm{m}$, and $\mathrm{j}$ are the atomic proportions of the metals with respect to uranium whereas the subscript $\mathrm{x}$ denotes the atomic ratio of $\mathrm{H}$ to the total metals excluding the $\mathrm{U}$. The uranium forms a separate metallic phase because its hydride $\left(\mathrm{UH}_{3}\right)$ is unstable at the reactor operating temperatures. The other constituents make a mixed-metal hydride $\left(\mathrm{Th}_{\mathrm{n}} \mathrm{Pu}_{\mathrm{m}} \mathrm{Zr}_{\mathrm{j}}\right) \mathrm{H}_{\mathrm{x}}$. The hydrogen density in these fuels is comparable to that in the water of PWR. Even though the experience with and data-base for thorium hydride and plutonium hydride fuels is small as compared with that of zirconium hydride fuel, these fuels are expected perform comparably, if not superior to $\mathrm{ZrH}_{1.6}$ fuel. According to Simnad (1986a), the developer of the $\mathrm{U}_{-} \mathrm{ZrH}_{1.6}$ TRIGA fuel, $\mathrm{U}-\mathrm{ThH}_{2}$ is even more stable than $\mathrm{U}-\mathrm{ZrH}_{1.6}$ fuel and can operate at higher temperatures. Plutonium also forms a very stable hydride; the equilibrium hydrogen pressure is 1 atm at $883^{\circ} \mathrm{C}$ for $\mathrm{ThH}_{2}, 810^{\circ} \mathrm{C}$ for $\mathrm{ZrH}_{1.6}$, and about $870^{\circ} \mathrm{C}$ for $\mathrm{PuH}_{2}$ (Simnad, 1986a).

\subsection{Scope of Work}

The economic analysis requires the following core performance characteristics as input: power level, average discharge fuel burnup and heavy metal loading. The power level depends on thermal-hydraulic design constraints. The discharge burnup depends on neutronic design constraints as well as on fuel rod clad integrity design constraints. Safety related design constraints further limit the acceptable power levels. As a result, a parametric study was performed in five disciplines the results from which were fed into 
the economic analysis - neutronics, thermal-hydraulics, clad integrity, fuel rod vibration and thermal transient analyses.

The assessment of the compatibility of $\mathrm{U}-\mathrm{ZrH}_{1.6}$ fuel with water and with zircaloy clad at typical LWR operating conditions was to supplement the design optimization studies. The plan was to use TRIGA fuel pellets for these experimental feasibility studies. Unfortunately, we were not able to acquire TRIGA fuel and the material compatibility study had been deferred. Instead we undertook an analytical evaluation of hydrogen redistribution in hydride fuel due to temperature and stress gradients, and a numerical evaluation of fuel rod performance analysis; both analyses were not included in the originally planned scope of work. 


\section{PWR - design approaches and methodology}

\subsection{Reference reactor}

The reference PWR core is defined based on the South Texas Project Electric Generating Station (STPEGS). Selected design and performance parameters of this reactor are summarized in Table 2.1 (Nine Mile Point Unit 2 USAR, 2004).

Table 2.1

Selected design and performance parameters of the reference PWR

\begin{tabular}{ll}
\hline Parameter & Value \\
\hline Effective core radius & $\sim 1.83 \mathrm{~m}(72 ”)$ \\
Active fuel length & $4.26 \mathrm{~m}(168 ”)$ \\
Fission gas plenum length & $17.8 \mathrm{~cm}(7 ”)$ \\
Clad outer diameter, $D$ & $9.5 \mathrm{~mm}$ \\
Square lattice pitch, $P$ & $12.6 \mathrm{~mm}$ \\
Pitch-to-diameter ratio & 1.326 \\
Number fuel rods per core & 50956 \\
\hline Core enthalpy rise & $204 \mathrm{~kJ} / \mathrm{kg}$ \\
Inlet temperature & $294 \mathrm{C}$ \\
System pressure & $2250 \mathrm{psia}$ \\
Radial peaking factor & 1.65 \\
Axial peaking factor & 1.55 \\
Power level & $3800 \mathrm{MWt}$ \\
Average linear heat rate & $174 \mathrm{~W} / \mathrm{cm}$ \\
Average power density & $99.85 \mathrm{~kW} / \mathrm{l}$ \\
Average specific power & $38.38 \mathrm{~W} / \mathrm{gU}$ \\
Average discharge burnup & $45.6 \mathrm{GWD} / \mathrm{t}$ \\
\hline
\end{tabular}

* Parameters in Italics are variables of this study. The other parameters are fixed.

\subsection{Design approaches}

Six different PWR design approaches have been considered:

- Uranium oxide fuel using square lattice and grid spacers

- Uranium hydride fuel using square lattice and grid spacers

- Uranium hydride fuel using hexagonal lattice and wire wraps 
- Uranium hydride fuel having inverted geometry

- MOX fuel using square lattice and grid spacers

- Plutonium containing hydride fuel using square lattice and grid spacers

In the following 7 sections we'll briefly describe the methodology used for the first two design studies - uranium oxide and hydride fuelled PWR cores using a square lattice and grid spacers. Deviations from this methodology introduced in subsequent studies will be defined later.

\subsection{Design variables}

The primary design variables considered are the fuel rod outer clad diameter, D, and the lattice pitch-to-diameter ratio, $\mathrm{P} / \mathrm{D}$. The design space explored is $0.65 \mathrm{~cm} \leq \mathrm{D} \leq 1.5$ $\mathrm{cm}$ and $1.074 \leq \mathrm{P} / \mathrm{D} \leq 1.54$. Additional design variables considered include the uranium enrichment level $-5 \%, 7.5 \%$ and $10 \%$ as well as $12.5 \%$ for hydride fuel, and the coolant pressure drop in the core -29 psia, as of the reference PWR, or 60 psia - assumed attainable with future technology. The number and characteristics of grid spacers used is as of the STPEGS plant.

The uranium dioxide is assumed at $95.5 \%$ of its nominal density. The zircaloy clad and gap thickness are assumed to be the following functions of the clad outer diameter:

Oxide fuel:

- $\mathrm{D}<7.747 \mathrm{~mm}$, clad thickness, $\mathrm{t}=0.508 \mathrm{~mm}$ and gap thickness, $\delta=0.0635 \mathrm{~mm}$

- $\mathrm{D}>7.747 \mathrm{~mm}$,

$$
\text { o } \quad \mathrm{t}(\mathrm{mm})=0.508+(\mathrm{D}-7.747) * 0.0362
$$




$$
0 \quad \delta(\mathrm{mm})=0.0635+(\mathrm{D}-7.747) * 0.0108
$$

Hydride fuel has the same clad thickness as oxide fuel but its gap thickness is burnup dependent:

$$
\mathrm{O} \delta(\mathrm{mm})=0.5 *\left[(\mathrm{D}-2 \mathrm{t}) * 1.1548 \times 10^{-3} * \mathrm{BU}\right] /\left[10+1.1548 \times 10^{-3} * \mathrm{BU}\right] \geq 0.0762
$$

The $\mathrm{BU}$ is given in atom percent of actinides and zirconium, combined.

\subsection{Neutronics}

The objective of the neutronic analysis is to determine the average discharge burnup of the acceptable geometries. The acceptable geometries are the combination of $\mathrm{D}$ and $\mathrm{P}$ (or P/D) for which the following reactivity coefficients are negative over the cycle: Doppler, moderator temperature and void. In addition to D, P/D and uranium enrichment the design variables include the amount of Integral Fuel Burnable Absorber (IFBA) or other burnable poison. The boron concentration in the water is adjusted with burnup so as to compensate for the remaining excess reactivity.

A special algorithm was developed for predicting in a self-consistent way the discharge burnup and burnup-dependent reactivity coefficients corresponding to a 3 batch fuel management based on unit cell calculations. This algorithm (Ganda, 2005c and Ganda, 2007c), accounts for non-linear $\mathrm{k}_{\infty}$ variation with burnup and for the burnupdependent soluble boron concentration. It has been benchmarked and found reliable (Ganda, 2005c and 2005d). It is assumed that all three batches are operating at the same average power density and that, at any given moment in time during the cycle, the core average value of parameter $\mathrm{X}(\mathrm{t})$ is the arithmetic mean of its value for the three batches: i.e. $\left[X_{1}(t)+X_{2}(t)+X_{3}(t)\right] / 3$. 


\subsection{Thermal hydraulics}

The objective of the thermal-hydraulic analysis is to find the maximum power the core can be designed to operate at for each of the considered combinations of $\mathrm{D}$ and $\mathrm{P} / \mathrm{D}$, i.e., geometries, while meeting safety related design constraints. The design constraints considered are Minimum Departure from Nucleate Boiling Ratio (MDNBR) of 2.17, average/peak fuel temperature of $1400 / 2800^{\circ} \mathrm{C}$ for oxide fuel and $750 / 1050^{\circ} \mathrm{C}$ for hydride fuel, and either 29 psia or 60 psia coolant pressure drop across the core corresponding to , respectively, the reference core design or to an upgraded design expected to be practical in the near future (Shuffler, 2007a; Greenspan, 2005)

An MIT upgraded version of the VIPRE sub-channel analysis code was used for the thermal-hydraulic analysis. VIPRE predicts the velocity, pressure, temperature and thermal energy fields as well as MDNBR for interconnected flow channels. MATLAB scripts were developed to drive VIPRE to iteratively determine the maximum power attainable for a given geometry and to automatically scan the wide range of geometries under consideration (Malen et al., 2004a, 2004b; Shuffler et al., 2004, 2007a).

\subsection{Fuel performance analysis}

The objective of this analysis is to determine the burnup limit the clad can withstand without failure. If this limit is more restrictive (i.e., smaller) than the reactivity limited burnup predicted by the neutronic analysis, it is used in the economic analysis of this geometry.

The fuel performance analysis considered three fuel integrity impairing mechanisms (Romano et al., 2007): (a) Clad corrosion on the water side - the maximum tolerable 
oxidation thickness is assumed to be $0.1 \mathrm{~mm}$, independent of the fuel rod diameter. (b) Clad Strain - the limit is assumed to be $1 \%$, in tension; it includes both elastic and plastic contributions and is due to the external coolant pressure, differential thermal expansion between the fuel and the cladding, fuel swelling due to irradiation and buildup of fission gases. (c) clad internal pressure - the maximum acceptable internal gas pressure is assumed 2500 psia. Contributions to the gas pressure buildup accounted for are release of volatile fission products and helium produced by neutron absorption in ${ }^{10} \mathrm{~B}$ of the IFBA.

The FALCON and later the TRANSURANUS codes used for the fuel performance analysis simulate the thermal-physical properties of $\mathrm{UO}_{2}$ fuel pins under steady-state conditions. The following additional assumptions were required to apply these codes to analyze the performance of hydride fuel: (a) the internal pressure constraint was neglected due to the very low fraction of fission gas release by hydride fuel (Olander et al., 2007). (b) The thermal expansion properties of hydride fuels, that affect clad deformation and the limit on clad strain, were assumed to be identical to those of oxide fuel. Although the swelling rate of hydride fuel is expected to be more pronounced than that of oxide fuel, the liquid-metal bonding assumed in this study can accommodate this swelling without straining the clad and without impairing the gap thermal conductance. (c) Based on the above assumptions, the hydride fuel discharge burnup will be limited by the corrosion constraint. The simulation codes prediction of the attainable burnup pertain to a $\mathrm{HM}$ density of conventional $\mathrm{UO}_{2}$ fuel. Because the heavy metal density in $\mathrm{U}-\mathrm{ZrH}_{1.6}$ is 2.5 times lower than in $\mathrm{UO}_{2}$, for the same $\mathrm{D}$ and linear heat generation rate the residence time of $\mathrm{U}-\mathrm{ZrH}_{1.6}$ corresponding to a given burnup will be 2.5 times shorter than that of $\mathrm{UO}_{2}$ fuel. The fuel performance induced burnup limit for $\mathrm{U}-\mathrm{ZrH}_{1.6}$ fuel is 
therefore obtained by multiplying the simulation code burnup prediction without the internal pressure constraint by 2.5 . This ensures the residence time for both fuel types when the constraint is the clad corrosion.

For conservatism, the fuel is assumed to operate at the peak linear heat generation rate.

\subsection{Vibration analysis}

The objective of this analysis is to define constraints on the maximum attainable power due to flow-induced vibrations of the fuel rods. Three flow-induced vibration mechanisms were considered: fluid elastic instability, vortex shedding lock-in from vortex-induced vibration, and turbulence-induced vibration in cross and axial flows. In addition, two wear mechanisms were considered: sliding wear and fretting wear (Shuffler, 2004; Shuffler et al., 2007a). Table 2.2 summarizes the vibration, related along with the steady-state thermal hydraulic design constraints imposed.

Fluid-elastic instability and vortex shedding lock-in are large amplitude "resonance" type vibrations that must be avoided. Fluid-elastic instability occurs when the cross-flow velocity over a tube bundle reaches the critical velocity, which is a function of fuel rod and coolant properties. Vortex shedding lock-in occurs when the frequency of vortices shed by cross-flows over a rod coincides with its natural frequency. Limits were placed on the cross-flow velocities in the core, and therefore the core power, to preclude these two mechanisms. 
Table 2.2

Vibration related and steady-state thermal hydraulic design constraints

\begin{tabular}{|c|c|c|}
\hline Design Constraints For: & Constrained Parameters & Design Limit \\
\hline Vortex-Shedding Lock-in & $V_{S M} M_{\text {lift }}, V_{\text {drag }}^{(a)}$ & $>0.3$ \\
\hline Fluid-Elastic Instability & $F I M^{(b)}$ & $<1$ \\
\hline Fretting Wear & $\dot{W}_{\text {fretting,new }} / \dot{W}_{\text {fretting,ref }}{ }^{(\mathrm{c})}$ & $\leq T_{c, \text { ref }} / T_{c, \text { new }}{ }^{(\mathrm{d})}$ \\
\hline Sliding Wear & $\dot{W}_{\text {sliding,new }} / \dot{W}_{\text {sliding, ref }}$ & $\leq T_{c, \text { ref }} / T_{c, \text { new }}$ \\
\hline DNBR & MDNBR & $>2.17$ \\
\hline Pressure Drop & $\Delta \mathrm{P}_{\text {rod bundle }}$ & $<29$ psia, 60 psia \\
\hline Fuel Temperature & $\begin{array}{l}\mathrm{T}_{\text {centerline }}-\mathrm{UZrH}_{1.6} \\
\mathrm{~T}_{\text {average }}-\mathrm{UO}_{2}\end{array}$ & $\begin{array}{l}<750 \mathrm{C} \\
<1400 \mathrm{C} \\
\end{array}$ \\
\hline
\end{tabular}

Turbulence-induced vibration in cross and axial flow cause smaller, unavoidable vibrations responsible for gradual fretting and sliding wear at the contact surface between the fuel rod and its support. Sufficient wear resistance must therefore exist in the fuel assembly components to preclude excessive clad wear. The fretting and sliding wear rates were determined using the vibration amplitudes associated with the cross and axial flow distributions in the core. Sliding and fretting wear limits were then imposed to constrain the cumulative wear to the level of cumulative sliding and fretting wear in the reference core geometry. The cumulative wear depends on the residence time of fuel in the core, and therefore is a function of both core power and discharge burnup.

The outcome of this analysis is down rating of the core power, if necessary to avoid exceeding any of the vibration constraints. The fuel residence time in the core and, hence, fuel cycle length is adjusted so as to provide the maximum permissible discharge burnup dictated by neutronic and clad integrity analyses. 


\subsection{Accident and transient analysis}

The objective of the accident and transient analyses was to modify, if necessary, the value of the maximum achievable power derived from the steady-state thermal-hydraulic and vibration and wear analyses; the power level of a geometry that was considered by the economic analysis was the smallest of that from the steady state analysis and that from the accident and transient analyses.

Due to resource limitations, the safety analysis was limited to two accidents and one transient: (a) An overpower transient due to a control rod bank withdrawal at full power as defined in the STPEGS FSAR. The constraint considered is that departure from nucleate boiling (DNB) will not occur. (b) A large break loss of coolant accident. The constraint considered is the peak clad-temperature - not to exceed $2200^{\circ} \mathrm{F}\left(1204^{\circ} \mathrm{C}\right)$. (c) A complete loss of flow accident (LOFA). The constraint is that DNB will not occur. The design limits used for these analyses are summarized in Table 2.3.

Table 2.3

Constraints considered for the accident and transient analysis

\begin{tabular}{|l|c|l|}
\hline Transient & Constrained Parameter & \multicolumn{1}{c|}{ Design Limit } \\
\hline LOCA & Peak cladding temperature & $\begin{array}{l}\text { Peak clad temperature following a } \\
\text { LOCA for the reference core }\end{array}$ \\
\hline LOFA & MDNBR & $\begin{array}{l}\text { The MDNBR during coast down for the } \\
\text { reference core }\end{array}$ \\
\hline Overpower & MDNBR & $\begin{array}{l}\text { The MDNBR during an } 18 \% \text { overpower } \\
\text { transient for the reference core }\end{array}$ \\
\hline
\end{tabular}

The safety analysis was done with the VIPRE sub-channel analysis tool interfaced with MATLAB scripts previously developed to automate VIPRE execution. RELAP was also used for simulating LOFA. (Trant, 2004; Shuffler et al., 2007a) 


\subsection{Economic analysis}

The economic analysis integrates and weights the results obtained in all the analyses described in Sections 2.4 through 2.8. The objective of the economic analysis is to identify that combination of core design variables that offer the lowest cost of electricity (COE). The methodology used for the economic analysis was that laid out by Saccheri (2003); it is based on an OECD/NEA recommended methodology for evaluation of nuclear fuel cycle economics (OECD/NEA, 1994). Although the OECD/NEA cost data and lead times may be outdated, it should be adequate for a relative comparison of different designs. Following is a brief summary of the assumptions and unit cost data used.

Table 2.4 gives the unit cost assumptions used for the fuel cycle cost analysis of oxide fuel. It was further assumed that $50 \%$ of the total fuel assembly fabrication cost component depends on the number of fuel rods in the core; the other $50 \%$ depends on the heavy metal (HM) loading. This assumption is necessary because the number of fuel rods in the core varies significantly over the range of geometries examined by our study. An additional assumption is made for hydride fuel - its fabrication cost is identical to that of oxide fuel of the same diameter, despite of the fact that the hydride fuel contains only $\sim 40 \%$ of the HM inventory of the equal volume oxide fuel. That is, on per unit HM basis, the fabrication cost of hydride fuel is higher than that of oxide fuel. Likewise for spent fuel storage - Assuming that the storage cost is dominated by the availability of space in the spent fuel pools and dry cask storage, storage costs for hydride fuel is assumed identical to that for equivalent volume oxide fuel. 
Table 2.5 gives the recommended lead and lag times while Table 2.6 gives the HM loss fraction assumed for the different steps in the fuel cycle.

Table 2.4

PWR fuel cycle unit costs for $\mathrm{UO}_{2}$

\begin{tabular}{ll}
\hline Cost Component & Unit Price \\
\hline Mining/Ore & $\$ 41 / \mathrm{kg}_{\mathrm{HM}}$ \\
Conversion & $\$ 8 / \mathrm{kg}_{\mathrm{HM}}$ \\
Enrichment & $\$ 108 / \mathrm{kg}_{\mathrm{SWU}}$ \\
Fabrication & $\$ 275 / \mathrm{kg}_{\mathrm{HM}}$ \\
Spent Fuel Storage & $\$ 250 / \mathrm{kg}_{\mathrm{HM}}$ \\
Waste Disposal & $1 \mathrm{mill} / \mathrm{kWh}$ \\
\hline
\end{tabular}

Table 2.5

$\mathrm{OECD} / \mathrm{NEA}$ recommended lead and lag times for fuel cycle processes

\begin{tabular}{ll}
\hline Transaction & Value \\
\hline Fuel Fabrication & $1 \mathrm{yr}$ \\
Uranium Enrichment & $1.5 \mathrm{yr}$ \\
Uranium Conversion & $1.5 \mathrm{yr}$ \\
Uranium Ore Purchase & $2 \mathrm{yr}$ \\
Spent Fuel Storage & $-\mathrm{T}_{\mathrm{C}}{ }^{*}$ \\
\hline $\mathrm{T}_{\mathrm{c}}$ is the cycle length. A negative sign implies that \\
the storage costs need to be referred back in time to \\
the reference date.
\end{tabular}

Table 2.6

Mass loss fractions for front end fuel cycle processes

\begin{tabular}{ll}
\hline Mass Loss & Value \\
\hline Mining/Ore & 0 \\
Conversion & 0.005 \\
Enrichment & Varies \\
Fabrication & 0.01 \\
\hline
\end{tabular}

The unit costs assumed for the O\&M are summarized in Table 2.7. The outage time for the reference plant is assumed to be 20 days and to consist of 13 days for refuelling and 7 days for maintenance. The latter is scaled with the cycle length so as to preserve the total annual maintenance days devoted to critical-path non-refueling activities at shutdown. Table 2.8 gives a number of fixed performance parameters. 20 years of 
additional plant life is assumed based on current NRC license extensions for existing LWR's.

Table 2.7

Assumed PWR operations and maintenance variable and fixed components

\begin{tabular}{ll}
\hline Variable & \\
\hline $\begin{array}{l}\text { Refueling Outage } \\
\text { Forced Outage }\end{array}$ & $\$ 800,000 /$ day \\
Replacement & 30 mills/kWh \\
\hline Fixed & \\
\hline Personnel & $\$ 150,000 /$ person- \\
Number & 600 \\
Refueling Outage & 20 days/cycle \\
Forced Outage & $1 \%$ \\
Availability & $99 \%$ \\
\hline
\end{tabular}

Table 2.8

Fixed plant operating parameters

\begin{tabular}{ll}
\hline Parameter & Value \\
\hline Thermal Efficiency & 0.33 \\
Number of Batches & 3 \\
Plant Life Extension & $20 \mathrm{yrs}$ \\
\hline
\end{tabular}

Two scenarios were considered. (1) A "minor backfit" - the reference core layout is maintained . Replacement of the steam generators and modifications to the high-pressure turbine are required to accommodate designs offering higher power than the reference core. Thus, the capital cost investment for minor backfits includes the costs to replace the steam generators and upgrade the turbine units if the new geometries offer increased power; it is assumed that the turbine has untapped capacity that can be exploited. Coolant pumps will also require upgrades, but their contribution to the capital investment is relatively small and so will not be considered (2) A "major backfit" - resulting from significant changes to the layout of fuel assemblies and control rods in the core in addition to significant power uprates. This mandates that in addition to steam generator 
replacement and turbine upgrades, the vessel head and core internals need be replaced. Coolant pumps will also require upgrades but will have a small relative contribution to the capital cost. Table 2.9 gives the assumed cost components and their scaling with the power ratios.

Table 2.9

Cost estimates for installed nuclear components

\begin{tabular}{lll}
\hline Cost Component & $\begin{array}{l}\text { Price } \\
\left(\$ 10^{6}\right)\end{array}$ & $\begin{array}{l}\text { Scaling } \\
\text { Factor }\end{array}$ \\
\hline Steam Generators & 100 & 0.6 \\
Vessel Head & 25 & - \\
Core Internals & 25 & - \\
Turbine Generator & 338 & 0.8 \\
Existing Fuel Value & 67 & - \\
\hline
\end{tabular}

The above assumptions, while acceptable for modest power uprates in the $0-15 \%$ range consistent with the current PWR experience of industry, may not be fully adequate for larger uprates that our analysis indicates are technically feasible. Extra costs not accounted for in this analysis include replacement power during the extended outage for large uprate projects. 


\section{PWR - results for square lattice designs}

\subsection{Neutronics}

Figures 3.1 gives the attainable burnup over the design space for $5 \%$ enriched $\mathrm{UO}_{2}$ cores without accounting for reactivity feedback related constraints while Figure 3.2 gives the reactivity constrained attainable burnup. What restricts the acceptable range of geometries is, primarily, the coolant temperature coefficient (CTC) of reactivity. The cores considered in Figure 3.2 contains IFBA $-0.2 \mathrm{D} / \mathrm{D}_{\text {ref }} \mathrm{mg} / \mathrm{cm}{ }^{10} \mathrm{~B}$ where $\mathrm{D}_{\text {ref }}$ is 0.95 $\mathrm{cm}$, and use soluble boron to compensate for the rest of the excess reactivity. Geometries exceeding $\mathrm{P} / \mathrm{D}$ of $\sim 1.4$ at large $\mathrm{D}$ and exceeding $\mathrm{P} / \mathrm{D} \sim 1.5$ at small $\mathrm{D}$ have positive $\mathrm{CTC}$ and are unacceptable.

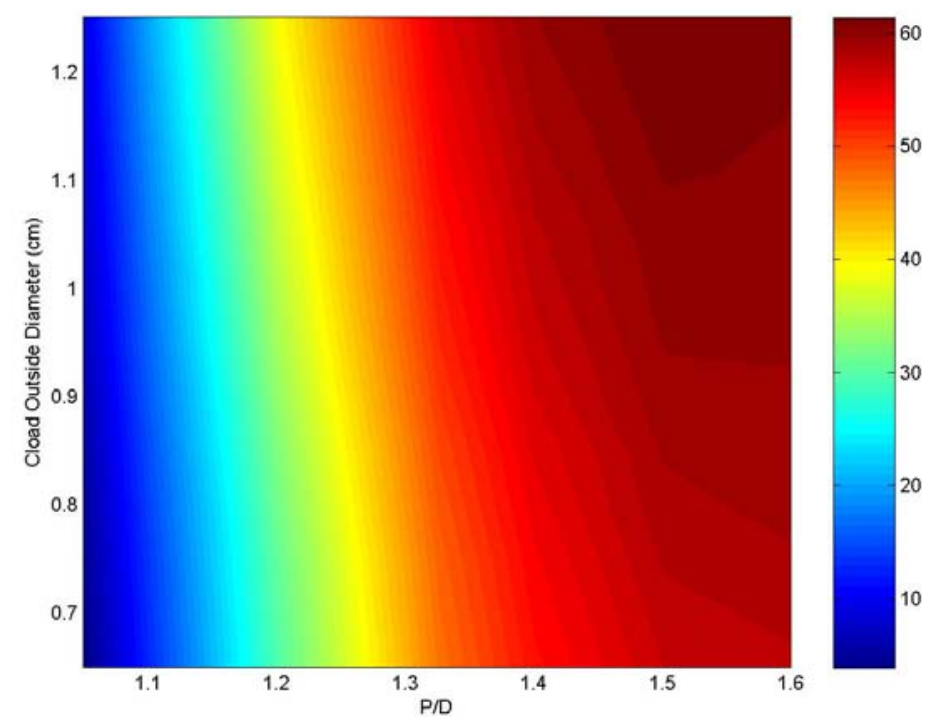

Figure 3.1 Attainable burnup in $\mathrm{GWD} / \mathrm{tHM}$ with 5\% enriched $\mathrm{UO}_{2}$; no reactivity constraints 


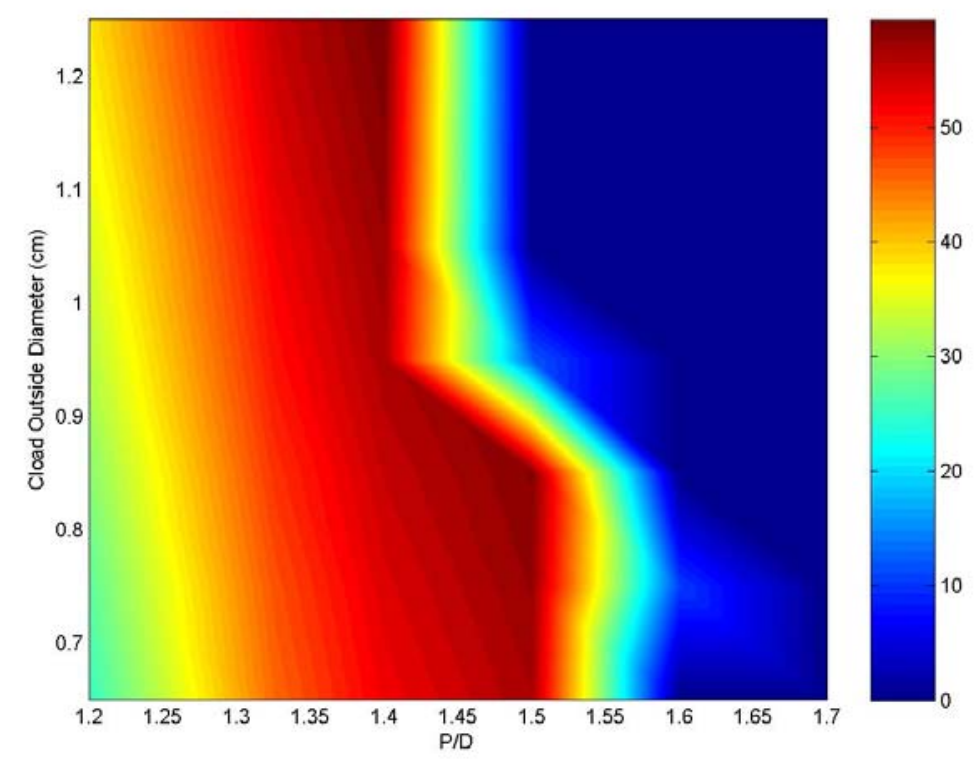

Figure 3.2 Attainable burnup in GWD/tHM with $5 \%$ enriched $\mathrm{UO}_{2}$ accounting for reactivity constraints. Amount of IFBA used is $0.2 \mathrm{D} / \mathrm{D}_{\text {ref }} \mathrm{mg}^{10} \mathrm{~B} / \mathrm{cm}$ where $\mathrm{D}_{\text {ref }}$ is 0.95 . Soluble boron compensates for rest of excess reactivity.

Figures 3.3 and 3.4 give the discharge burnup attainable from a 3-batch core fuelled with $\mathrm{U}-\mathrm{ZrH}_{1.6}$ having, respectively, $5 \%$ and $12.5 \%$ enriched uranium. The discharge burnup values displayed in these figures were calculated without accounting for neither reactivity constraints nor burnable poison and soluble boron. Detailed study of hydride fuel light water lattices (Ganda et al., 2007a) concluded that by replacing on the order of $10 \%$ of the zirconium hydride by thorium hydride and adding IFBA to the fuel it is possible to operate the hydride fuel to the same effective burnup as given in Figures 3.3 and 3.4 while maintaining all reactivity coefficients negative throughout the cycle.

Alternatively, using erbium burnable poison it is possible to decrease the amount of soluble boron required at BOL and thereby attain negative CTC over the entire geometry range considered. However, the use of erbium involves a few percent penalty in the 


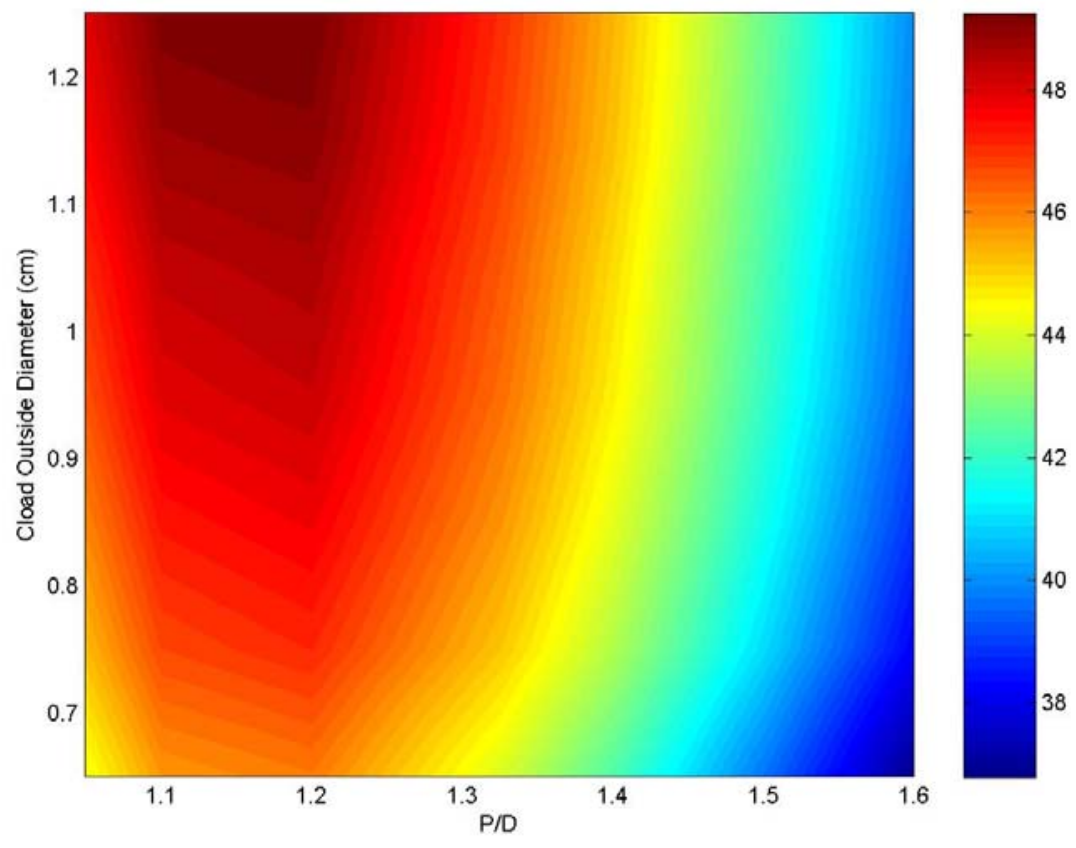

Figure 3.3 Attainable burnup in GWD/tHM with 5\% enriched $\mathrm{U}-\mathrm{ZrH}_{1.6}$; no reactivity constraints.

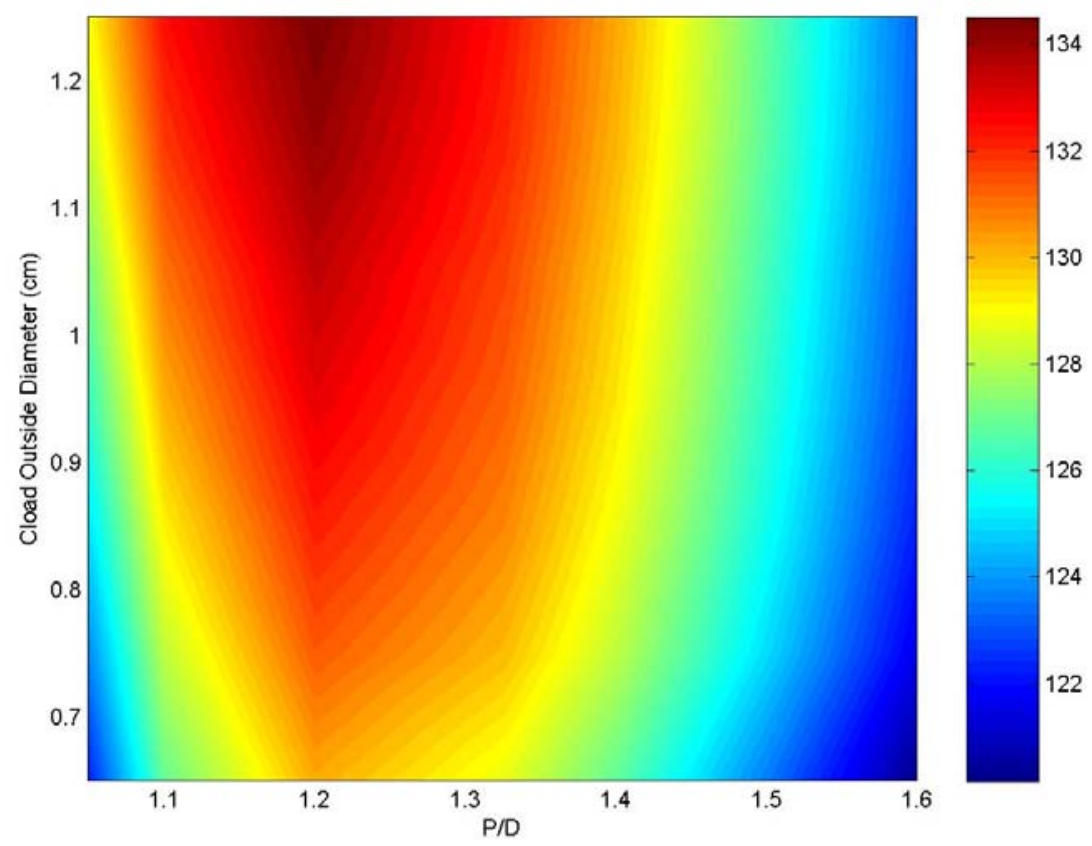

Figure 3.4 Attainable burnup in GWD/tHM with $12.5 \%$ enriched $\mathrm{U}-\mathrm{ZrH}_{1.6}$; no reactivity constraints. 
attainable discharge burnup and is therefore less effective than the replacement of a relatively small amount of zirconium hydride by thorium hydride. The economic analysis results reported for hydride fuel pertain to $\mathrm{U}-\mathrm{ZrH}_{1.6}$ fuel in which a fraction of the $\mathrm{ZrH}_{1.6}$ is replaced by $\mathrm{ThH}_{2}$ and to which some IFBA is added. Uranium-thorium-zirconium hydride fuel has been developed and characterized by Yamawaki et al., (1997; 1998; 1999; 2000).

Comparison of Figure 3.1 and Figures 3.2 and 3.3 shows that whereas for oxide fuel the peak burnup is achieved for $\mathrm{P} / \mathrm{D}$ of $\sim 1.5$, for hydride fuel it is obtained for $\mathrm{P} / \mathrm{D} \sim 1.2$. The smaller optimal P/D for hydride fuel is due to a couple of factors - reduced HM density and inclusion of hydrogen in the fuel. As a consequence, from the neutronics point of view, more hydride fuel rods can be loaded into a given PWR fuel assembly of a fixed volume than oxide fuel rods.

\subsection{Thermal-hydraulics accounting for vibration and wear}

The maximum achievable power for $\mathrm{UO}_{2}$ fueled core as a function of fuel rod diameter and pitch-to-diameter ratio is shown in Figures 3.5 and 3.6 for, respectively, 29 and 60 psia pressure drop. Constraints imposed by vibrations and wear are accounted for in addition to steady-state thermal-hydraulic constraints. It is found that by designing the PWR core to have smaller fuel rod diameter and larger P/D it is possible to increase the attainable core power by $\sim 11 \%$, without changing the core coolant pressure drop. If, in addition to changing $\mathrm{D}$ and $\mathrm{P} / \mathrm{D}$ the pressure drop is increased to $60 \mathrm{psia}$, the attainable power gain is $\sim 31 \%$. 


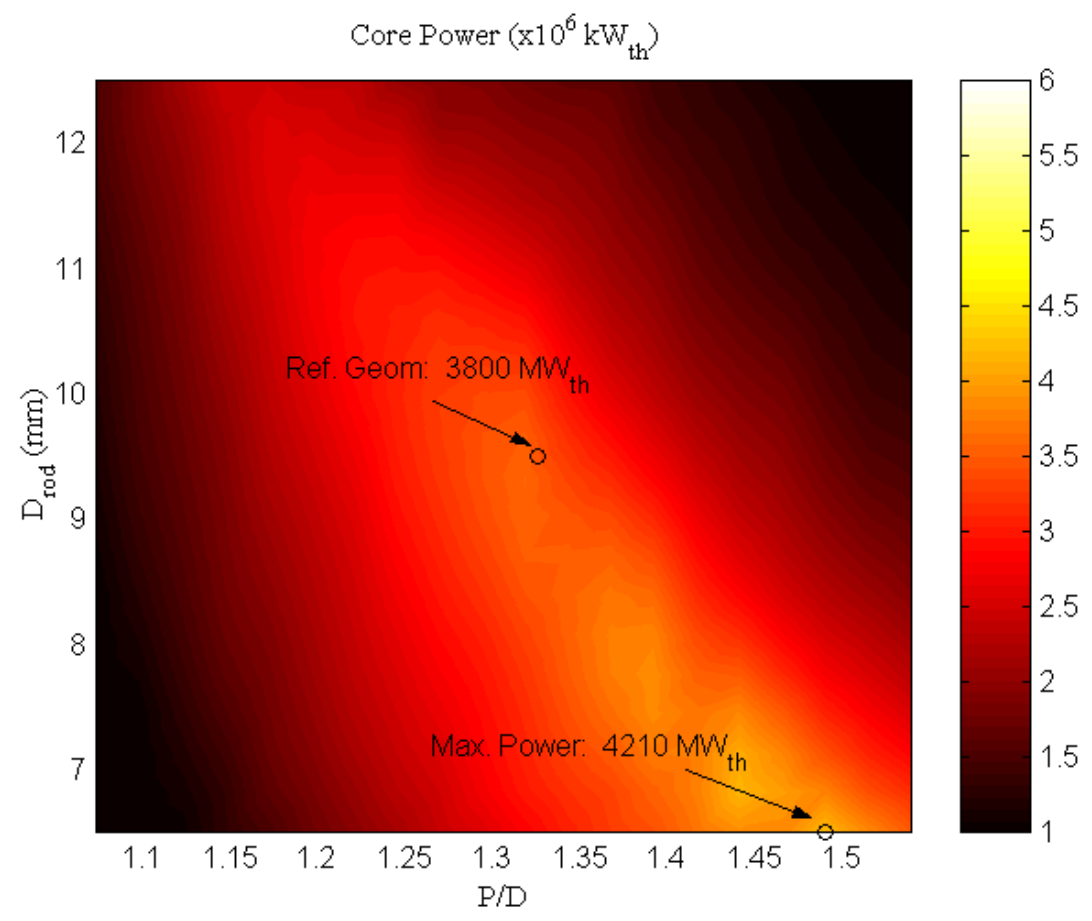

Figure 3.5 Maximum achievable power for $\mathrm{UO}_{2}$ fuel at 29 psia core pressure drop accounting for fuel rod vibration and wear

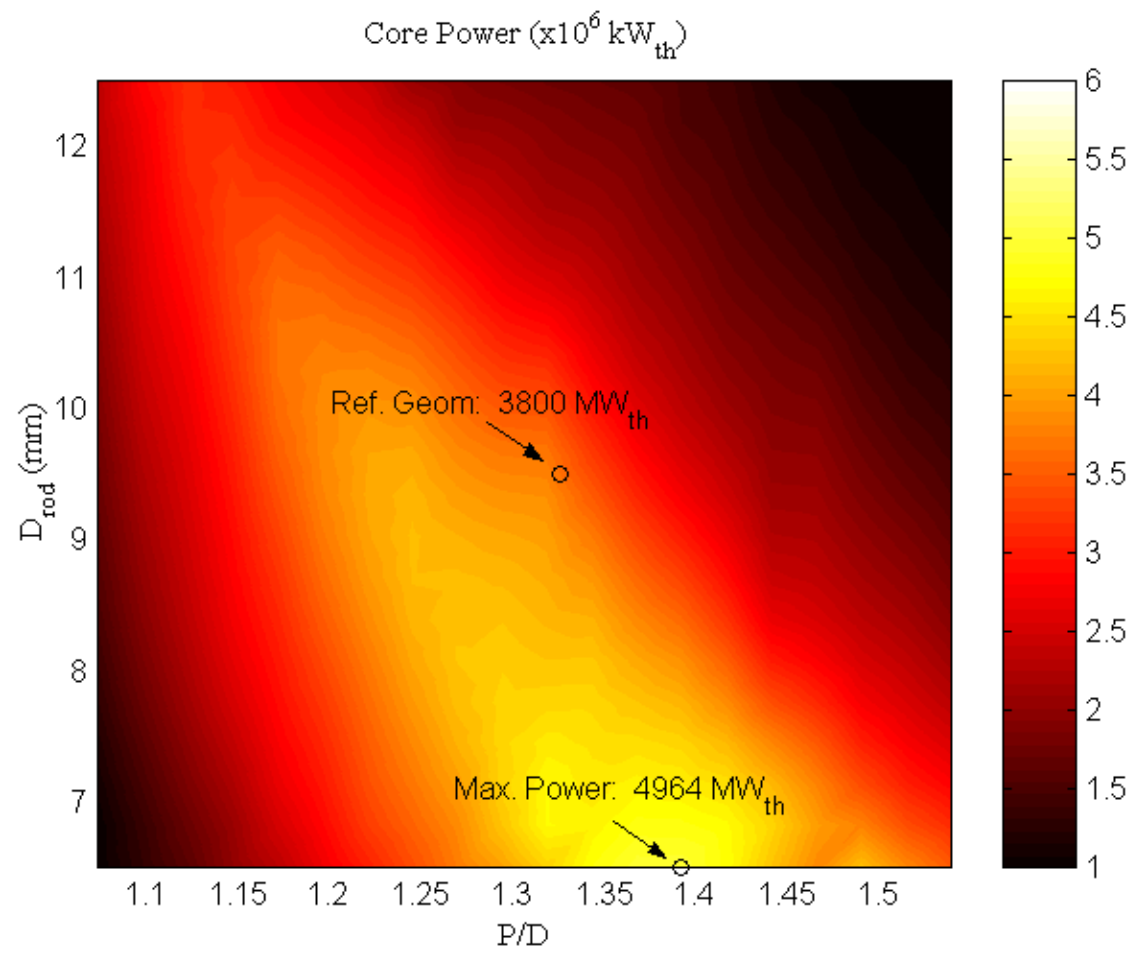

Figure 3.6 Maximum achievable power for $\mathrm{UO}_{2}$ fuel at 60 psia core pressure drop accounting for fuel rod vibration and wear 
The power achievable with hydride fuel is, in principle, comparable to that achievable with oxide fuel under the same operating conditions, because neither the oxide nor the hydride peak fuel temperature reach their limit. However, as the economic analysis to be reported in Section 3.6 found that the minimum COE for hydride fuelled core is obtained using $12.5 \%$ enriched uranium whereas that for oxide fuel is obtained using $5 \%$ enriched uranium, the optimal hydride fuel resident time in the core is longer than that of oxide fuel and thereby is subjected to enhanced vibration induced ware. In order to compensate for the enhanced ware the power level of the hydride fuel needs be reduced, as shown in Figures 3.7 and 3.8. Fortunately, this penalty does not affect the peak power core designs. Table 3.1 compare these peak power designs of hydride and oxide fuelled PWR cores using square lattice with grid spacers support.

Table 3.1

Attainable power levels based on steady-state thermal hydraulic analysis accounting for vibrations and wear limits

\begin{tabular}{|c|c|c|c|c|c|}
\hline & Power $\left(M W_{t h}\right)$ & $Q / Q_{\text {ref }}{ }^{(a)}$ & $q^{\prime} / q_{r e f}^{\prime}{ }^{(b)}$ & $P / D$ & $D(\mathrm{~mm})$ \\
\hline \multicolumn{6}{|l|}{29 psia } \\
\hline $\begin{array}{l}\mathrm{UO}_{2} \\
\text { Ref. Geom }\end{array}$ & 3800 & 1 & 1 & 1.326 & 9.5 \\
\hline $\begin{array}{l}\mathrm{UZrH}_{1.6} \\
\text { Peak Power }\end{array}$ & 4210 & 1.11 & 0.66 & 1.49 & 6.5 \\
\hline $\begin{array}{l}\mathrm{UO}_{2} \\
\text { Peak Power }\end{array}$ & 4210 & 1.11 & 0.66 & 1.49 & 6.5 \\
\hline \multicolumn{6}{|l|}{60 psia } \\
\hline $\begin{array}{l}\text { UzrH }_{1.6} \\
\text { Peak Power }\end{array}$ & 5017 & 1.32 & 0.66 & 1.37 & 6.5 \\
\hline $\begin{array}{l}\mathrm{UO}_{2} \\
\text { Peak Power }\end{array}$ & 4964 & 1.306 & 0.674 & 1.39 & 6.5 \\
\hline
\end{tabular}

${ }^{(a)}$ Relative coolant mass flow rate ${ }^{(b)}$ Relative linear heat generation rate 


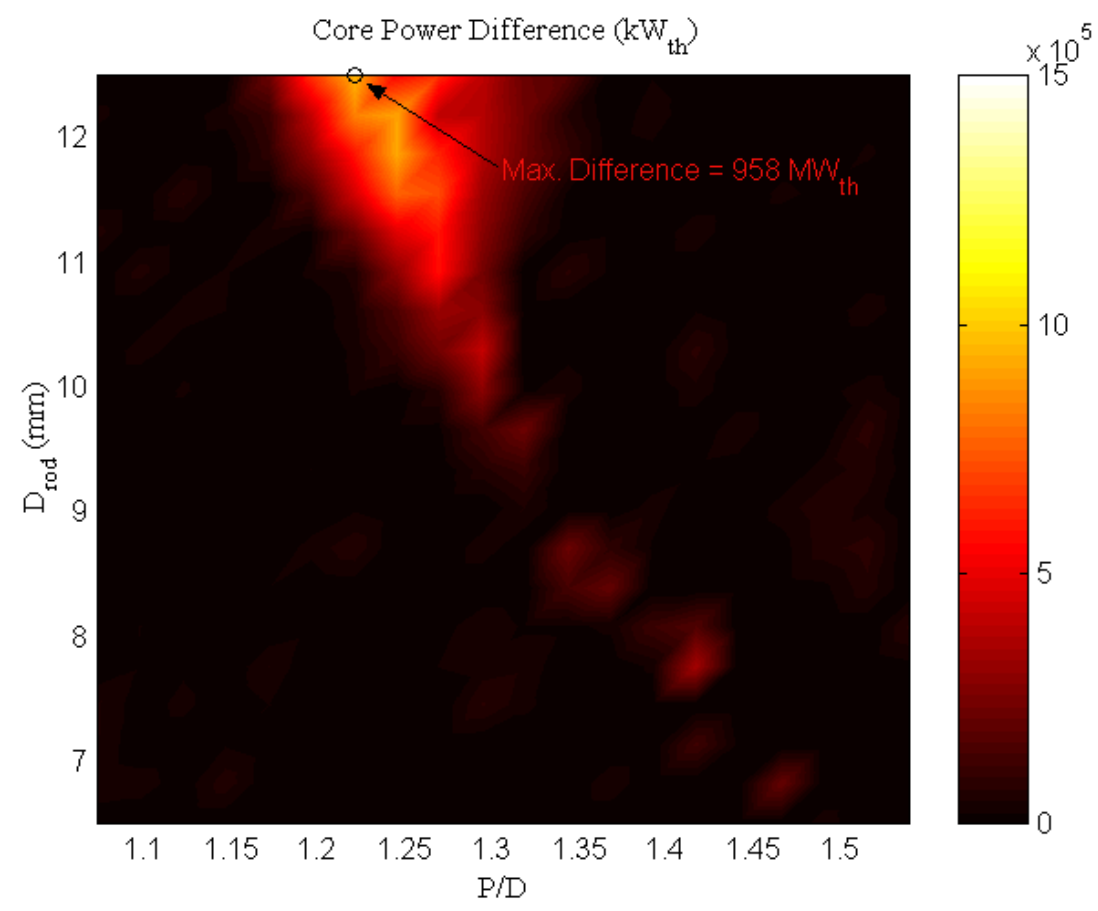

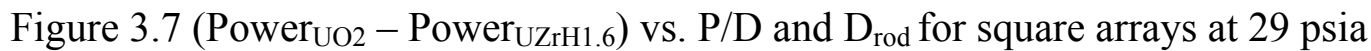
with vibrations and wear imposed design limits

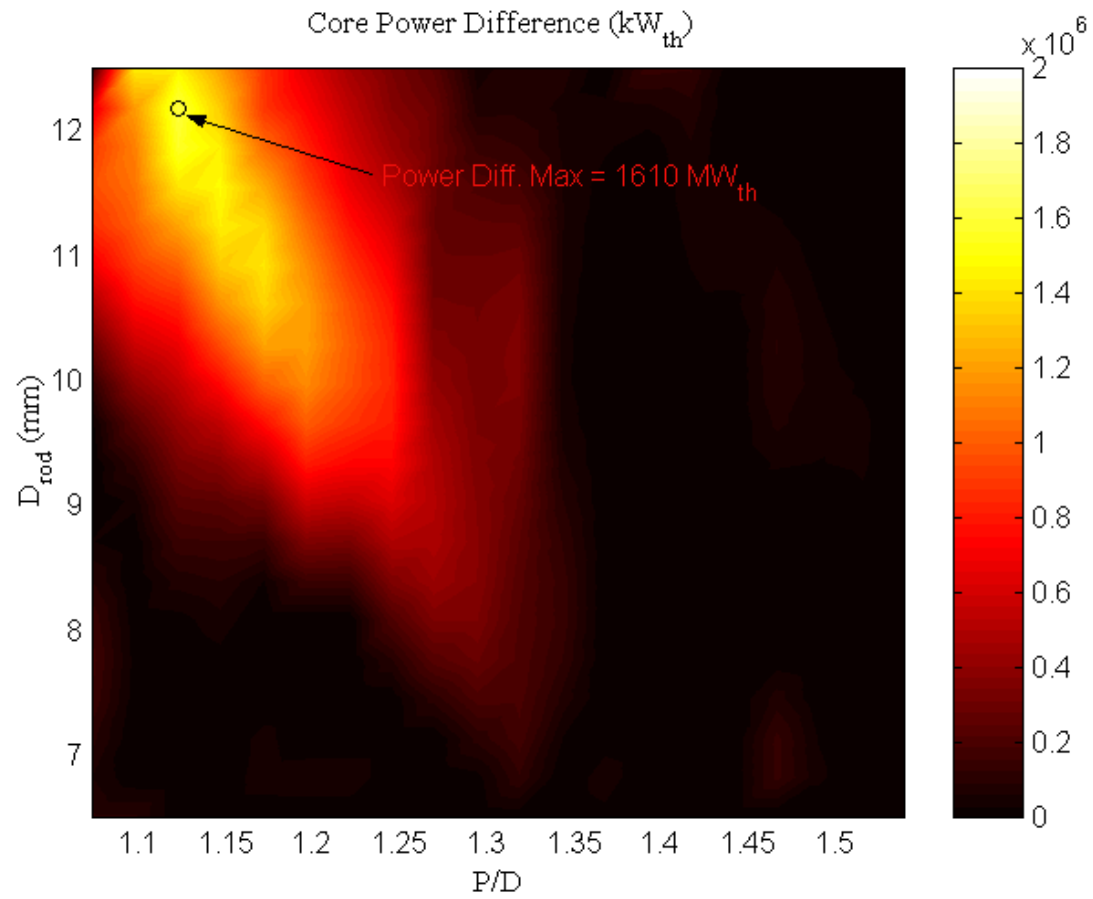

Figure 3.8 (Power $_{\mathrm{UO} 2}-$ Power $_{\mathrm{UZrH1}}$.6) vs. $\mathrm{P} / \mathrm{D}$ and $\mathrm{D}_{\text {rod }}$ for square arrays at 60 psia with vibrations and wear imposed design limits 


\subsection{Clad integrity}

For a given geometry, the discharge burnup fed into the economic analysis is the smaller of the FRAPCON predicted burnup and the burnup from the neutronic analysis. Figures 3.9 and 3.10 give the attainable burnup for, respectively, hydride and oxide fuel using different uranium enrichments. The results given are for 60 psia coolant pressure drop across the core. Similar results were obtained for a pressure drop of 29 psia. The burnup limits imposed due to reactivity constraints are not integrated into these burnup maps.

With the exception of very small rod diameters and P/D ratios, the burnup for $\mathrm{UZrH}_{1.6}$ is limited by the neutronics. $\mathrm{UO}_{2}$ is limited primarily by neutronics for smaller $\mathrm{P} / \mathrm{D}$ ratios, and fuel performance for larger $\mathrm{P} / \mathrm{D}$ ratios, though as the enrichment increases fuel performance takes on a more dominant role.

\subsection{Transient analysis}

The overpower transient reduces the maximum attainable power of both the hydride fueled and oxide fueled cores relative to that predicted by steady-state analysis. For 29 psia pressure drop designs the peak steady-state power is reduced by $3.3 \%$ whereas for 60 psia pressure drop designs the reduction is by $6 \%$.

The LOCA also limits the attainable power of oxide fueled cores but not that of hydride fueled cores. This is due to the high thermal conductivity of the hydride fuel yielding lower initial fuel temperatures from stored energy redistribution and lower temperature increase over time from decay heat due to the higher volumetric heat 

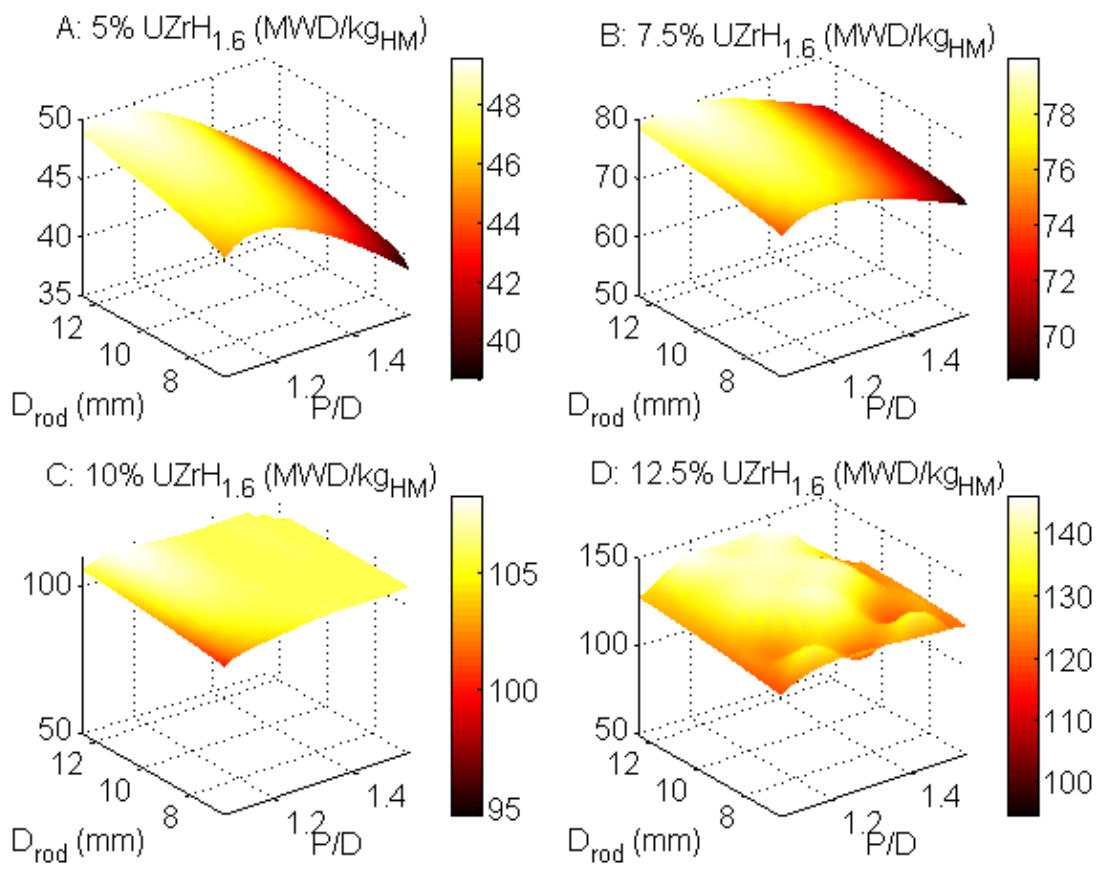

Figure 3.9 Maximum achievable burnup for square arrays of hydride fuel at $60 \mathrm{psia}$ coolant pressure drop accounting for fuel performance constraints
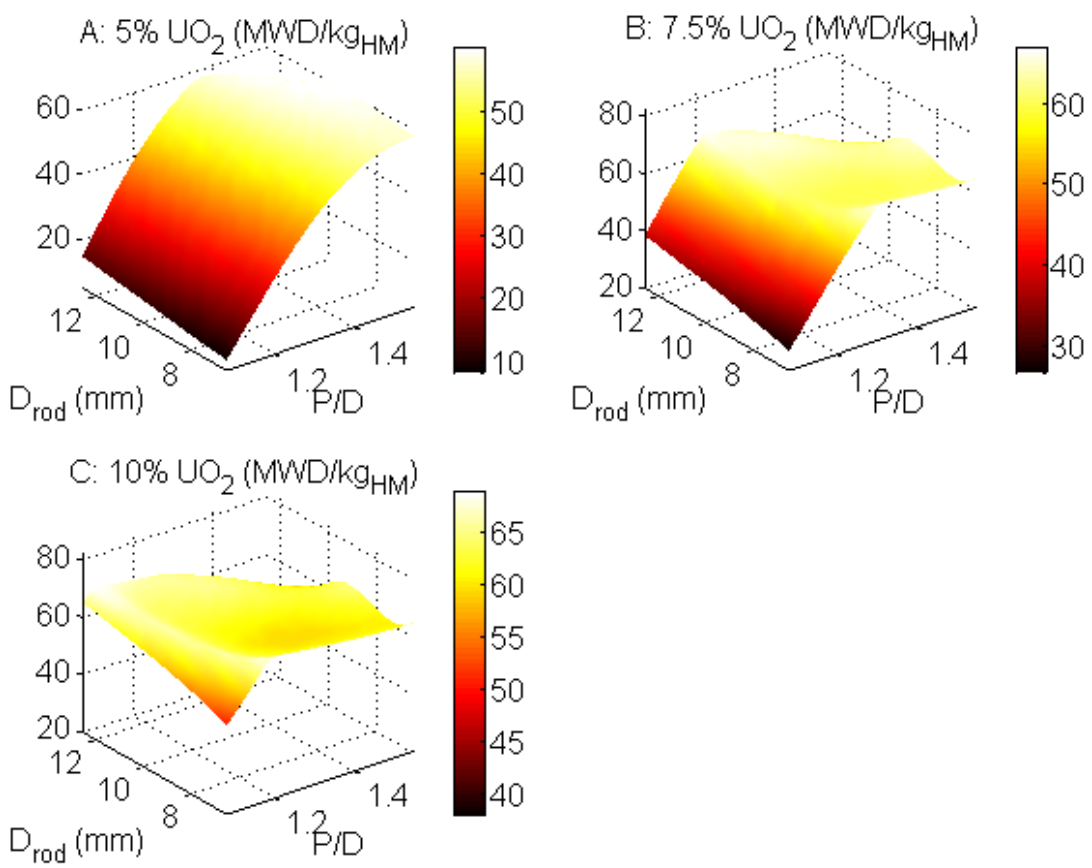

Figure 3.10 Maximum achievable burnup for square arrays of oxide fuel at 60 psia coolant pressure drop accounting for fuel performance constraints 
capacity of hydride fuels. The peak power reduction of oxide fuel is estimated at $1.6 \%$ and $9.4 \%$ for, respectively, 29 psia and 60 psia designs.

The LOFA does not penalize the maximum achievable power of the economically advantageous cores for both fuels and for both pressure drops.

Figures 3.11 and 3.12 summarize the results of the accident and transient analyses; they give the maximum attainable power accounting for all the constraints considered in this work for, respectively, 29 psia and 60 psia designs.
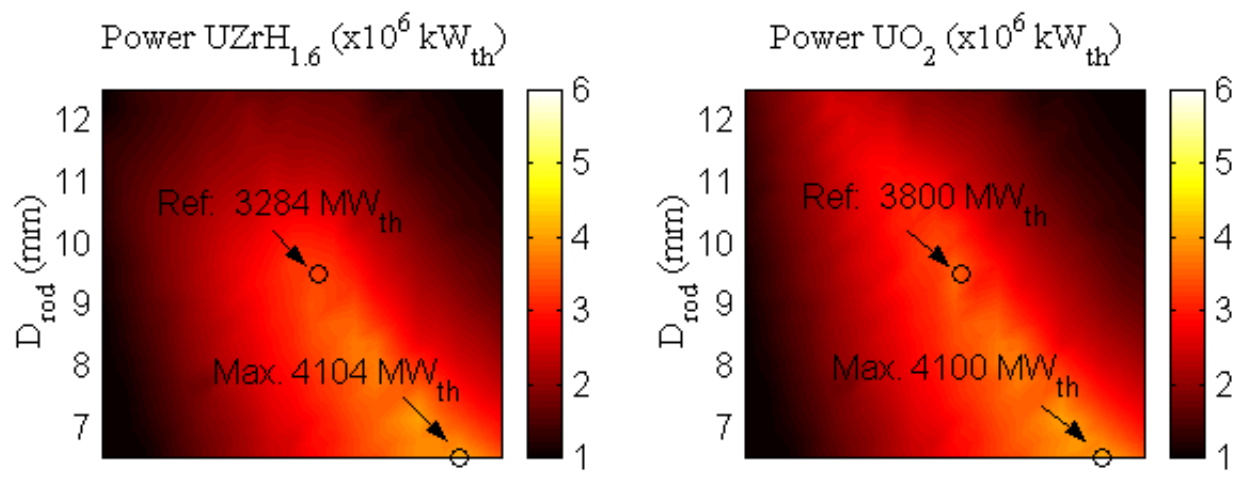

Figure 3.11 Maximum achievable power at 29 psia of hydride and oxide cores accounting for all design constraints
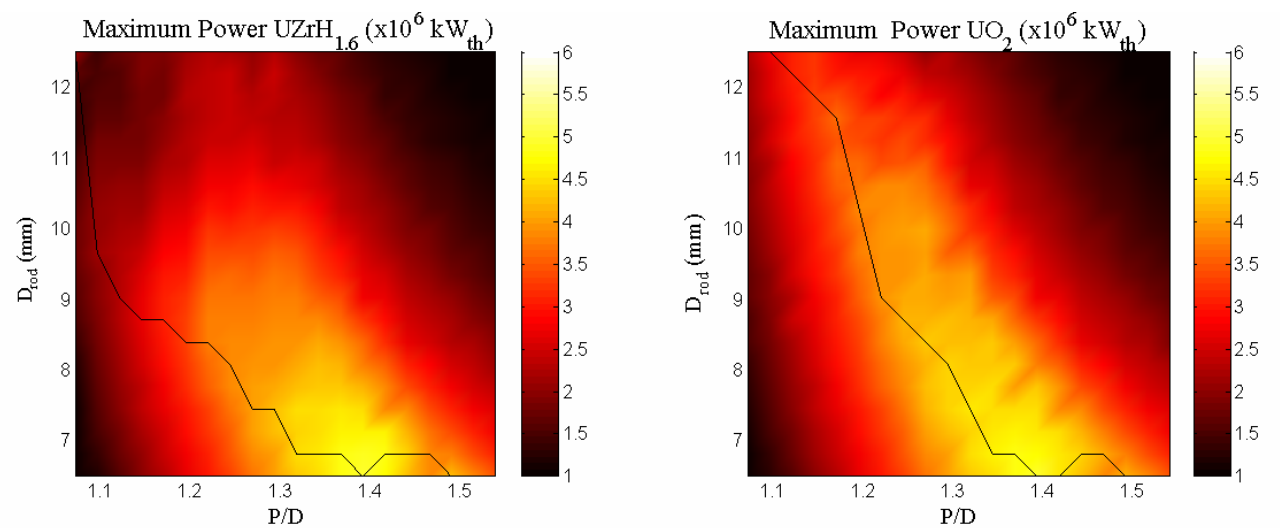

Figure 3.12 Maximum achievable power at 60 psia of hydride and oxide cores accounting for all design constraints. Black line denotes maximum power for a given $\mathrm{P} / \mathrm{D}$ 


\subsection{Economics}

The lifetime levelized unit cost of electricity for the major backfit scenario at 60 psia is shown in Figures 3.13 and 3.14 for different enrichments for $\mathrm{U}-\mathrm{ZrH}_{1.6}$ and $\mathrm{UO}_{2}$ fuelled cores. Also shown on each plot, as a black line, is the minimum COE at each P/D ratio. The minimum COE for $\mathrm{U}-\mathrm{ZrH}_{1.6}$ of 18.34 mills/kWh is obtained for $12.5 \%$ enriched uranium at $\mathrm{P} / \mathrm{D}=1.32, \mathrm{D}_{\text {rod }}=9 \mathrm{~mm}$. This geometry is very close to the reference core configuration but over the range of $1.22<\mathrm{P} / \mathrm{D}<1.42$ the $\mathrm{COE}$ is within a small fraction of this minimum value. The minimum $\mathrm{COE}$ for $\mathrm{UO}_{2}$ of $17.9 \mathrm{mills} / \mathrm{kWh}$ is obtained for $5 \%$ enriched uranium at $\mathrm{P} / \mathrm{D}=1.39, \mathrm{D}_{\text {rod }}=6.5 \mathrm{~mm}$. $\mathrm{UZrH}_{1.6}$ appears to offer the potential for cost savings over $\mathrm{UO}_{2}$ in the $\mathrm{P} / \mathrm{D}$ range of 1.2 to $\sim 1.35$.

Figures 3.15 and 3.16 compare the minimum $\mathrm{COE}$ and its components as a function for P/D for hydride and oxide fuel designs. Not shown in the figures is the fuel rod diameter that gives the minimum $\mathrm{COE}$; its value varies with $\mathrm{P} / \mathrm{D}$, enrichment level and fuel type. For $\mathrm{UZrH}_{1.6}$ the $\mathrm{COE}$ is minimized at the highest enrichment considered. The opposite is true of oxide for most of the geometry range. Also different is the COE trend of variation with $\mathrm{P} / \mathrm{D}$. The $\mathrm{UZrH}_{1.6} \mathrm{COE}$ rapidly approaches the most economical geometries as P/D increases and then begins a gradual trend of increased cost - due to rising fuel cycle and $\mathrm{O} \& \mathrm{M}$ costs (Figure $3.15 \mathrm{~B}$ and $\mathrm{C}$ ). The $\mathrm{UO}_{2} \mathrm{COE}$ shows a more gradual descent with $\mathrm{P} / \mathrm{D}$. The discontinuity in the capital cost component reflects a transition from geometries that feature the reference or below reference power level to geometries that offer above-reference power level. The latter geometries require capital cost investment for plant upgrade. In the region where the power is below the reference core power, the capital expenditure (replacement of core internals, vessel head, remaining 
value of lost fuel), is fixed and the capital cost component depends solely on the power/energy production from the plant.
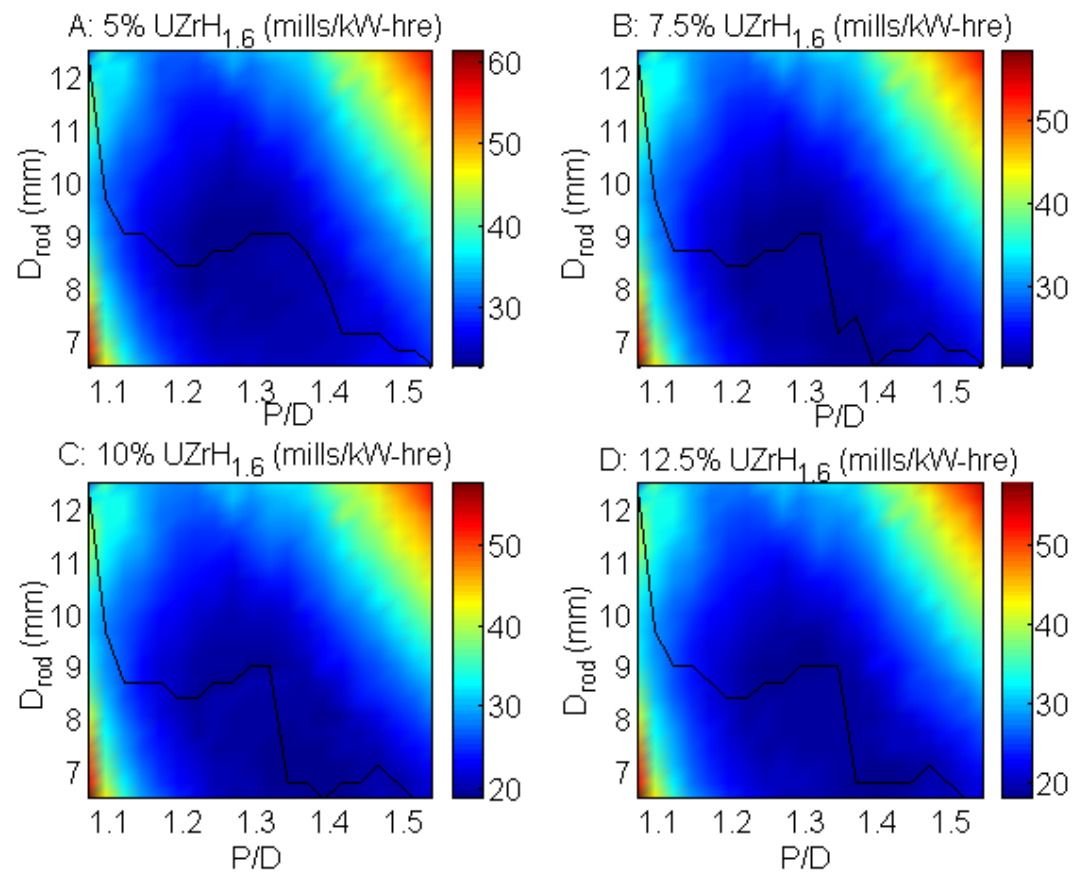

Figure 3.13 Lifetime levelized unit $\mathrm{COE}$ for $\mathrm{U}-\mathrm{ZrH}_{1.6}$ at 60 psia major backfit scenario
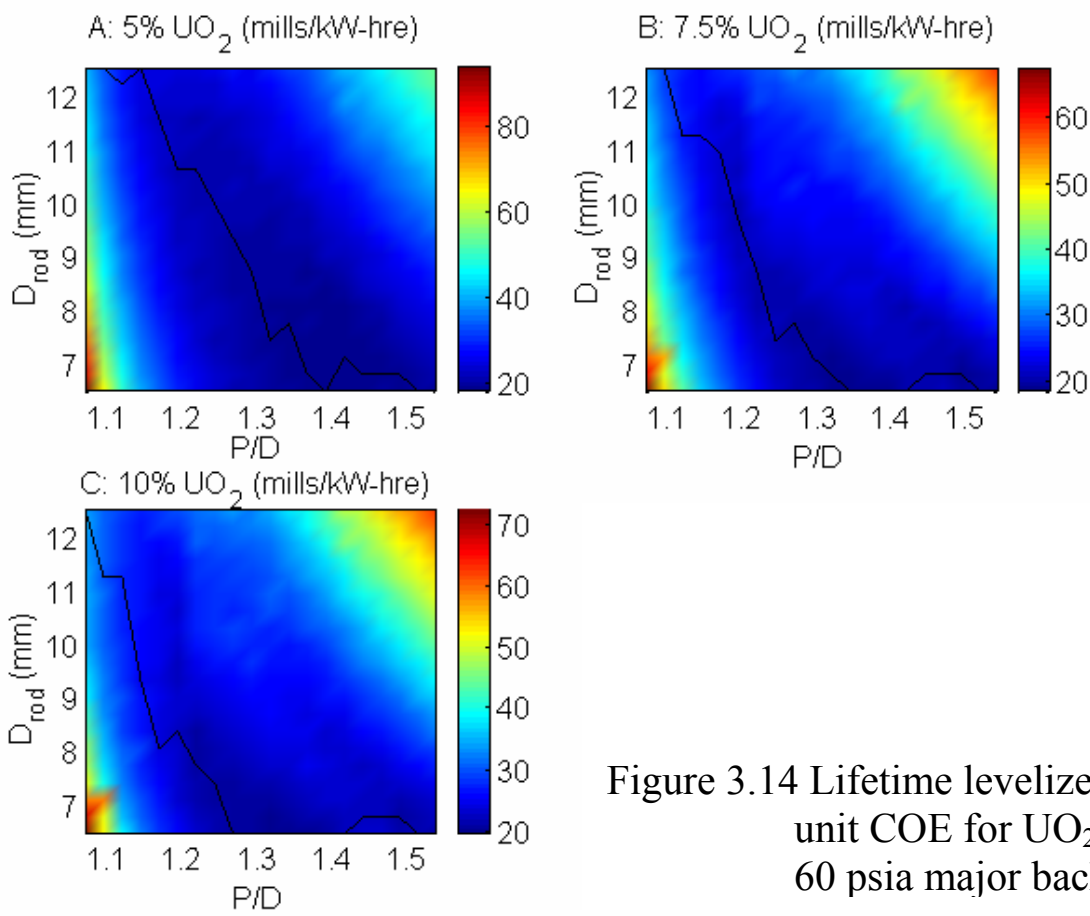

Figure 3.14 Lifetime levelized unit $\mathrm{COE}$ for $\mathrm{UO}_{2}$ at 60 psia major backfit 

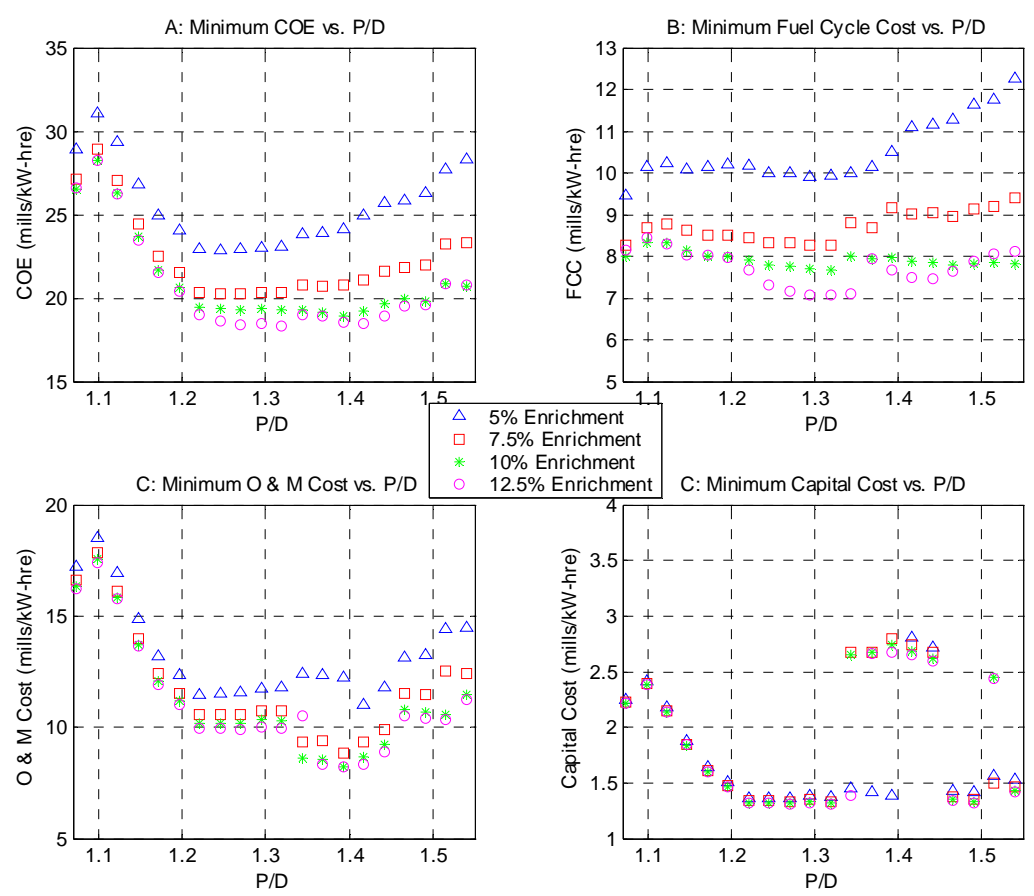

Figure 3.15 Minimum COE and its components vs. $\mathrm{P} / \mathrm{D}$ for $\mathrm{UZrH}_{1.6}$ at 60 psia major backfit scenario
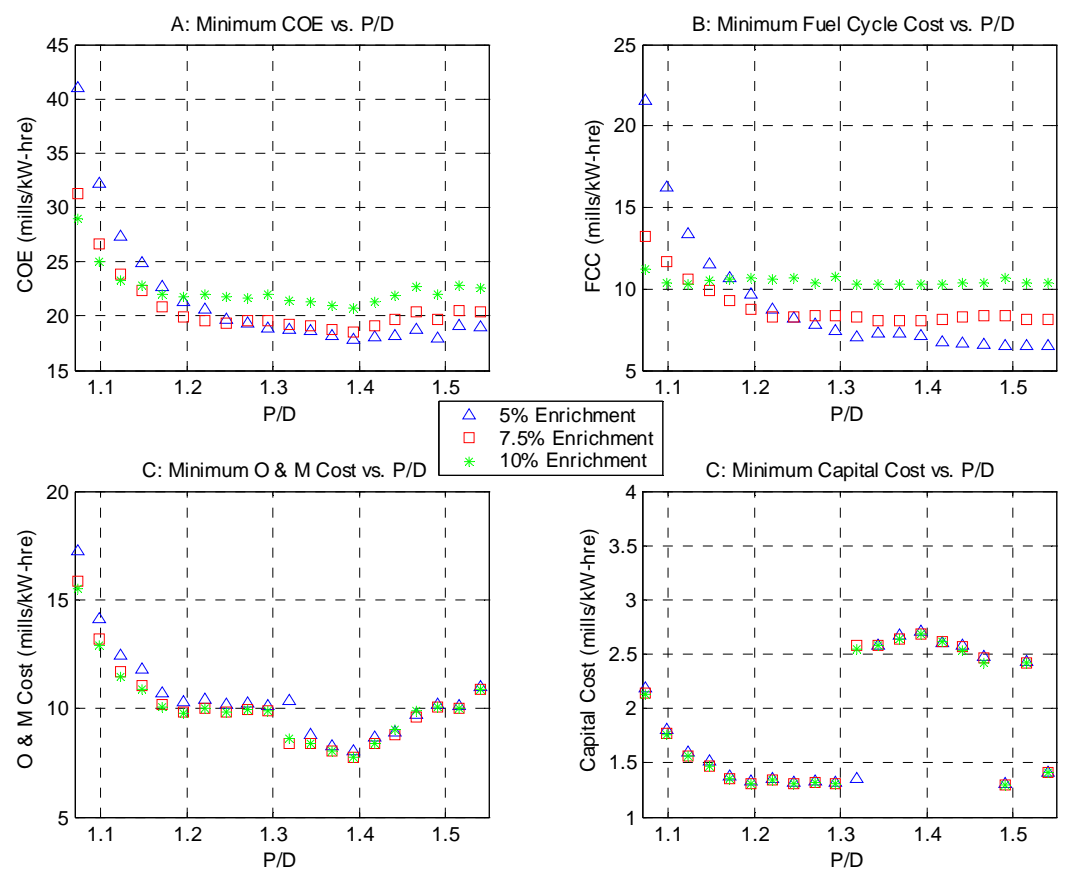

Figure 3.16 Minimum COE and its components vs. $\mathrm{P} / \mathrm{D}$ for $\mathrm{UZrH}_{1.6}$ at 60 psia major backfit scenario 

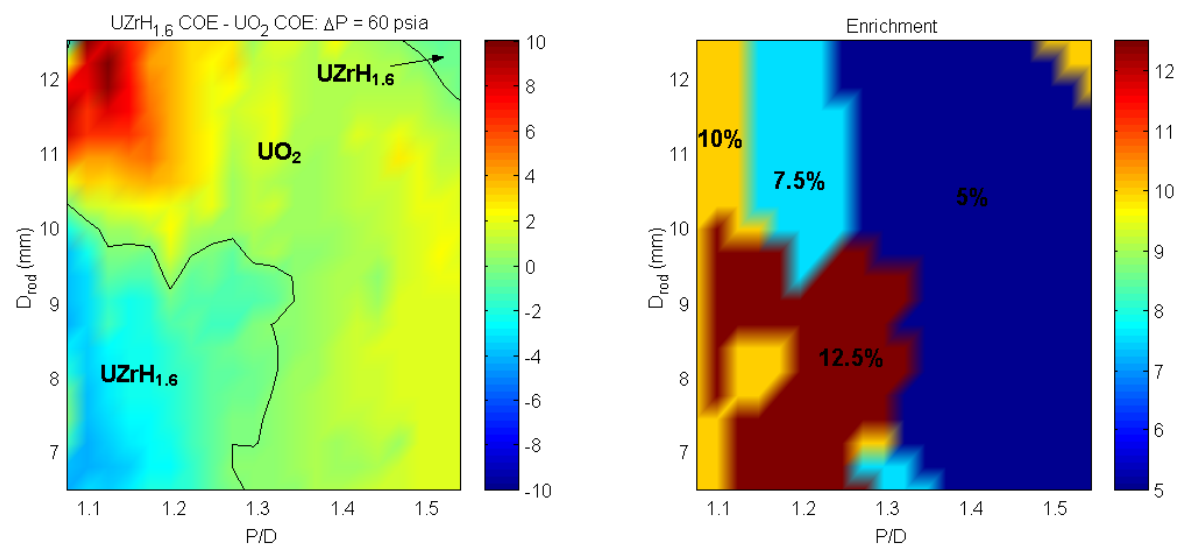

Figure 3.17 Lifetime COE difference between hydride and oxide fuel and optimal enrichment at 60 psia and major backfit scenario
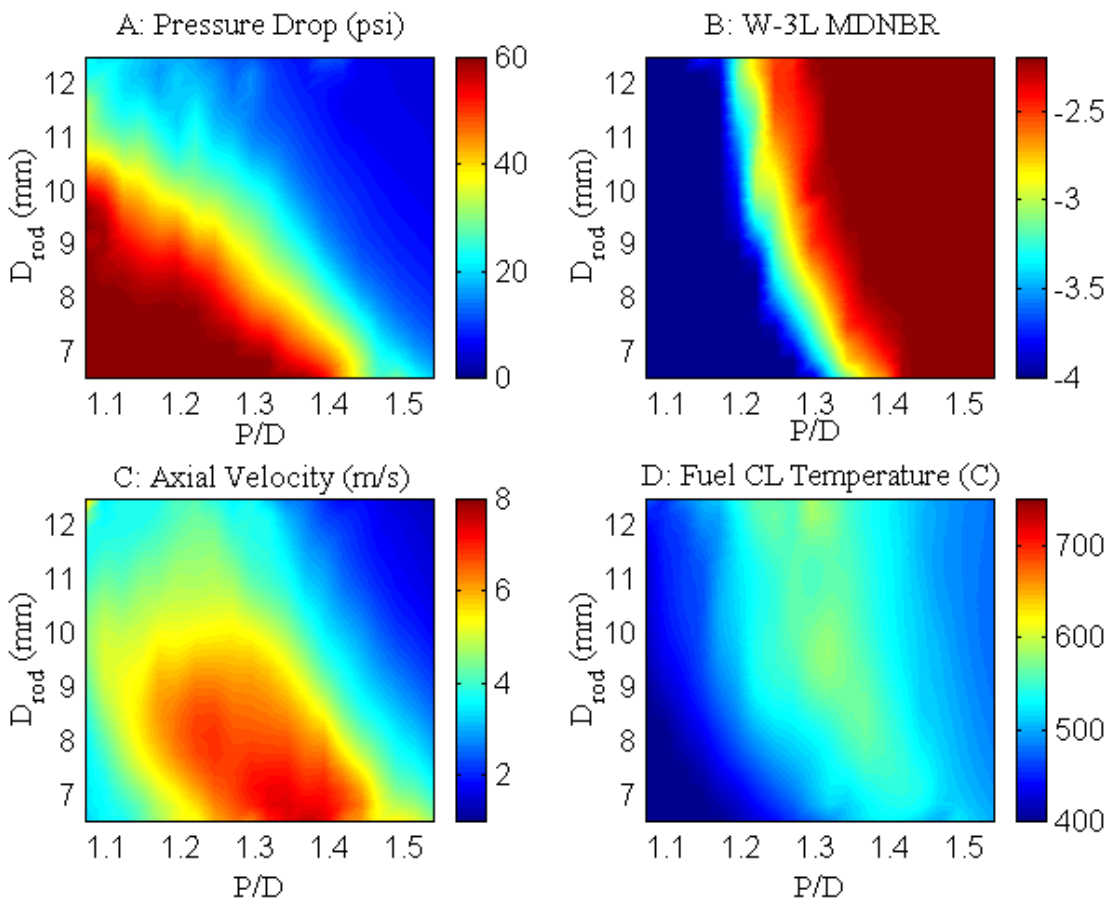

Figure 3.18 Thermal hydraulic constraining parameters for $\mathrm{UZrH}_{1.6}$ at 60 psia accounting for vibrations and wear imposed design limits

Figure 3.17, left side, gives the difference in the minimum $\mathrm{COE}$ between $\mathrm{U}-\mathrm{ZrH}_{1.6}$ and $\mathrm{UO}_{2}$ as a function of $\mathrm{P} / \mathrm{D}$ ratio and rod diameter. The black contour is the loci of geometries for which the cost difference is zero. The right hand side of Figure 3.17 gives 
the enrichment level providing the minimum $\mathrm{COE}$ for each design point. Hydride fuel offers lower $\mathrm{COE}$ in the small $\mathrm{P} / \mathrm{D}$, small to medium $\mathrm{D}$ design range. In this design range the attainable power is limited primarily by the coolant pressure drop, as shown in Figure 3.18A. Had it been possible to design PWR's to accommodate core pressure drops exceeding 60 psia, hydride fuel may offer noticeable advantage over oxide fuel.

However, Figure 3.18C indicates that vibration and wear considerations may be limiting the power gain that could have been achieved by increasing the pressure drop. As was suggested by Figure 3.4, the neutronically ideal $\mathrm{P} / \mathrm{D}$ is $\sim 1.2$; this is within the range of economic advantage of hydride fuel (Figure 3.15).

A comparison of Figures 3.19 and 3.20 shows that the specific power and burnup attainable from the hydride fuel far exceed those of the oxide fuel. However, the total power and total energy generated per core are comparable. The higher specific power of hydride fuel is due, primarily, to its relatively low HM density whereas its high burnup is due to the higher uranium enrichment $-12.5 \%$ versus $5 \%$ for the oxide fuel.

The $\mathrm{D}$ and $\mathrm{P} / \mathrm{D}$ dependence of the cycle length and, correspondingly, capacity factor and outage duration compared in Figures 3.21 and 3.22 is quite different for the hydride and oxide fuels considered. Whereas for hydride fuel the maximum cycle length and capacity factor are obtained at low $\mathrm{P} / \mathrm{D}$, in which the fuel volume fraction is the highest, for hydride fuel they peak in the high $\mathrm{P} / \mathrm{D}$ and high $\mathrm{D}$ design subspace in which the achievable fuel burnup is relatively high. The power level attainable at the peak cycle length domain for both fuels is, however, relatively low. 

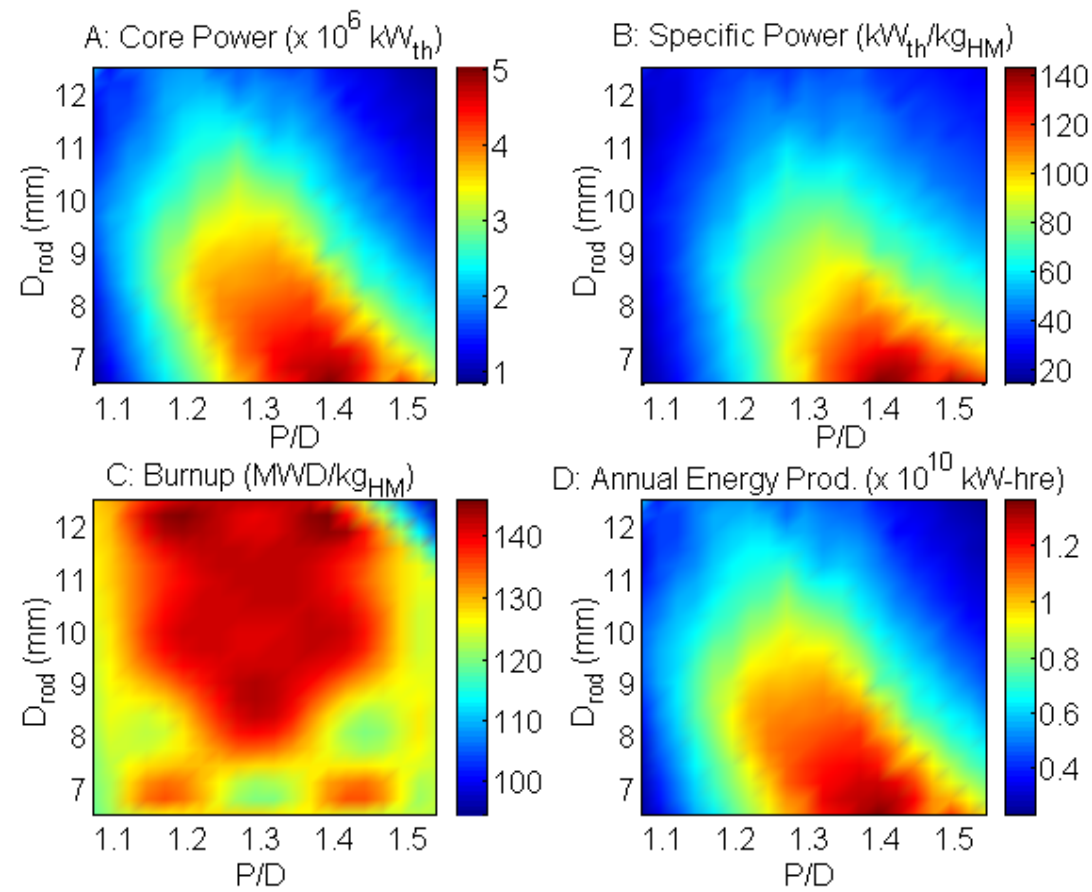

D: Annual Energy Prod. ( $\times 10^{10} \mathrm{~kW}$-hre)

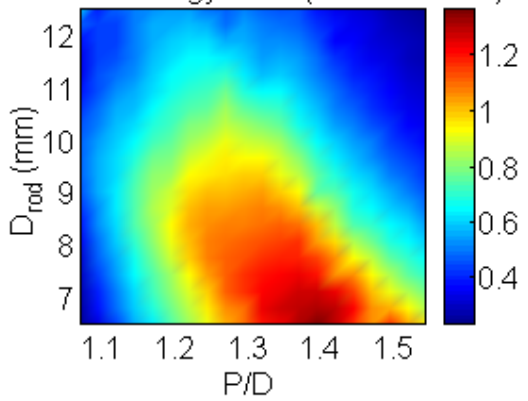

Figure 3.19 Selected characteristics for $12.5 \%$ enriched $\mathrm{U}-\mathrm{ZrH}_{1.6}$ cores at 60 psia
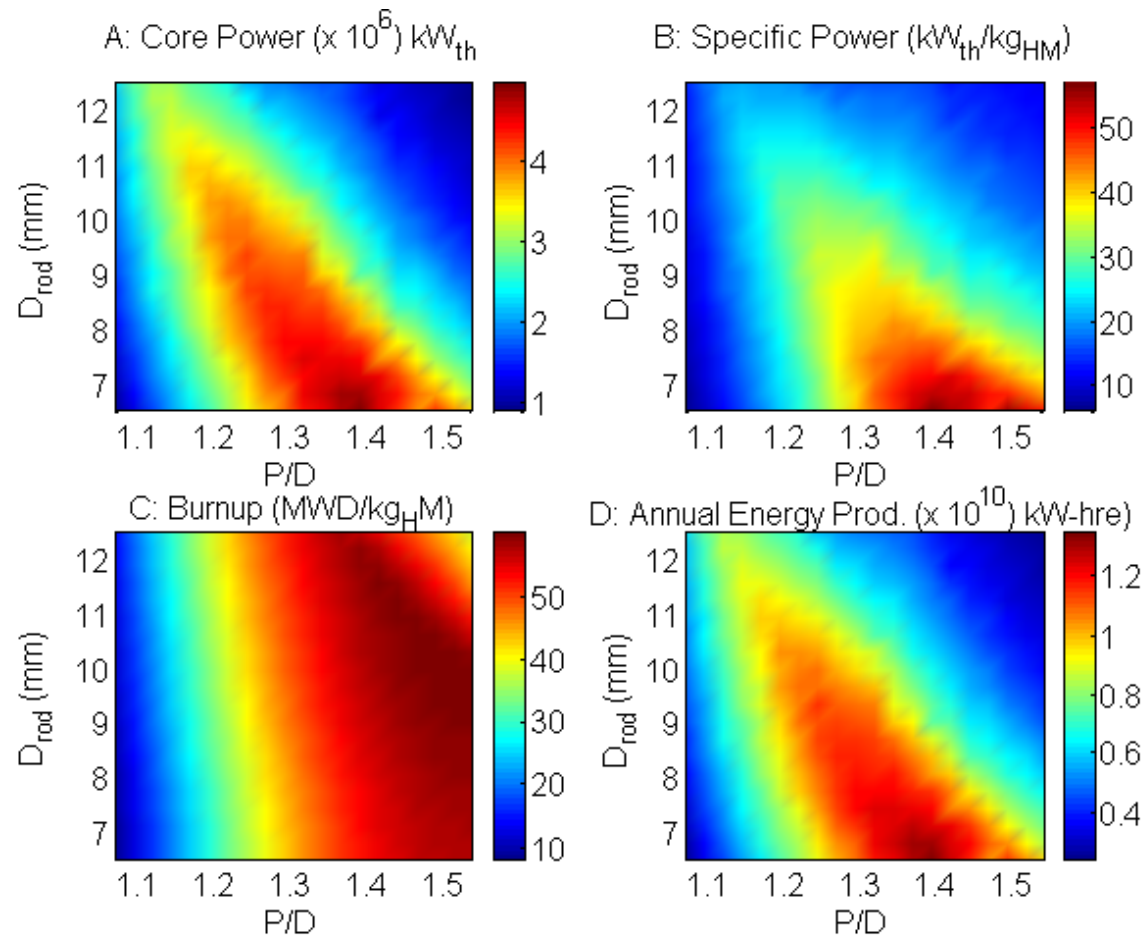

D: Annual Energy Prod. ( $\left.\times 10^{10}\right) \mathrm{kW}$-hre)

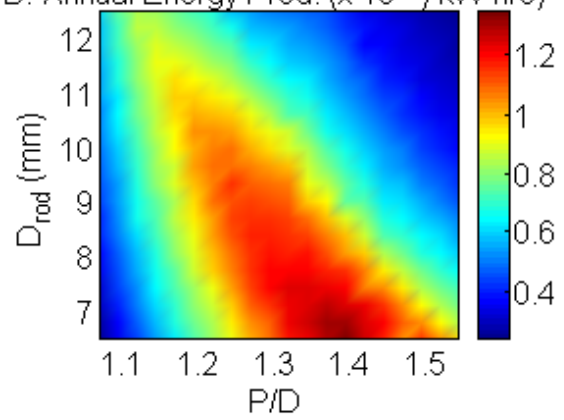

Figure 3.20 Selected characteristics for $5 \%$ enriched $\mathrm{UO}_{2}$ cores at 60 psia 

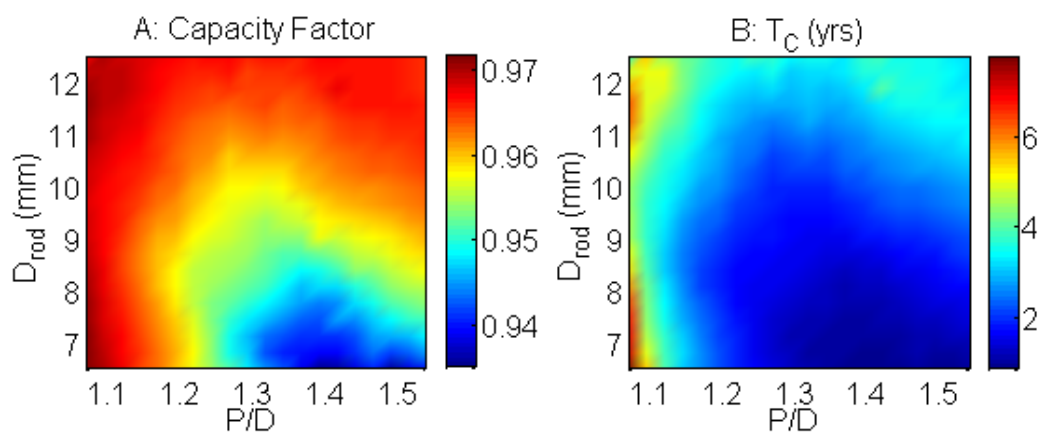

C: Annual Outage Length (days/yr)

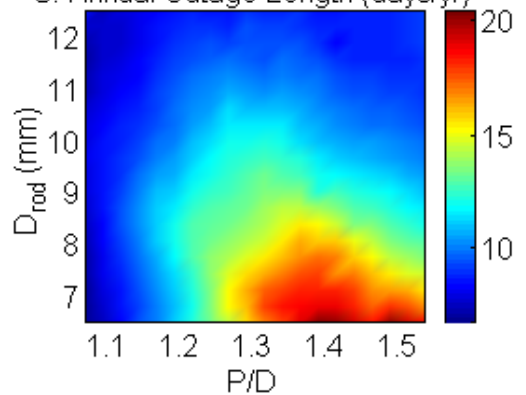

D: Planned Outage Length (days/cycle)

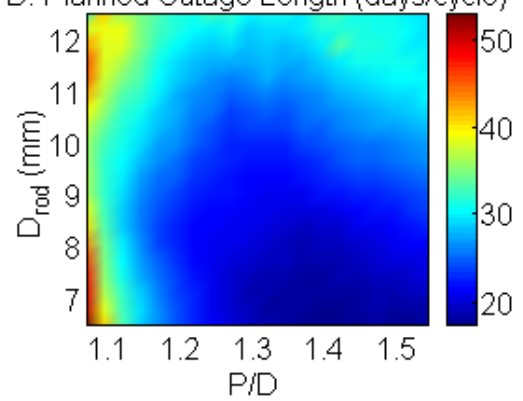

Figure 3.21 Cycle characteristics for $12.5 \%$ enriched $\mathrm{U}-\mathrm{ZrH}_{1.6}$ cores at 60 psia
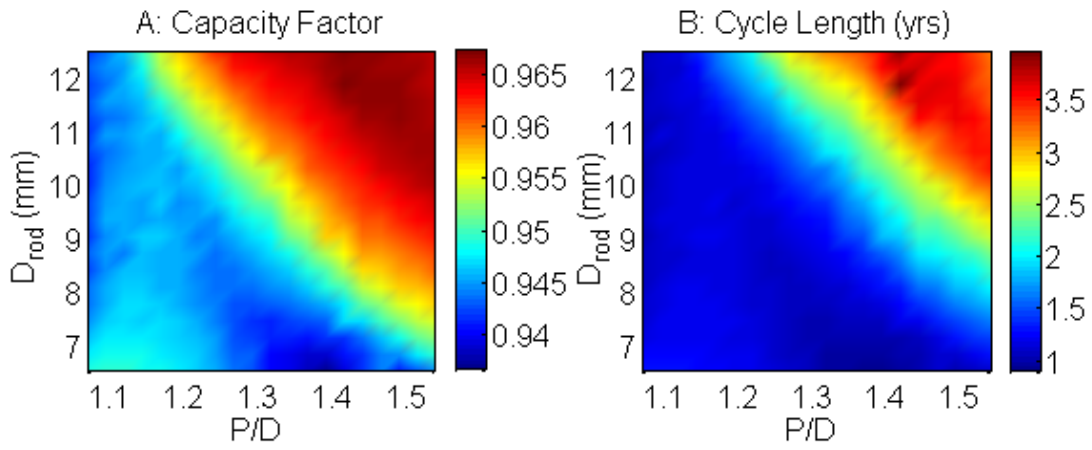

C. Annual Outage Length (days/yr)

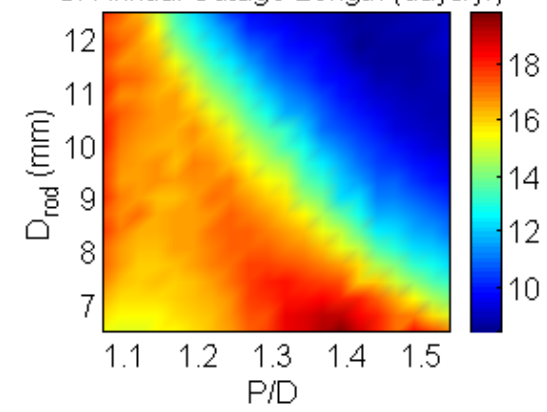

D: Planned Outage Length (days/cycle)

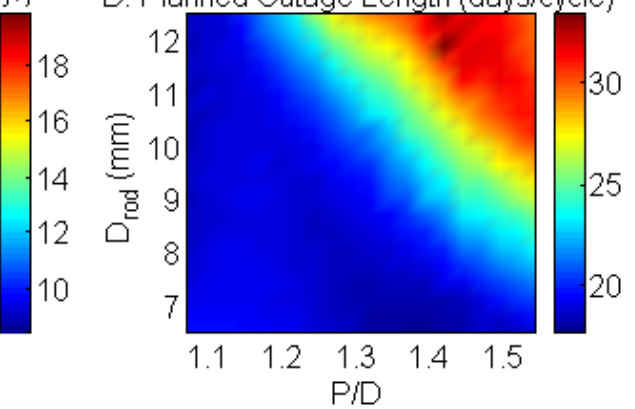

Figure 3.22 Cycle characteristics for $5 \%$ enriched $\mathrm{UO}_{2}$ cores at 60 psia 
Figures 3.23 and 3.24 compare the minimum $\mathrm{COE}$ and its components as a function of $\mathrm{P} / \mathrm{D}$ for hydride versus oxide fuel for the minor backfit scenario at 60 psia coolant pressure drop. For $\mathrm{UZrH}_{1.6}$, the minimum COE is $18.85 \mathrm{mills} / \mathrm{kWh}$ for $12.5 \%$ enriched fuel, and occurs at $\mathrm{P} / \mathrm{D} \sim 1.30, \mathrm{D}_{\text {rod }}=9.66 \mathrm{~mm}$. This is almost identical to the major backfit minimum COE, which is marginally lower at $18.34 \mathrm{mills} / \mathrm{kWh}$. For $\mathrm{UO}_{2}$, the minimum COE is 18.3 mills $/ \mathrm{kWh}$ for $5 \%$ enriched fuel, and occurs at $\mathrm{P} / \mathrm{D} \sim 1.30, \mathrm{D}_{\text {rod }}=$ $9.66 \mathrm{~mm}$. This is slightly larger than the major backfit minimum COE, which is 17.9 mills/kWh.

Figures 3.25 and 3.26 bring a similar comparison for a major backfit scenario but for design limited to 29 psia coolant pressure drop across the core. The minimum COE for $\mathrm{UZrH}_{1.6}$ is $19 \mathrm{mills} / \mathrm{kWh}$ for $12.5 \%$ enriched fuel at: $\mathrm{P} / \mathrm{D}=1.37, \mathrm{D}_{\text {rod }}=8.4 \mathrm{~mm}$. The minimum $\mathrm{COE}$ for $\mathrm{UO}_{2}$ is lower at $17.92 \mathrm{mills} / \mathrm{kWh}$ for $5 \%$ enriched fuel at: $\mathrm{P} / \mathrm{D}=1.47$, $\mathrm{D}_{\text {rod }}=7.13 \mathrm{~mm}$.

Finally, Figures 3.27 and 3.28 compare the economics of hydride and oxide fuel designs for a minor backfit with 29 psia. Like in the higher pressure drop case, the minimum COE for each fuel occurs very close to the reference core geometry. For $\mathrm{UZrH}_{1.6}$ the minimum $\mathrm{COE}$ is $19.3 \mathrm{mills} / \mathrm{kWh}$ at $\mathrm{P} / \mathrm{D} \sim 1.35, \mathrm{D}_{\text {rod }}=9.34 \mathrm{~mm}$. For $\mathrm{UO}_{2}$ the minimum COE occurs at a similar geometry with the same cost: $19.3 \mathrm{mills} / \mathrm{kWh}$ at $\mathrm{P} / \mathrm{D} \sim 1.31, \mathrm{D}_{\text {rod }}=9.66 \mathrm{~mm}$. 

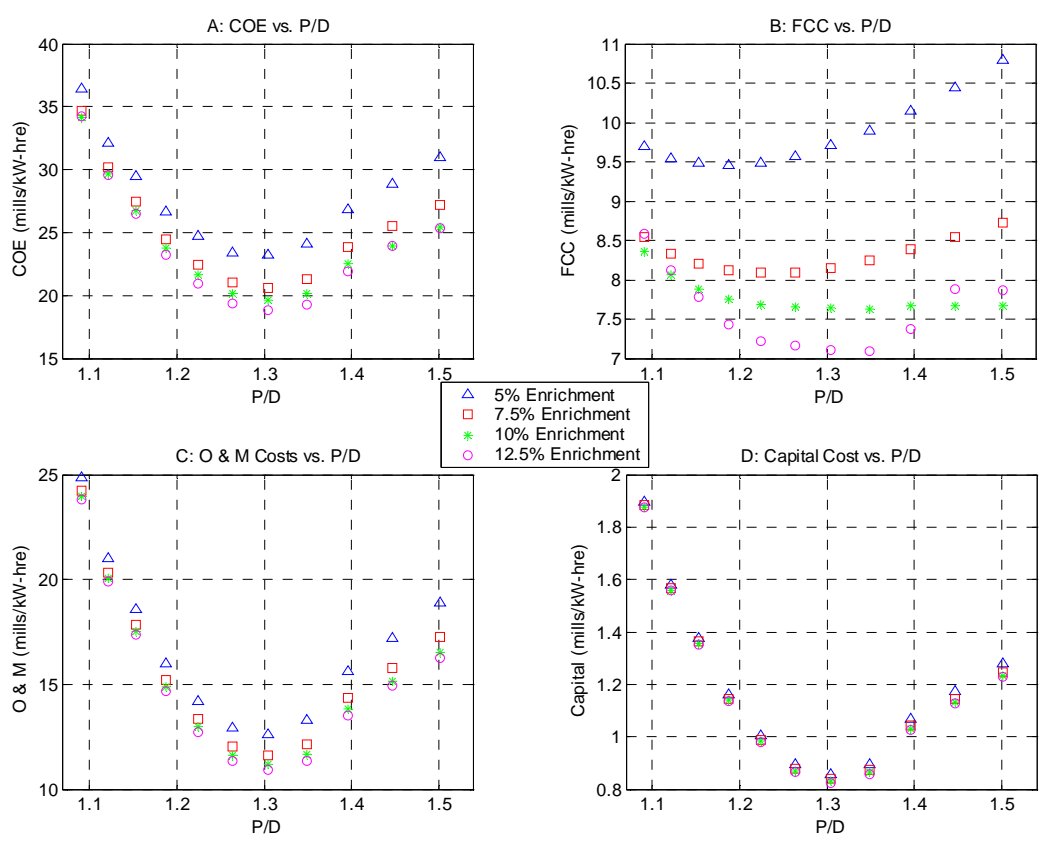

Figure 3.23 Minimum COE and its components vs. P/D for $\mathrm{UZrH}_{1.6}$ at 60 psia minor backfit scenario
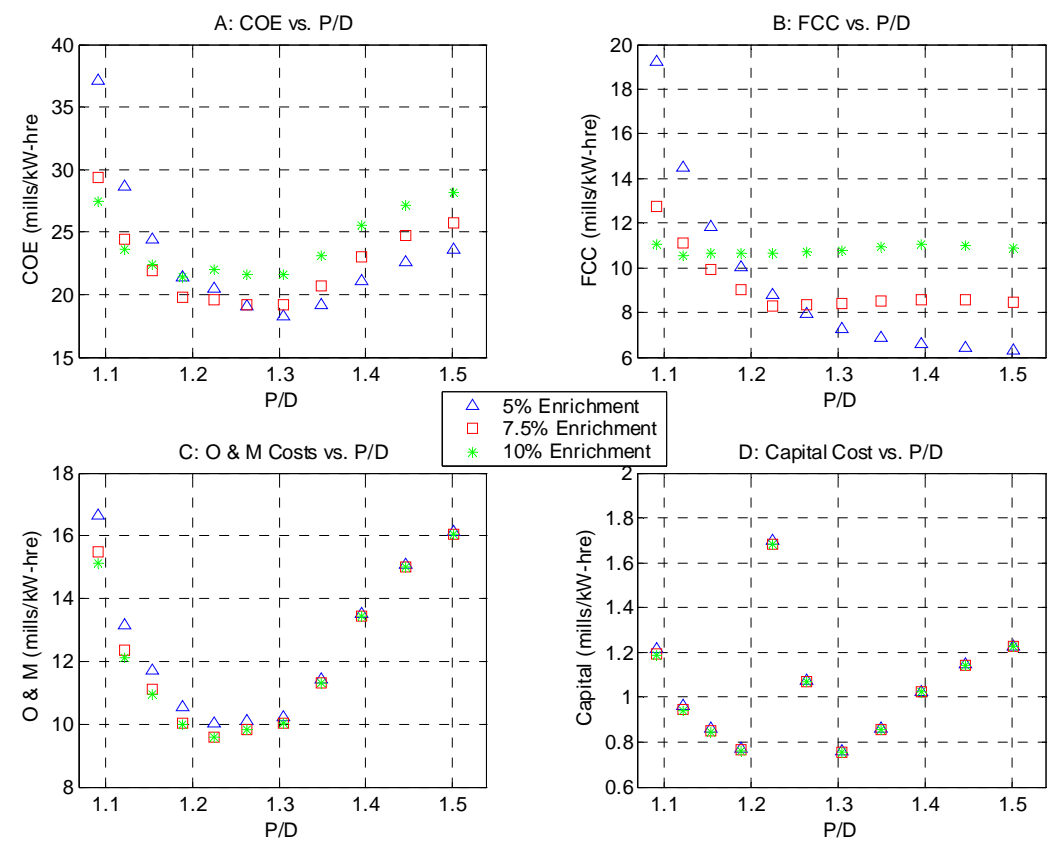

Figure 3.24 Minimum $\mathrm{COE}$ and its components vs. $\mathrm{P} / \mathrm{D}$ for $\mathrm{UO}_{2}$ at 60 psia minor backfit scenario 

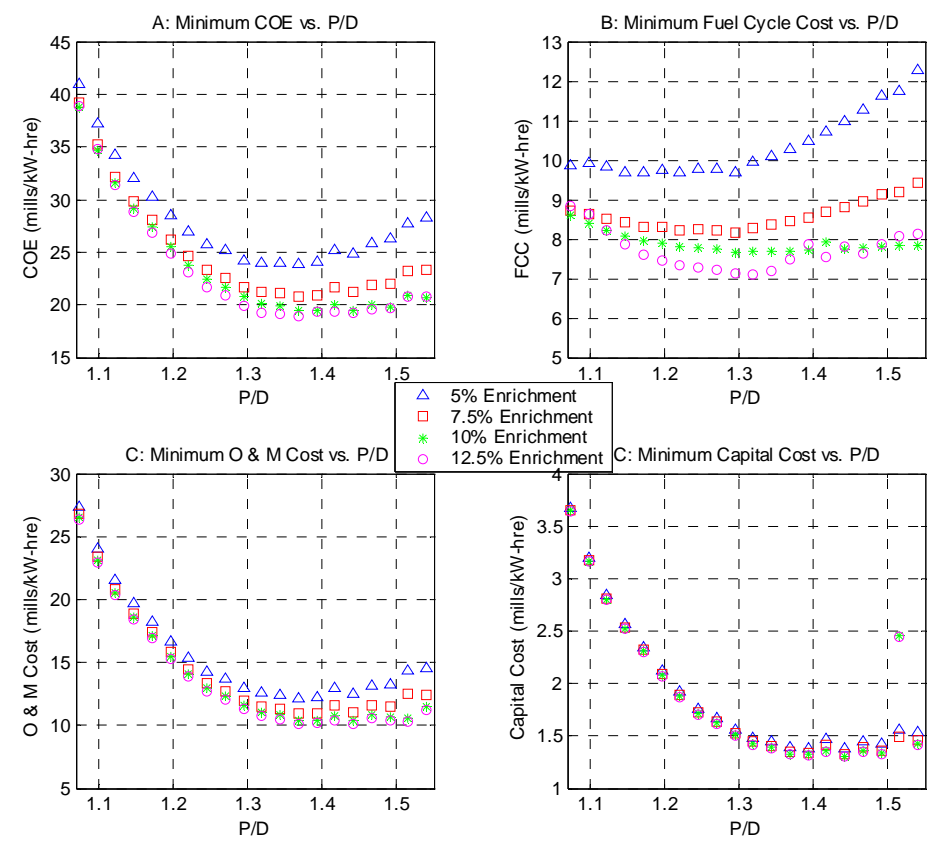

Figure 3.25 Minimum $\mathrm{COE}$ and its components vs. $\mathrm{P} / \mathrm{D}$ for $\mathrm{UZrH}_{1.6}$ at 29 psia major backfit scenario
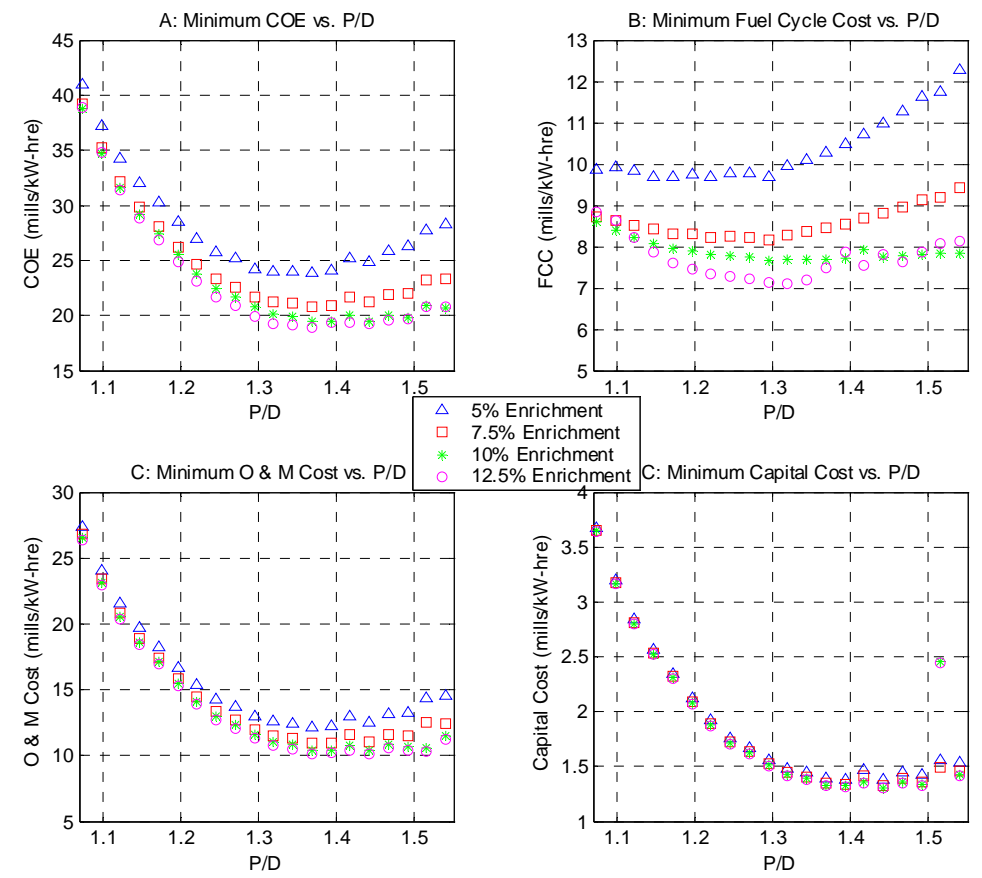

Figure 3.26 Minimum COE and its components vs. $\mathrm{P} / \mathrm{D}$ for $\mathrm{UO}_{2}$ at 29 psia major backfit scenario 

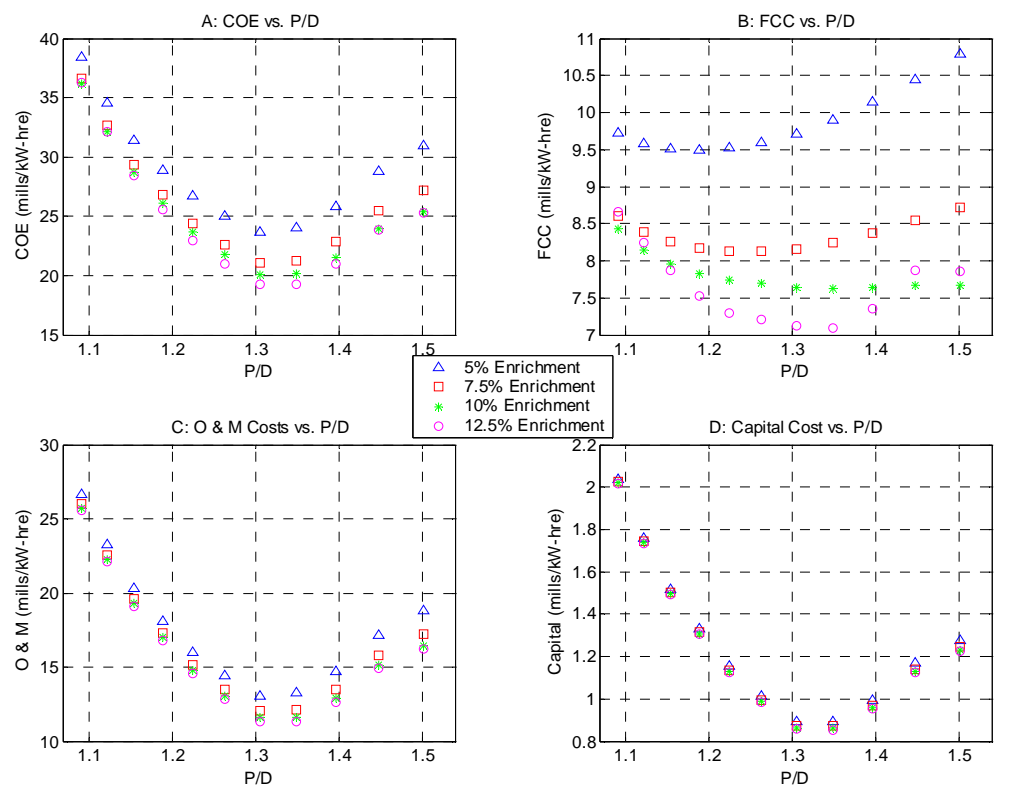

Figure 3.27 Minimum $\mathrm{COE}$ and its components vs. $\mathrm{P} / \mathrm{D}$ for $\mathrm{UZrH}_{1.6}$ at 29 psia minor backfit scenario
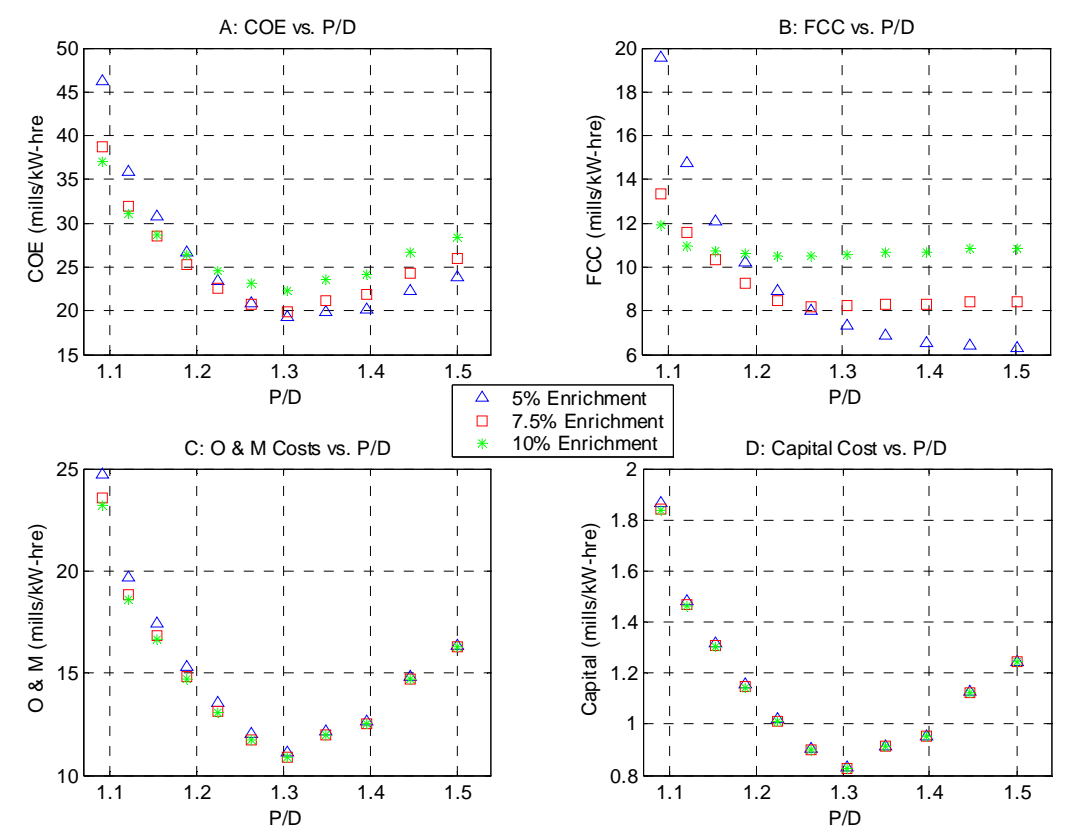

Figure 3.28 Minimum COE and its components vs. P/D for $\mathrm{UO}_{2}$ at 29 psia minor backfit scenario 


\subsection{Discussion}

Under the set of constraints assumed in this work, hydride fuel was not found to offer any power density or economic advantage over oxide fuel in PWR cores when using fuel assembly designs featuring square lattice and grid spacers. This is because, contrary to our initial expectations, thermal-hydraulic constraints prevented stacking hydride fuel with a relatively small $\mathrm{P} / \mathrm{D}$ ratio of around 1.2 or less, where it offers the highest reactivity and a higher $\mathrm{HM}$ loading. The primary $\mathrm{T}-\mathrm{H}$ constraining parameter is the pressure drop. The attainable power density and economics of hydride fuel designs are expected to improve relative to those of oxide fuel with increase in the allowable pressure drop across the core. Alternatively, hydride fuel designs could be advantageous to oxide fuel for relatively small PWR's as, for the same D, P and coolant flow rat, the pressure drop is inversely proportional to the core height.

Another promising design approach for hydride fueled PWR's involves use of hexagonal lattice with wire wrap instead of square lattice with grid spacers as the wire wrap design approach features lower coolant friction losses. This design approach is explores in Section 4.

As a spin-off of the comparison between hydride and oxide fuel performance it was found that oxide fueled PWR cores could be designed to have a significantly higher power density and lower COE than the reference design. Table 3.2 compares selected characteristics of a number of optimal $\mathrm{UO}_{2}$ core designs identified in this work with the reference design. For the reference core pressure drop of 29 psia in a square lattice with grid spacers, the lowest COE is obtained for 5\% enriched uranium at the reference geometry of $\mathrm{D}=9.5 \mathrm{~mm}$ and $\mathrm{P} / \mathrm{D}=1.326$. This is because the investment required for 
retrofitting the reactor to be able to accept a new core design more than offsets the lower attainable fuel cycle and O\&M costs. However, for a new 3800 MWth PWR to be constructed, the minimum COE will be obtained from a core having a significantly different geometry: $\mathrm{D}=7.13 \mathrm{~mm}$ and $\mathrm{P} / \mathrm{D}=1.47$; it is $[(7.65+10.10)-(6.53+10.15)] 1.07$ mills/kWh smaller than the COE from the reference PWR (assuming the capital cost of the two new PWR is the same).

Table 3.2

Comparison of optimal and reference geometries for $\mathrm{UO}_{2}$ fueled PWR cores

\begin{tabular}{|l|l|l|l|l|}
\hline \multirow{2}{*}{ Characteristic } & \multicolumn{2}{|l|}{29 psia } & 60 psia \\
\cline { 2 - 5 } & Reference & Optimal $^{\mathrm{a}}$ & Reference $^{\mathrm{c}}$ & Optimal \\
\hline COE (mills/kWe-hr) & 17.75 & $18.0^{\mathrm{b}}$ & 23.5 & 17.9 \\
\hline Capital & 0 & $1.3^{\mathrm{b}}$ & 5.75 & 2.7 \\
\hline Fuel Cycle & 7.65 & 6.53 & 7.65 & 7.13 \\
\hline O\&M & 10.1 & 10.15 & 10.1 & 8.1 \\
\hline Power (MWth) & 3800 & 3800 & $4929^{\mathrm{c}}$ & 4929 \\
\hline Geometry: D (mm) & 9.5 & 7.13 & 9.5 & 6.5 \\
\hline P/D & 1.326 & 1.47 & 1.326 & 1.39 \\
\hline Number of fuel rods & 50,956 & 73,966 & 50,956 & 98,699 \\
\hline U inventory (kg_HM) & 105,170 & 81,581 & 105,170 & 87,104 \\
\hline Linear heat rate (kW/ft) & 5.30 & 3.67 & 5.3 & 3.56 \\
\hline Power density (kW/liter) & 99.85 & 99.85 & 99.85 & 129.52 \\
\hline Specific power (kW/kg_HM) & 36.1 & 46.6 & 36.1 & 56.6 \\
\hline Average burnup (MWd/kg) & 45.6 & 56.55 & 45.6 & 52.3 \\
\hline Cycle length (yrs) & 1.22 & 1.17 & 1.22 & 0.9 \\
\hline Capacity factor & 0.95 & 0.94 & 0.95 & 0.94 \\
\hline MDNBR & 2.17 & 2.17 & 2.17 & 2.65 \\
\hline Peak fuel temp (F) & 2700 & 1906 & 2700 & 1879 \\
\hline
\end{tabular}

${ }^{a}$ Optimal for a newly constructed PWR, not a retrofit;

${ }^{\mathrm{b}}$ Capital cost component (and total COE) for a retrofitted PWR.

${ }^{c} 3800 \mathrm{MW}$ from the existing reference PWR plus $1129 \mathrm{MW}$ from newly constructed $3800 \mathrm{MW}$ PWR of the reference design.

If primary coolant pumps could be designed to provide a coolant pressure drop across the core of 60 psia and the pressure vessel internals could accommodate it, the minimum COE is obtained for $5 \%$ enriched fuel at the geometry: $\mathrm{D}=6.5 \mathrm{~mm} ; \mathrm{P} / \mathrm{D}=1.39$. The 
corresponding power density is $30 \%$ higher than the reference power density. The $\mathrm{COE}$ is estimated to be $\sim 24 \%$ lower than the cost to achieve the same total power of 4929 MW from the reference core (3800 MW) supplemented by power purchased from a new 3800 MW PWR using the reference core design (1129 MW). The capital cost assumed for the newly constructed PWR is $1800 \$ / \mathrm{kWe}$.

Relative to the reference core design, the optimal $\mathrm{UO}_{2}$ core designs arrived at in this work feature smaller uranium inventory per core loading, larger number of fuel rods, shorter cycle length, smaller linear heat rate, significantly smaller peak fuel temperature, somewhat higher discharge burnup and higher specific power.

A possible implication of the increased power density is that new PWR's could be designed for a significantly higher power - possibly up to $2000 \mathrm{MWe}$, than when using the contemporary core designs, without exceeding contemporary pressure vessel dimensions. 


\section{PWR - wire wrapped hexagonal lattice designs}

\subsection{Introduction}

The study presented in this section evaluates the relative merits of designs with hexagonal lattice having wire wrapped fuel rods instead of square lattice with grid spacers support using either hydride or oxide fuel. Relative to square lattice, hexagonal lattice can be designed to have a smaller coolant-to-fuel volume ratio - a feature that was expected to be of interest for hydride fuel that does not rely on the coolant as the sole moderator. For a given coolant-to-fuel volume ratio, wire wrap design features lower coolant pressure drop, especially in the low P/D range, illustrated in Figure 4.1 (Diller et al., 2007) - a feature that was also expected tbe particularly beneficial for hydride fuel.

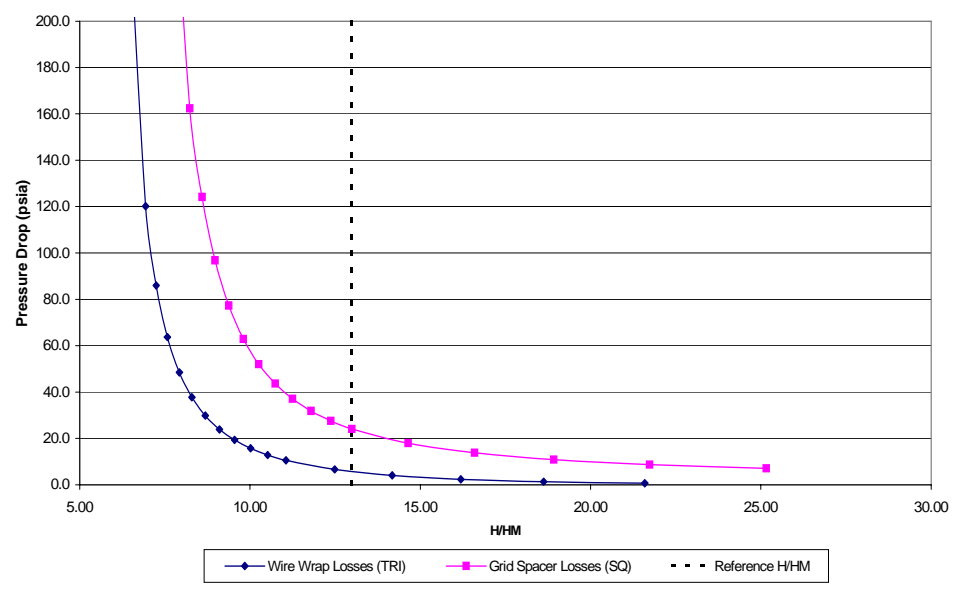

Figure 4.1 Wire wrap versus grid spacer pressure losses. Wire lead $\mathrm{H}=14$ in. versus 15 grid spacers; $\mathrm{P}=1.26 \mathrm{~cm} ; \mathrm{D}=0.80 \mathrm{~cm}-1.15 \mathrm{~cm}$.

The scope of the study performed for the hexagonal lattice wire wrapped design is similar to that used for the square lattice grid spacer design reported in Section 3. The study methodology was also similar, with few exceptions described below. More details can be found at Diller et al. (2007). 


\subsection{Methodology - general}

The reference PWR reactor and the design variables used for this study are the same used for the square lattice PWR design with grid spacers defined in Section 2. The range of pitch-to-diameter ratio considered is $1.15 \leq \mathrm{P} / \mathrm{D}_{\text {wire }} \leq 1.42$; it is comparable to the range considered for the square lattice when expressed in terms of water-to-fuel volume ratio as $\mathrm{P}_{\text {hex }}=1.0746 \mathrm{P}_{\text {square }}$. An additional design variable introduced in this study is the

axial pitch, $H$. For grid spacers, $H_{\text {grid }}$ is the reference core distance between spacers, and for wire wraps, $\mathrm{H}_{\text {wire }}$ is the axial distance over which the wire completely wraps around the rod. Due to the availability of data, all of the designs analyzed are single start hexagonal wire-wrapped assemblies -historically by far the most common wire wrap design.

Two scenarios were considered (Diller et al., 2007):

(a) Achievable Case - corresponding to conservative set of assumptions as specified in Table 4.1.

(b) Stretch Case - using more demanding constraints that are outside the range of experience but shows the potential advantages of wire wraps. Table 4.2 specifies these constraints.

\section{Table 4.1}

Steady-state achievable case constraints

\begin{tabular}{ccc} 
Constraint & Acceptable values & Calculated using \\
\hline CHF & MDNBR $>$ MDNBR $_{\text {ref }}$ & W-3L correlation \\
Axial velocity & $\mathrm{V}<\mathrm{V}_{\text {crit }}$ & Connors analysis \\
Peak fuel temperature & $\mathrm{T}_{\mathrm{CL}}<750{ }^{\circ} \mathrm{C}$ & VIPRE \\
Clad temperature & $\mathrm{T}_{\mathrm{Clad}}<350{ }^{\circ} \mathrm{C}$ & VIPRE \\
Coolant pressure drop & $<60$ psia &
\end{tabular}


Table 4.2

Steady-state stretch case constraints

\begin{tabular}{ccc} 
Constraint & Acceptable values & Calculated using \\
\hline CHF & MDNBR $>\mathrm{MDNBR}_{\text {ref }}$ & Dalle Donne \\
Axial velocity & $\mathrm{V}<\mathrm{V}_{\text {crit }}$ & Connors analysis \\
Peak fuel temperature & $\mathrm{T}_{\mathrm{CL}}<750{ }^{\circ} \mathrm{C}$ & VIPRE \\
Clad temperature & $\mathrm{T}_{\mathrm{Clad}}<350{ }^{\circ} \mathrm{C}$ & VIPRE \\
Coolant pressure drop & $<90$ psia & \\
Wrap wire axial pitch & $0.75 \cdot \mathrm{H}_{\text {grid }}$ &
\end{tabular}

The neutronic and thermal-hydraulic analyses were done for square lattices and the results were transformed to hexagonal lattices using equivalence relationships (Diller et al, 2007).

The fuel rod gap is assumed to be filled with liquid metal having a thermal conductivity of $35 \mathrm{~W} / \mathrm{m}-\mathrm{K}$ - as assumed for the designs considered in all of this study.

\subsection{Methodology - neutronics}

The neutronic characteristics for the wire wrapped hexagonal fuel assemblies were inferred from those calculated for the square lattice assemblies with grid spacers based on equivalency of H/HM ratio for a given D (Diller et al., 2007). The methodology for the neutronic analyses for square lattice geometries is described in Section 2.4.

\subsection{Methodology - thermal-hydraulics}

Grid spacers hold all of the rods together while wire wraps only provide spacing. As a result, while bundle boxes are not necessary for PWR bundles with grid spacers, they are required with wire wrap designs to keep the fuel rods together. Rather than closed bundle boxes as in BWR's, it is possible to use highly perforated box walls that will provide the needed mechanical support while enabling coolant cross mixing. Nevertheless, to be on the conservative side the thermal hydraulic analysis was performed assuming no 
subchannel mixing. This assumption resulted in only $\sim 2.3 \%$ reduction in the maximum attainable core power relative to an open box analysis.

Turbulent mixing with wire wraps is calculated using a correlation developed by Cheng and Todreas (Diller et al., 2007). The subchannel mixing is proportional to the gap size, P-D. Since VIPRE is run for square subchannels, the gap size and thus, mixing coefficient, will be incorrect for the hexagonal subchannels it will be applied to. However, our study found that the core power is relatively insensitive to the mixing coefficient $-\sim 5 \%$ power reduction with no mixing coefficient over most of the power map. Consequently, this approximation is expected to have little impact on the conclusions of this study.

While the CHF database for bundles with grid spacers is extremely well developed, this is not the case with wire wraps. The geometries of interest to this study - large $P / D$, large H/D and small D, have particularly scarce data. Hence a conservative bound on the CHF was used for the Achievable Case, and a best estimate correlation was used for the Stretch Case.

For all of the wire wrap CHF experiments examined in this study, the CHF performance of wire wraps was comparable to, or better than, grid spacer performance (Diller et al., 2007). As a result, for the Achievable Case scenarios the MDNBR was calculated using the W-3L correlation - identical to the approach used for the grid spacer designs. This is a conservative approach.

Dalle Donne created the most commonly referred to wire wrap CHF correlation. This is a correlation for a spacer coefficient used in Bowring's WSC-2 CHF correlation. However, the WSC-2 correlation behaves differently than the W-3L correlation over the 
power map, and its direct application gave results inconsistent with previous results using the W-3L correlation. Consequently, at each geometry the WSC-2 limit was found that allowed the same maximum power as predictable by the constant W-3L for MDNBR of 2.17, guaranteeing consistent power maps with the two correlations. Dalle Donne's wire wrap spacer coefficient was used in the WSC-2 correlation with the WSC-2 limit equivalent to the W-3L MDNBR limit of 2.17 (Diller et al., 2007).

The pressure drop was calculated using the Cheng/Todreas friction factor correlation for wire wraps (Diller et al., 2007).

The steady-state constraints applied are similar to those for the grid spacers designs described in Section 2.5 and are summarized in Tables 4.1 and 4.2. An exception is the maximum allowable coolant pressure drop across the core assumed 90 psia for the "stretch case" scenario.

\subsection{Methodology - vibrations}

Two types of vibrations are considered - thermal-hydraulic vibrations (THV), and flow-induced vibrations (FIV). The Otsubo model was used for a conservative analysis of THV (Diller et al., 2007); these are low frequency vibrations caused by feedback between the fluid flow and rod bow due to thermal expansion in the fuel rods. An empirical equation for the critical cross-flow velocity of a rod bundle pinned at both ends derived by Connors was used for the analysis of FIV (Diller et al., 2007) - high frequency vibrations caused by local pressure variations due to the nature of the turbulent flow. The cross-flow velocity was calculated for each geometry from the axial-flow velocity using the sweep angle of the wire wraps, so that the FIV limit was effectively a limit on the axial velocity. 
Fretting wear is a significant concern when implementing wire wraps, as the wires of one rod directly contact the adjacent rod. Shuffler (2004; also Section 2.7) calculated the total fretting wear for gridded arrays over the fuel cycle length and constrained this to be less than the reference core total fretting wear. The fretting wear rate was calculated for the reference geometry at the reference power. This was done using grid spacers and wire wraps, and the wire wrap fretting wear rate was found to be $10.4 \%$ lower than the grid spacer fretting wear rate. This is promising, but fretting wear experiments are needed perhaps more than any other type of experiment to verify wire wrap performance.

\subsection{Methodology - clad integrity}

Although the clad integrity imposed limit on the attainable burnup depends on the attainable hot-rod power, no self-consistent fuel performance analysis was performed for wire wrap designs. Instead, the burnup map created for the 60 psia grid spacer designs and reported in Section 3.3 was assumed applicable for the wire wrap designs; the power levels of the wire wrap designs are closest to those of the 60 psia grid spacers designs. The methodology used for the clad integrity analysis is described in Section 2.6.

\subsection{Methodology - economics}

The economic analysis methodology used is similar to that described in Section 2.9. Due to the inherent fuel assembly geometry change required to accommodate hexagonal lattice of wire wraps rods, minor backfits scenarios are not possible for wire wrap designs; the economic analysis is performed only for major backfit scenarios.

\subsection{Results - steady-state}


The steady-state power maps for the Achievable and Stretch Case with hydride fuel are shown in Figures 4.2 and 4.3, respectively, where $\mathrm{P} / \mathrm{D}_{\mathrm{sq}}$ is the thermal-hydraulic equivalent square lattice $\mathrm{P} / \mathrm{D}$ of $\mathrm{P} / \mathrm{D}_{\text {wire }}$ that applies to the actual hexagonal wire wrap lattice P/D (Diller et al., 2007). Fuel temperature is the only limit that depends on fuel type. However, the fuel temperature limits are not constraining for regions of maximum

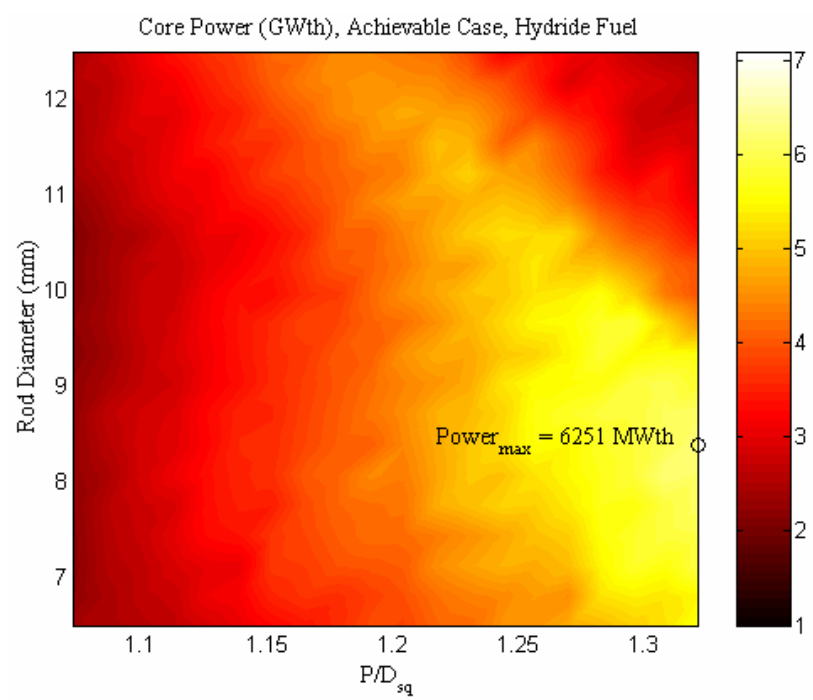

Figure 4.2 Achievable Case hydride power map; steady-state analysis

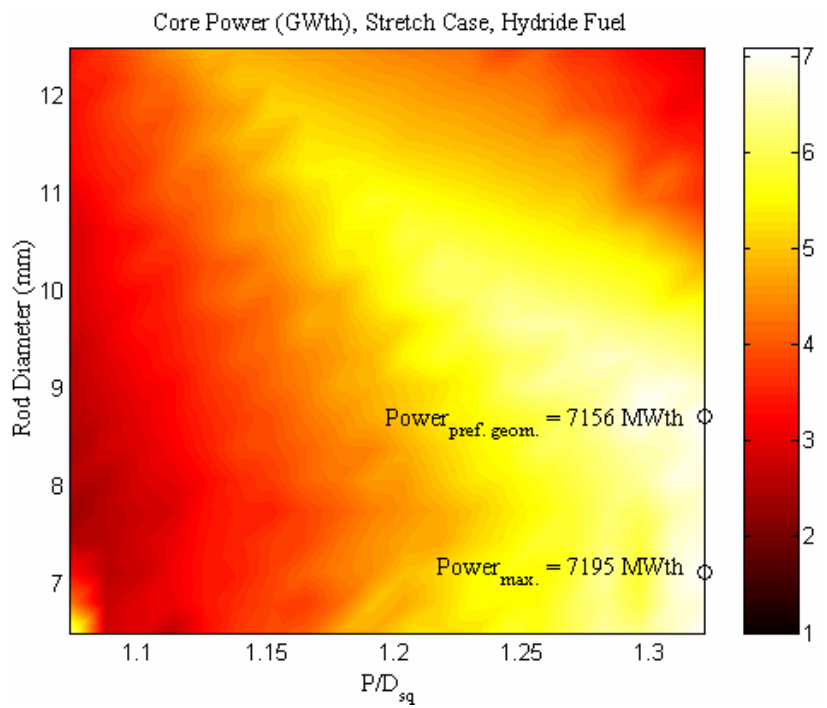

Figure 4.3 Stretch Case hydride power map; steady-state analysis 
power. Consequently, the steady-state achievable power for hydride and oxide fuel designs is almost identical, and in practice is identical for the regions of maximum power.

A $64.5 \%$ power increase over the reference core is obtained for the Achievable Case (6251 MWth), and 88.3\% for the Stretch Case (7156 MWth). The Achievable Case maximum power geometry is $\mathrm{D}=8.39 \mathrm{~mm}, \mathrm{P} / \mathrm{D}_{\text {wire }}=1.42$. The latter is equivalent to $\mathrm{P} / \mathrm{D}_{\mathrm{sq}}=1.321$. The Stretch Case preferable geometry is $\mathrm{D}=8.71 \mathrm{~mm}$ with $\mathrm{P} / \mathrm{D}_{\text {wire }}=1.42$. The power at the preferable geometry is very slightly lower than the maximum attainable, but due to it's larger pin diameter is more feasible.

\subsection{Results - transient analysis}

The transient performance of wire wraps was analyzed for the overpower transient and the loss of coolant accident (LOCA); as reported in Section 3.4, loss-of-flow accidents were found not to limit the attainable power of square lattice designs. The overpower transient was evaluated using the MATLAB/VIPRE interface, analogous to the steady-state analysis (See Sections 2.5 and 2.7). The only difference is that the average linear heat generation rate of the core is increased by $17.267 \%$, the stated overpower value of the reference core. The MDNBR of the reference core is recalculated with the new linear heat rate, and is taken as the new MDNBR limit for the overpower transient. This new MDNBR limit is more constraining than the steady-state MDNBR limit and the axial velocity is generally higher as well. As a result, the achievable powers of the overpower transient are lower than the steady-state with a reduction in maximum power of 3.6\% for the Achievable Case and 5\% for the Stretch Case. As for the steadystate analysis, the hydride and oxide power maps are essentially identical. 
The LOCA performance of wire wraps was calculated using RELAP 5-3D for both hydride and oxide fuels. The constraining limits are a cladding temperature of $1204^{\circ} \mathrm{C}$ for oxide and a fuel temperature of $1050^{\circ} \mathrm{C}$ for hydride. The LOCA analysis was only performed for the Achievable Case maximum power geometry. The safety injection (SI) system was assumed to scale with the power, allowing the core to eventually cool, even for power uprates on the order of $100 \%$. It was found that the cladding temperature limits oxide fuel, while the fuel temperature limits hydride fuel. It was also found that the power predicted using steady state analysis for the Achievable Case scenario is within the limits for both of the fuels, while both of the fuels exceed their design limits for the Stretch Case scenario.

Figures 4.4 and 4.5 give the attainable power as calculated using, respectively, the Achievable Case and Stretch Case scenarios, accounting for the overpower transient and LOCA. The maximum power of the Stretch Case - $6251 \mathrm{MWth}$, is only $4 \%$ higher than the maximum power of the Achievable Case - 6025 MWth. Considering the liberal assumptions applied to the Stretch Case, this marginal increase in power undermines the case for further consideration of the Stretch Case. Hence, the maximum power of a wire wrapped hexagonal lattice design is taken to be $6025 \mathrm{MWth}$ - a 59\% power increase over the reference core.

\subsection{Results - burnup limits}

The burnup limits used for the economic analysis are the smaller of the values determined by the neutronic analysis (Section 4.3 ) and by the clad integrity analysis (Section 4.6). Figures 4.6 and 4.7 give the neutronically limited burnup maps for hydride and oxide fuels with $12.5 \%$ and $7.5 \%$ enrichments, respectively. These enrichments were 
found to have the lowest $\mathrm{COE}$ in the economic analysis. Figures 4.8 and 4.9 give the clad integrity limited burnups used; they are independent of the fuel enrichment.

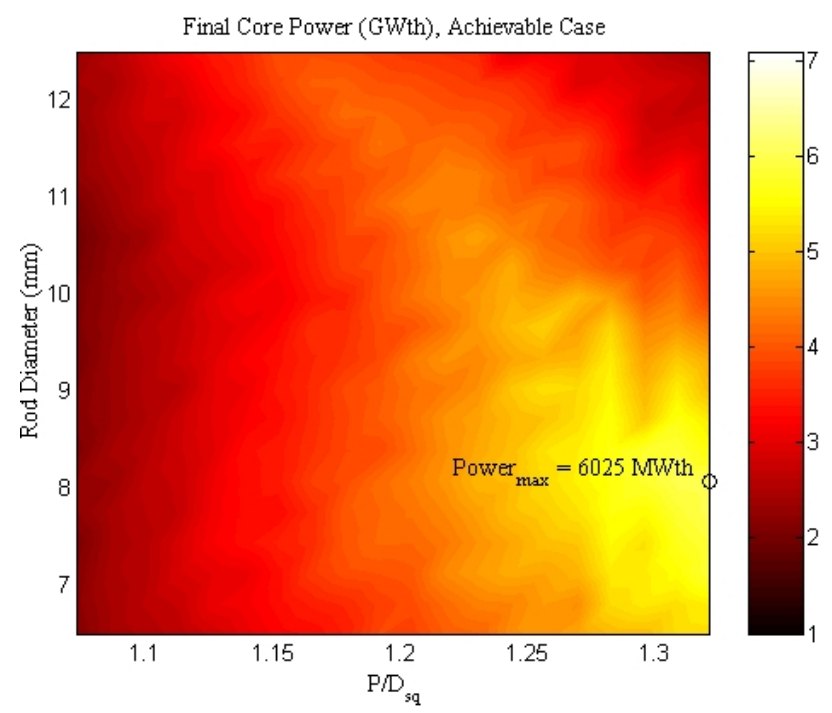

Figure 4.4 Achievable Case hydride power map accounting for transients

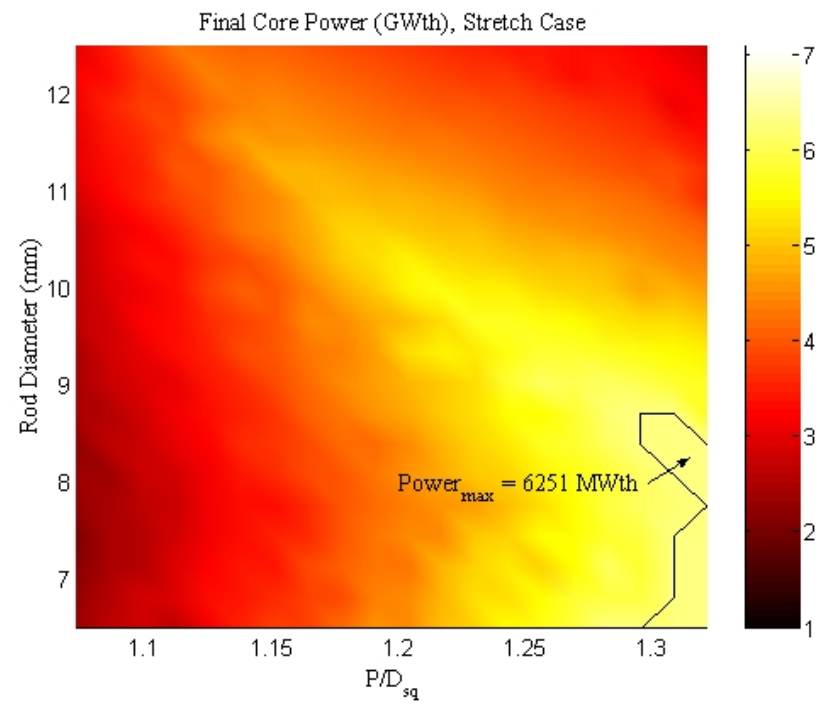

Figure 4.5 Stretched Case hydride power map accounting for transients 


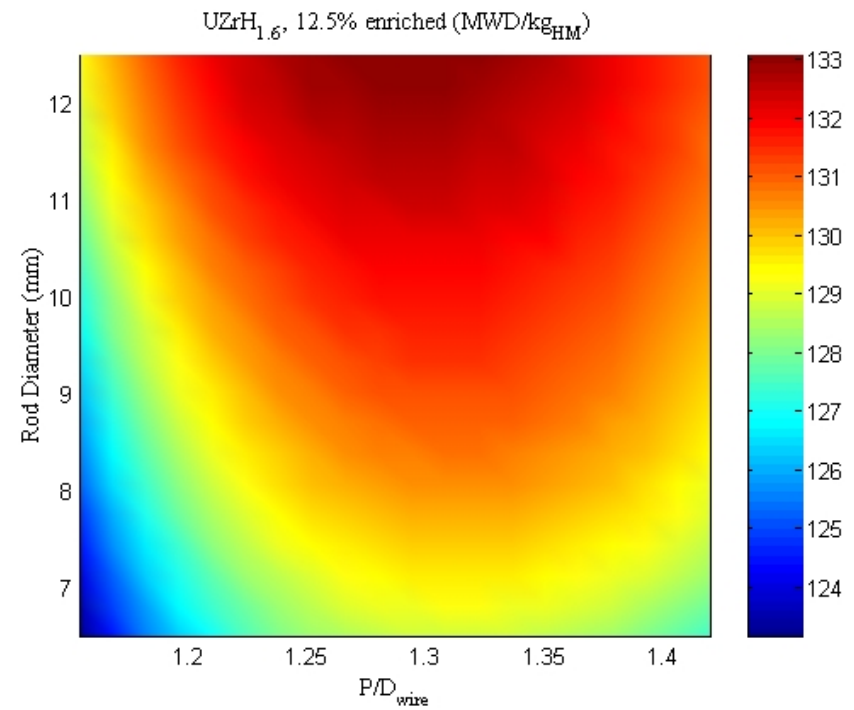

Figure 4.6 Neutronics limited burnup for $12.5 \% \mathrm{UZrH}_{1.6}$ wire wrapped lattices

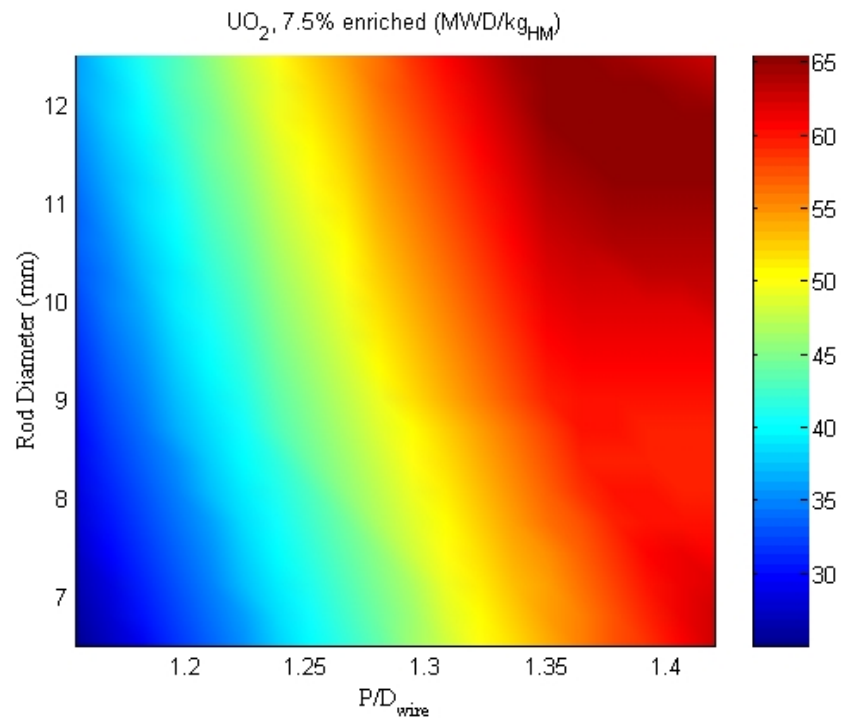

Figure 4.7 Neutronics limited burnup for for $7.5 \% \mathrm{UO}_{2}$ wire wrapped lattices 


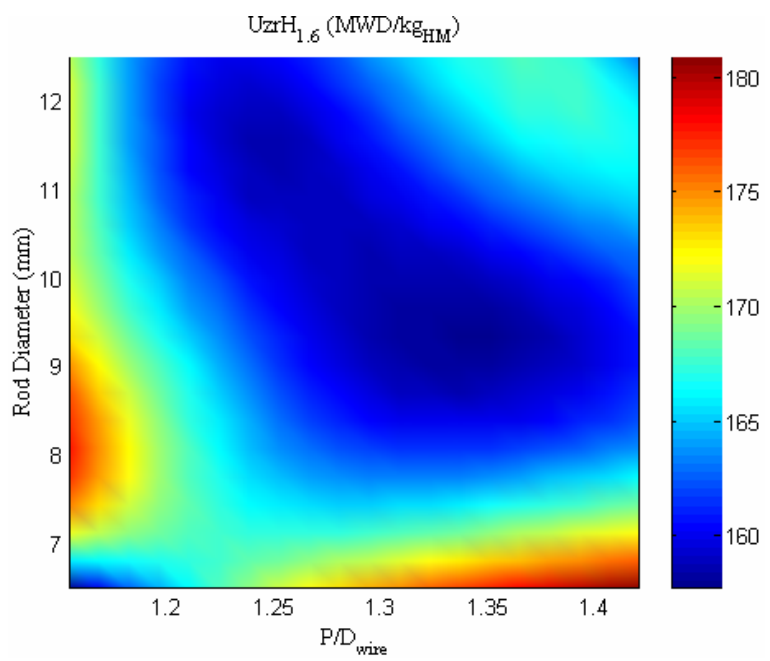

Figure 4.8 Clad integrity limited burnup for $\mathrm{UZrH}_{1.6}$ wire wrapped designs

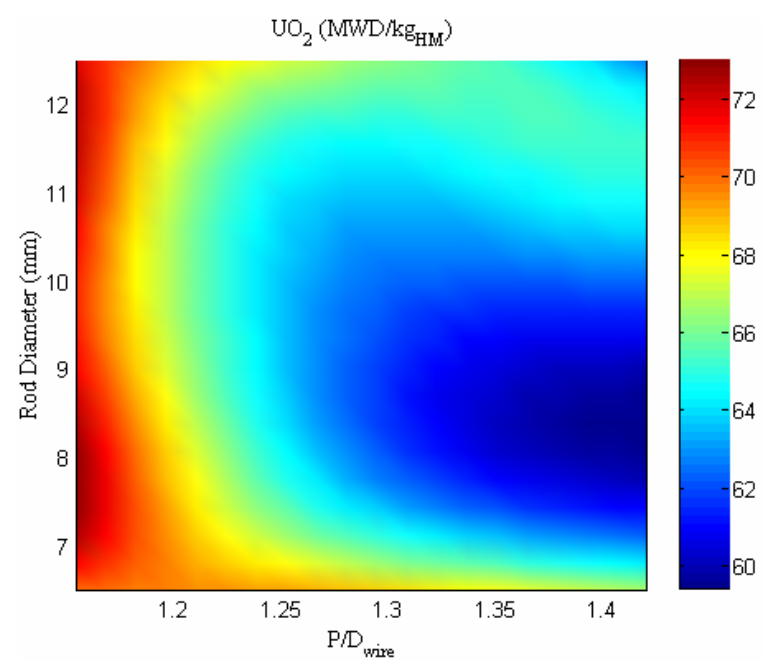

Figure 4.9 Clad integrity limited burnup for $\mathrm{UO}_{2}$ wire wrapped designs

\subsection{Results - economics}

The economic analysis was performed over all of the geometries considered for oxide and hydride fuels. Table 4.3 summarizes the findings for optimal wire wrap designs and compares them against the optimal grid spacers designs reported in Section 3.5. All cases are for cores that fit in the reference plant reactor vessel. The three Major Backfit cases use new fuel assembly envelopes and control rod layouts, thus requiring new vessel heads 
and internals as well as larger primary loop components for the increased power ratings.

The Achievable Case results given in Table 4.3 pertain to the final power map; i.e., it accounts for the transient constraints. The Stretch Case results, on the other hand, account only for the steady-state constraints. These two scenarios act as bounding cases for the economic performance of wire wraps.

Table 4.3

COE comparison of grid spacers and wire wraps with optimal fuel type and enrichment

\begin{tabular}{|c|c|c|c|c|c|}
\hline \multirow[b]{3}{*}{ Characteristic } & \multicolumn{3}{|c|}{ Major Backfit } & \multicolumn{2}{|c|}{ No Backfit } \\
\hline & \multicolumn{2}{|c|}{ Wire Wraps } & \multicolumn{3}{|c|}{ Grid Spacers } \\
\hline & $\begin{array}{c}\text { Achievable } \\
\text { Case }\end{array}$ & $\begin{array}{l}\text { Stretch } \\
\text { Case }\end{array}$ & Uprate & $\begin{array}{c}1.58 \\
\text { Reference } \\
\text { plants }\end{array}$ & $\begin{array}{c}\text { Reference } \\
\text { plant }\end{array}$ \\
\hline Fuel Type & $\mathrm{UZrH}_{1.6}{ }^{*}$ & $\mathrm{UZRH}_{1.6}{ }^{*}$ & $\mathrm{UO}_{2}$ & $\mathrm{UO}_{2}$ & $\mathrm{UO}_{2}$ \\
\hline Enrichment & $12.5 \%$ & $12.5 \%$ & $5 \%$ & $5 \%$ & $5 \%$ \\
\hline $\mathrm{D}(\mathrm{mm})$ & 8.08 & 8.71 & 6.5 & 9.5 & 9.5 \\
\hline $\mathrm{P} / \mathrm{D}_{\text {actual }}$ & 1.41 & 1.42 & 1.39 & 1.326 & 1.326 \\
\hline Linear heat rate $(\mathrm{kW} / \mathrm{ft})$ & 6.05 & 8.23 & 3.56 & 5.30 & 5.30 \\
\hline Power (MWth) & 6011 & 7156 & 4929 & 6011 & 3800 \\
\hline Capacity factor & 0.94 & 0.93 & 0.94 & 0.95 & 0.95 \\
\hline Cycle length (yrs) & 0.90 & 0.76 & 0.9 & 1.22 & 1.22 \\
\hline COE (mils/kWe-hr) & 17.11 & 16.11 & 17.9 & 26.98 & 17.75 \\
\hline Fuel cycle cost & 7.63 & 7.45 & 7.13 & 7.65 & 7.65 \\
\hline O\&M cost & 6.65 & 5.74 & 8.1 & 10.1 & 10.1 \\
\hline Capital cost & 2.83 & 2.92 & 2.7 & 9.23 & 0 \\
\hline
\end{tabular}

* the COE of oxide was found an average of $4 \%$, or $0.7 \mathrm{mils} / \mathrm{kWe}-\mathrm{hr}$ higher than hydride for the same case

It is found that the Achievable Case - the most conservative hydride fuel wire wrap design, has a COE of 17.11 mils/kWe-hr. It is lower than the COE of all the grid spacer design alternatives, including the Reference oxide plant. The minimum COE of the oxide core design, not shown in the table, was found to be $0.7 \mathrm{mils} / \mathrm{kWe}-\mathrm{hr}$ higher than that of the hydride core design pertaining to the same scenario. 
The "1.58 Reference Plants" case of Table 4.3 is the reference against which the Achievable Case wire wrap design is to be compared with - it consists of one reference plant (as of the rightmost column of Table 4.3) plus 58\% of a new reference-like plant that needs to be constructed in order to provide a combined power of 6011 MWth that is comparable to the power attainable from the backfit "Achievable Case". The FCC and O\&M COE are the same as for the reference plant, but the new reference plant capital cost is charged $1800 \$ / \mathrm{kWe}$ for the $58 \%$, i.e., $2211 \mathrm{MWth}$, of its rated energy. It is found that wire wrap Major Backfit design approach offers $\sim 40 \%$ lower COE than a construction of a new reference plant to provide the same total power -17.11 versus $26.98 \mathrm{mils} / \mathrm{kWe}-\mathrm{hr}$.

\subsection{Discussion}

While any shift from the use of square lattices with grid spacers to hexagonal lattices with wire wraps would require a major development and major retrofitting, the potential performance advantages of wire wrap designs justify their further investigation. The most notable advantage of wire wraps over grid spacers is their significant reduction in pressure drop and CHF. Contrary to intuition, wire wraps could also provide improved vibrations characteristics - wire wraps do not relax with exposure and provide support at many more axial locations thus improving both the fretting wear and FIV performance. Neither FIV nor fretting has ever been observed in wire wrap testing.

The reduced pressure drop of wire-wrap designs enable to significantly increase the power density attainable from PWR cores and, thereby, significantly improve their economics. The power density increase and COE attainable with hydride fuel are comparable to those attainable with oxide fuel. The fuel rod outer diameter and lattice 
pitch of the optimal wire wrap designs found are in the range of $\mathrm{D}=0.8$ to $0.9 \mathrm{~mm}$ and P/D slightly larger than 1.4.

There are design variations in wire wraps not explored in this work due to the lack of data. Most notably, wire wrap assemblies can be arranged in a square lattice. This may allow for the introduction of wire wrap fuel without the replacement of the vessel head and core internals. 


\section{PWR - inverted geometry designs}

\subsection{Introduction}

By inverted geometry we mean that rather than having cylindrical fuel rods surrounded by coolant, the core consists of hexagonally shaped fuel prisms with circular coolant channels penetrating them. Figure 5.1 shows an inverted geometry unit cell versus a standard unit cell. Characteristics of the inverted design that prompted our investigation include manufacturability with hydride fuels, lack of vibration concerns, reduced pressure drop due to lack of grid spacers, and the potential for improved correlation between high power, high heavy metal loading, and high burnup geometries, relative to the standard core.

The inverted geometry is characterized by two parameters - channel diameter and pitch. For standard rod bundles the subchannel is a coolant channel surrounded by fuel rods while for the inverted design the subchannel is a fuel subprism surrounded by circular coolant channels - See Figure 5.1. The circular channels are arranged within the fuel in triangular arrays to minimize the conduction length between the channel wall and the center of the fuel subprism.

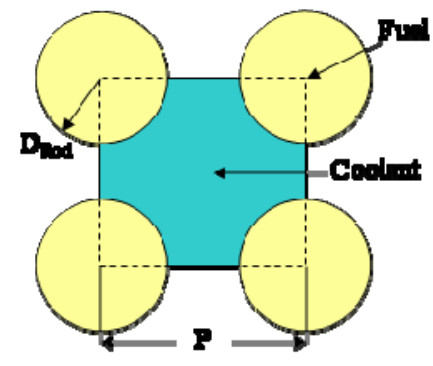

Etandard Rod Bundl.

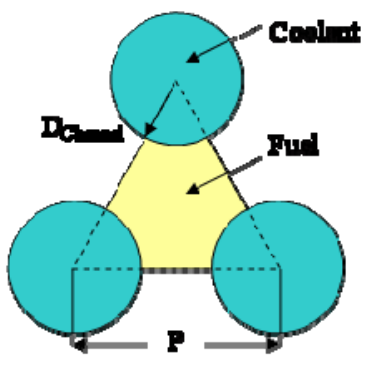

Imrortad Danign

Figure 5.1 Unit cell of inverted geometry core versus standard core 
The number and height of subchannels within each block of fuel, and the number of blocks of fuel in the core may vary. This study assumes a single block of fuel that is $12 \mathrm{ft}$. tall that fills a fixed core volume and is penetrated by uniformly spaced coolant channels. The coolant channels are only connected at the core inlet and outlet, where flow distribution is determined.

\subsection{Methodology}

A comparison was made between the inverted and standard designs by performing, for both designs, a thermal-hydraulic parametric study covering a wide range of fuel to coolant ratios (FCRs). Whereas Section 3 reports upon full core analysis of a standard design featuring $14 \mathrm{ft}$ high cores, the analysis was redone for a $12 \mathrm{ft}$ core so as to have a consistent comparison with the $12 \mathrm{ft}$ inverted core designs. Assumptions used for the present analysis include a fixed enthalpy rise of $192.1 \mathrm{~kJ} / \mathrm{kg}$, coolant inlet temperature of $294{ }^{\circ} \mathrm{C}$, system pressure of 2250 psia and radial and axial peak to average power ratios of 1.65 and 1.55 , respectively.

The thrust of the thermal hydraulic and transients analyses was to determine the maximum achievable power for the considered inverted and standard geometries subjected to the steady state and transient constraints. The transients considered are those found in Section 3.4 to limit the attainable core power below that predicted by steadystate analysis - Overpower and Loss of Coolant Accident (LOCA). The constraints imposed are, essentially, those defined in Sections 2.5 and 2.8 with few exceptions: (a) No flow velocity constraint was applied to the inverted geometry, as its performance is not expected to be affected by vibrations. A $8 \mathrm{~m} / \mathrm{s}$ limit was imposed on the flow velocity of the standard design. (b) The Groenveld 1995 lookup table was used to predict the CHF 
for the inverted design (Shuffler et al., 2007a) in case of overpower transient, whereas the W3-L correlation was used to predict the MDNBR constraint for the standard design. Although core pressure drop is a realistic limitation, it is not a safety concern with a hard upper limit. Hence, we've chosen to compare inverted and standard core designs by evaluating the maximum pressure drop for the inverted core over the entire design range and, for consistency, assigning that as a limit to the core pressure drop for the standard core. The pressure drop imposed was 48 psia. The LOCA analysis was performed using RELAP. All other analyses were performed using a single channel VIPRE model of the hot channel.

\subsection{Results}

Figure 5.2 compares the maximum attainable power from inverted and standard geometries having the same FCR. The FCR is directly proportional to hydrogen to heavy metal ratio so that, to first order approximation, the standard and inverted geometries of equal FCR are neutronically similar. The power of the standard design is peaked at 4600 MWt at an FCR of $\sim 0.45$, while the power of the inverted design is monotonically decreasing with FCR, offering a maximum power of $4400 \mathrm{MWt}$ at an FCR of 0.3 . The standard design exhibits a peak because it is limited by pressure drop at high FCR and DNBR at low FCR while, in considered design range, the inverted design is only limited by MDNBR. The inverted geometry achieves the maximum power at a very low pressure drop of $\sim 20$ psia whereas the standard geometry achieves its maximum power at the limiting pressure drop of $48 \mathrm{psia}$. It is concluded that reduced pumping capacity makes the inverted design more favorable while enhanced pumping capacity makes the inverted design less favorable. It is also seen from Figure 5.2 that the inverted core can achieve a 
higher power than the standard core at FCR $>0.9$ and that the maximum power of the inverted core is far less sensitive to FCR than that of the standard core. The optimal diameter corresponding to the peak power is given in Figure 5.3.

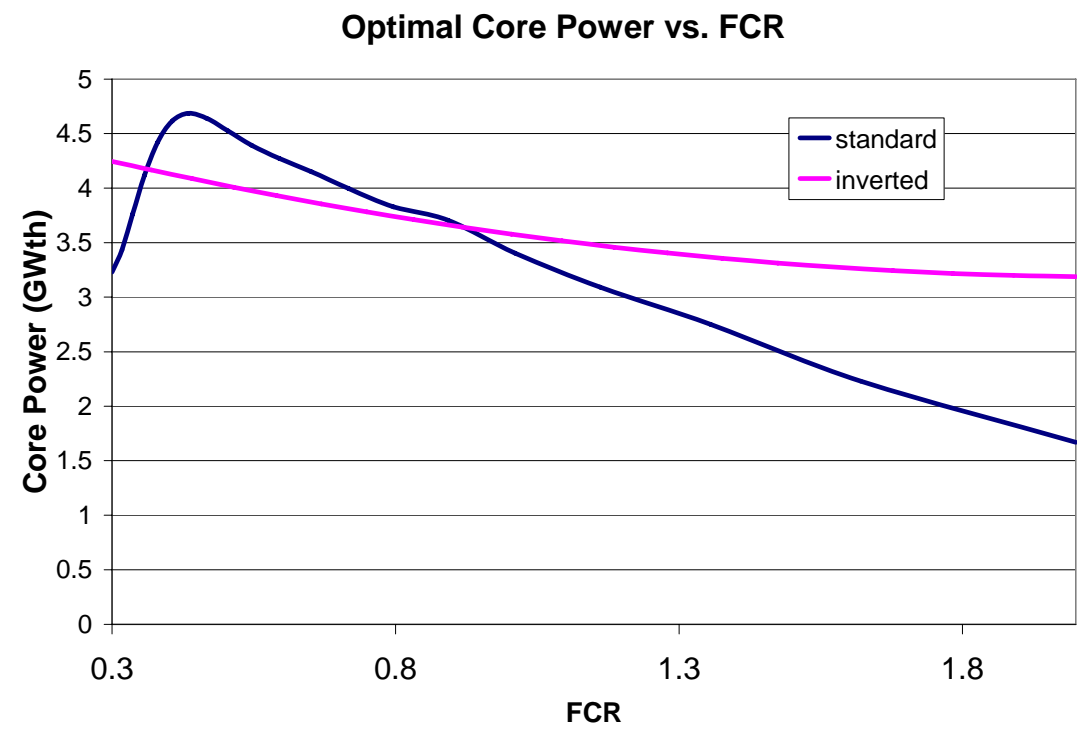

Figure 5.2 Attainable power for inverted versus standard core geometry using hydride fuel

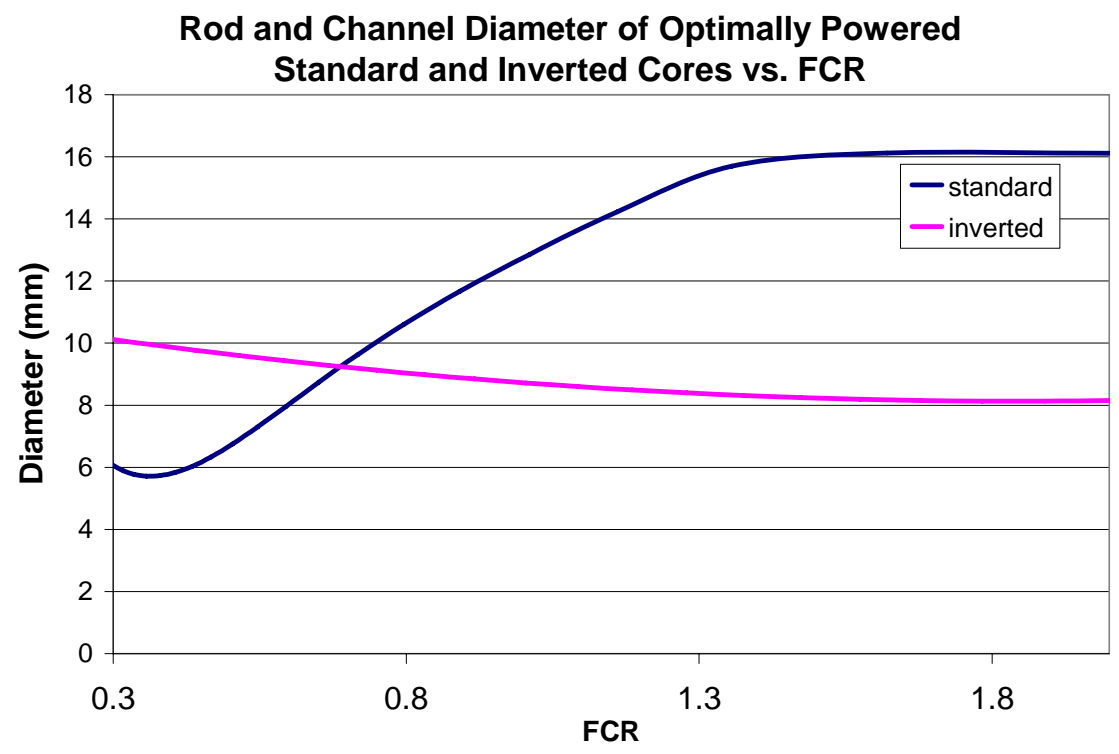

Figure 5.3 Optimal coolant channel diameter for inverted design and optimal fuel rod diameter for standard core geometry using hydride fuel 
Figure 5.4 shows the effective full power years (EFPY) of a hydride fuel assembly using $12.5 \%$ enriched uranium calculated as EFPY $=\left(B U \times \mathrm{M}_{\mathrm{HM}}\right) /(365.25 \times \mathrm{Q})$, where

$\mathrm{BU}$ is the average discharge burnup [MWD/kgHM],

$\mathrm{M}_{\mathrm{HM}}$ is the heavy metal (Uranium, in our case) inventory per fuel assembly $[\mathrm{Kg}]$ and

$\mathrm{Q}$ is the fuel assembly average power [MW].

The results of the neutronic analysis performed for hydride fuel, summarized in Section 3.1 , indicate that the burnup of $\mathrm{U}-\mathrm{ZrH}_{1.6}$ fuel peaks in the vicinity of FCR of $\sim 0.8$, drops off gradually for FCR $>0.8$ and drops off rapidly for FCR $<0.8$. The HM inventory increases with the FCR while the attainable power is shown in Figure 5.2. Figure 5.4 shows that the inverted and standard designs have similar EFPY for FCR $<0.8$ but the inverted design has lower EFPY for FCR $>0.8$ because it has much higher power in this range. The 4.5 EFPY currently used by industry for oxide fuel assembly designs can be obtained for FCR of $\sim 1.0$ using either standard or inverted designs. At this FCR the power attainable from the two designs is comparable. However, if industry would like to adopt a 2 year refueling interval, implying approximately 6 EFPY equivalent, the inverted core design is predicted to offer $\sim 3250$ MWth versus $\sim 3000$ MWth of the standard core, i.e., a $\sim 8 \%$ higher power level. This is too small of a gain to warrant development of such a revolutionary core design. 


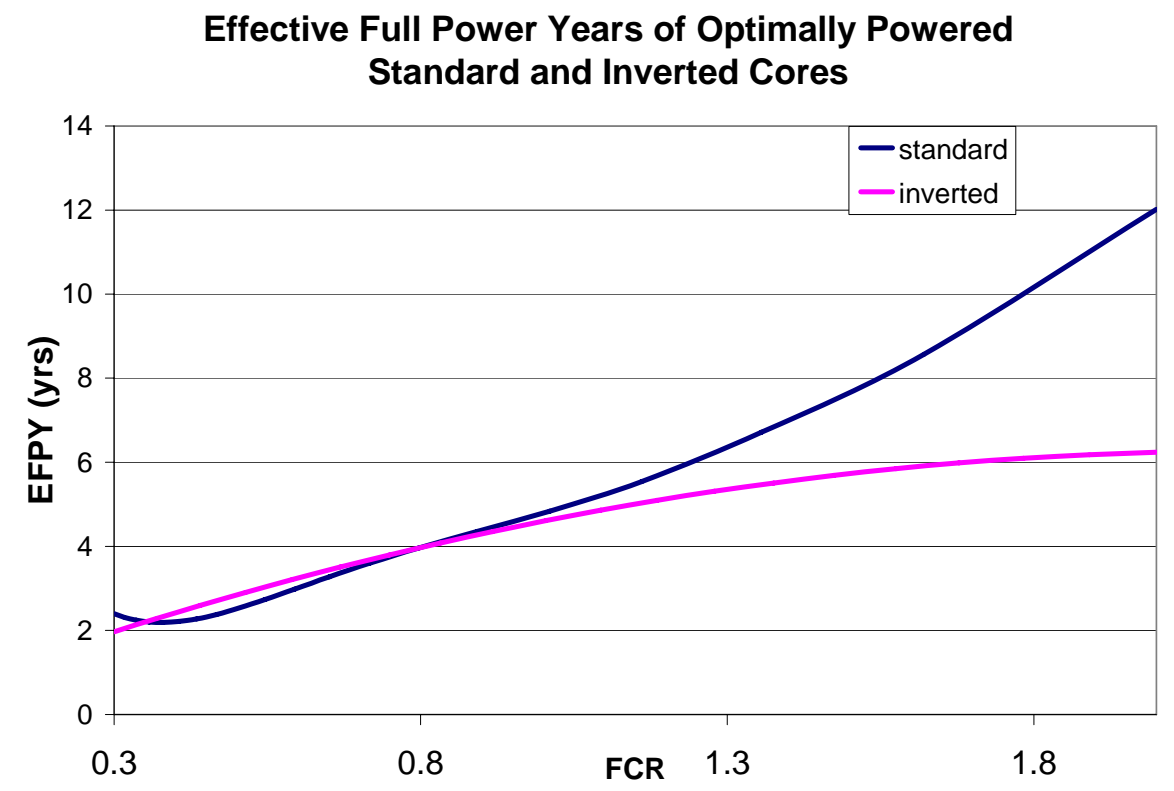

Figure 5.4 Attainable fuel lifetime for inverted versus standard core geometry using hydride fuel

\subsection{Discussion}

The maximum power attainable using the inverted core design approach is found lower than that attainable with the standard design approach but less sensitive to FCR. The inverted geometry is more favorable in systems with low pumping capacity. The MDNBR was the constraint most limiting the power attainable from the inverted design so that technologies to reduce $\mathrm{CHF}$ in circular tubes could make the inverted design more favorable relative to the standard design. Overall the benefits expected from the inverted core design approach appear too small to warrant development of such a revolutionary technology. 


\section{PWR - plutonium containing designs}

\subsection{Introduction}

A drawback of the hydride fuel considered so far is that, due to its relatively low HM density, it requires higher enrichment than oxide fuel to provide the reference PWR cycle length and to minimize the COE. However, if the primary fissile material is plutonium - as need be the case if the PWR is to recycle plutonium, the low HM inventory of hydride fuel is, in fact, an advantage, as is the enhanced moderation due to the hydrogen incorporated in the fuel. The primary objective of the work reported in this section is to compare the transmutation capability of PWR that is fueled with uniform fuel assemblies using either hydride or MOX fuel. This capability is measured by the fraction of $\mathrm{Pu}$ that is transmuted per cycle and by the radiotoxicity, neutron source strength and decay-heat of the discharged fuel. Being a very preliminary feasibility assessment, only neutronic analysis has been performed (Ganda and Greenspan, 2007c; 2005a; 2005b). It is assumed that the thermal hydraulic performance of the plutonium bearing fuel will be comparable to that of the enriched uranium fuel considered above.

If MOX fuel is used to replace all of the $\mathrm{UO}_{2}$ in the reference PWR fuel assembly geometry, this core neutron spectrum is significantly harder than that of the reference $\mathrm{UO}_{2}$ core, as illustrated in Figures 6.1 and 6.2. This relatively hard neutron spectrum impairs the achievable discharge burnup and fractional transmutation of $\mathrm{Pu}$ per cycle, reduces the reactivity worth of the control and safety rods as well as of the soluble boron, and limits the number of possible recycling due to positive void coefficient. Consequently, many fuel assemblies designed for Pu recycling feature higher water-to- 
fuel volume ratio than in the reference $\mathrm{UO}_{2}$ fueled PWR's, as can be found in references cited in Ganda and Greenspan (2005a; 2005b; 2007c).

MOX containing fuel assemblies that offer acceptable performance, like the so-called "CORAIL" design or "CONFU" design are highly heterogeneous (Youniou et al., 2001; Taiwo et al., 2003; Shwageraus et al., 2003). Other designs include addition of moderator volume on the expense of fuel volume (Trellue, 2004), thereby softening the neutron spectrum and improving the destruction efficiency and safety features of the core but also reducing the attainable power level and impairing the PWR economics.

Hydride fuel offers a number of new possibilities for loading $\mathrm{Pu}$ (and minor actinides; these were not considered in the present work) into PWR's. The hydride fuel we are proposing as the direct equivalent to $\mathrm{MOX}$ fuel is $\mathrm{U}-\mathrm{PuH}_{2}-\mathrm{ZrH}_{1.6}(\mathrm{PUZH})$ fuel. When loaded into the reference PWR fuel assembly it gives a significantly softer spectrum than MOX fuel assembly designed to generate the same amount of energy due to the larger hydrogen-to-Pu (also H-to-HM) ratio of the hydride fuel. Figure 6.1 shows that the spectrum at BOL is between that of MOX and that of the $\mathrm{UO}_{2}$ fueled PWR. At end of life, shown in Figure 6.2, the neutron spectrum is even softer than that of the reference PWR because of the significant consumption of $\mathrm{Pu}$, that increases the $\mathrm{H} / \mathrm{HM}$ ratio. 


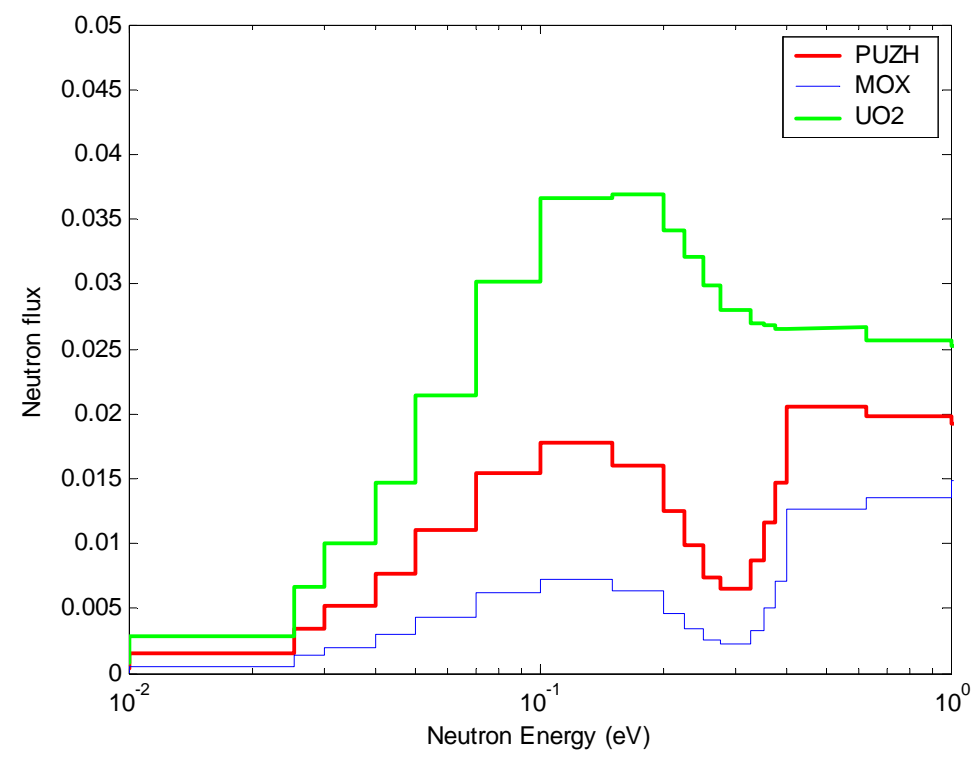

Figure 6.1 BOL thermal neutron spectrum (per unit lethargy) in the fuel

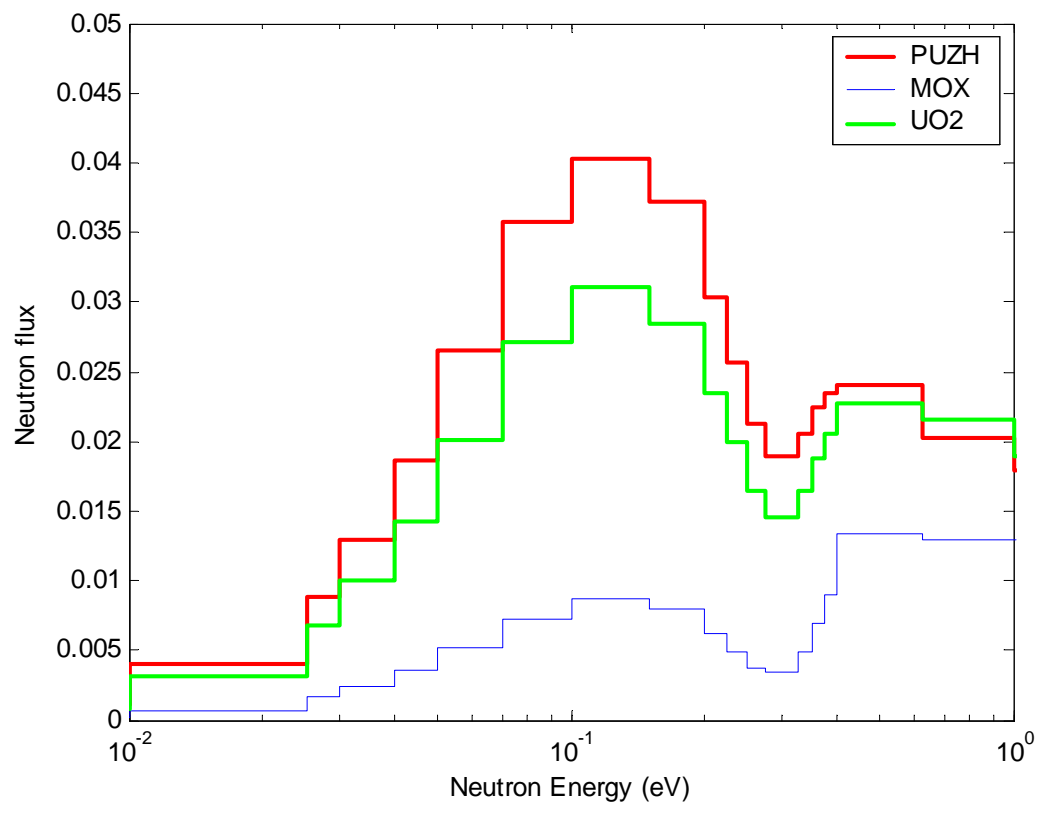

Figure 6.2 EOL thermal neutron spectrum (per unit lethargy) in the fuel 
The amount of Pu loaded into the MOX and PUZH fuel referred to in Figures 6.1 and 6.2 is that required to make their cycle length identical to that of the reference $\mathrm{UO}_{2}$ fueled PWR in a 3-batch fuel management. The latter uses 5\% enriched U.

Being a very preliminary feasibility assessment, only neutronic analysis has been performed. It is assumed that the thermal hydraulic performance of the plutonium bearing fuel will be comparable to that of the enriched uranium fuel considered above.

\subsection{Methodology}

A scoping study was first performed covering the following design space (Ganda and Greenspan, 2007c; 2005a; 2005b): clad outside diameters, D, ranging from $0.65 \mathrm{~cm}$ to $1.25 \mathrm{~cm}$ and lattice pitch-to-diameter ratio, $\mathrm{P} / \mathrm{D}$, ranging from 1.05 to 2.0. For each of these geometries (77 in total) the achievable 3 batch burnup and the reactivity coefficients along the fuel life were calculated. A "feasibility map" was then constructed for each fuel type based on the requirement that a geometry is feasible only when all the reactivity coefficients (averaged over the 3 batches) are negative at any time during the cycle. The study then focused on the reference PWR unit cell geometry and made a detailed comparison of the plutonium recycling capabilities of PUZH versus MOX fuel. This latter comparison is described below.

The reference PWR unit cell dimensions and specific power are summarized in Table 6.1. The plutonium composition assumed for BOL is typical of the Pu discharged from PWR; it consists of 1, 62, 22, 12 and 3 atom percent of, respectively, ${ }^{238} \mathrm{Pu},{ }^{239} \mathrm{Pu},{ }^{240} \mathrm{Pu}$, ${ }^{241} \mathrm{Pu},{ }^{242} \mathrm{Pu}$. The amount of plutonium loaded into MOX and PUZH fuels is adjusted to give the same cycle length as of the reference $5 \%$ enriched $\mathrm{UO}_{2}$ PWR with all cores assumed to operate at the same linear heat rate unit cell. Table 6.2 gives the MOX and 
PUZH fuel initial composition. The methodology used for the neutronic analysis of Pubearing PWR fuels is the same as that described in Section 2.4. For all three fuel types considered, the burnup dependent excess reactivity is compensate for by adjusting the soluble boron concentration in the water. In case of the $\mathrm{UO}_{2}$ fuel, IFBA is also used to compensate for the excess reactivity; otherwise the BOC CTC is positive.

Table 6.1

Specifications of the reference unit cell

\begin{tabular}{|c|c|}
\hline Clad outside diameter & $0.95 \mathrm{~cm}$ \\
\hline P/D & 1.3261 \\
\hline Fuel diameter & $0.8192 \mathrm{~cm}$ \\
\hline Clad inside diameter & $0.8357 \mathrm{~cm}$ \\
\hline Pitch & $1.25 \mathrm{~cm}$ \\
\hline Specific power & $36.138 \mathrm{~W} / \mathrm{giHM}$ \\
\hline
\end{tabular}

Table 6.2

Initial Composition (atoms $/ \mathrm{b} \mathrm{cm}$ ) of MOX and PUZH fuels

\begin{tabular}{l|ll}
\hline Isotope & $M O X$ & $P U Z H$ \\
\hline $\mathrm{U}-235$ & $5.3241 \mathrm{E}-05$ & $2.4585 \mathrm{E}-05$ \\
$\mathrm{U}-238$ & $2.1243 \mathrm{E}-02$ & $9.8093 \mathrm{E}-03$ \\
PU-238 & $2.1344 \mathrm{E}-05$ & $1.5868 \mathrm{E}-05$ \\
PU-239 & $1.3233 \mathrm{E}-03$ & $9.8384 \mathrm{E}-04$ \\
PU-240 & $4.6957 \mathrm{E}-04$ & $3.4910 \mathrm{E}-04$ \\
PU-241 & $2.5613 \mathrm{E}-04$ & $1.9042 \mathrm{E}-04$ \\
PU-242 & $6.4033 \mathrm{E}-05$ & $4.7605 \mathrm{E}-05$ \\
\hline Tot U & $\mathbf{2 . 1 2 9 6 7 E - 0 2}$ & $\mathbf{9 . 8 3 4 0 8 E - 0 3}$ \\
TOT Pu & $\mathbf{2 . 1 3 4 3 8 E - 0 3}$ & $\mathbf{1 . 5 8 6 8 3 E - 0 3}$ \\
Pu atom & $\mathbf{9 . 1 0 9}$ & $\mathbf{1 3 . 8 9 4}$ \\
fraction (\%) &
\end{tabular}

\subsection{Results}

Figure 6.3 compares the $\mathrm{k}_{\infty}$ evolution of the PUZH and MOX fuelled unit cells designed to provide the same cycle length as the reference $5 \%$ enriched $\mathrm{UO}_{2}$ unit cell also shown in the figure. It is found that the PUZH fueled lattice has very similar burnup 
dependent $\mathrm{k}_{\infty}$ as that of the reference $\mathrm{UO}_{2}$ fueled lattice whereas the MOX fueled lattice has a flatter $\mathrm{k}_{\infty}$ evolution as a result of a higher conversion ratio.

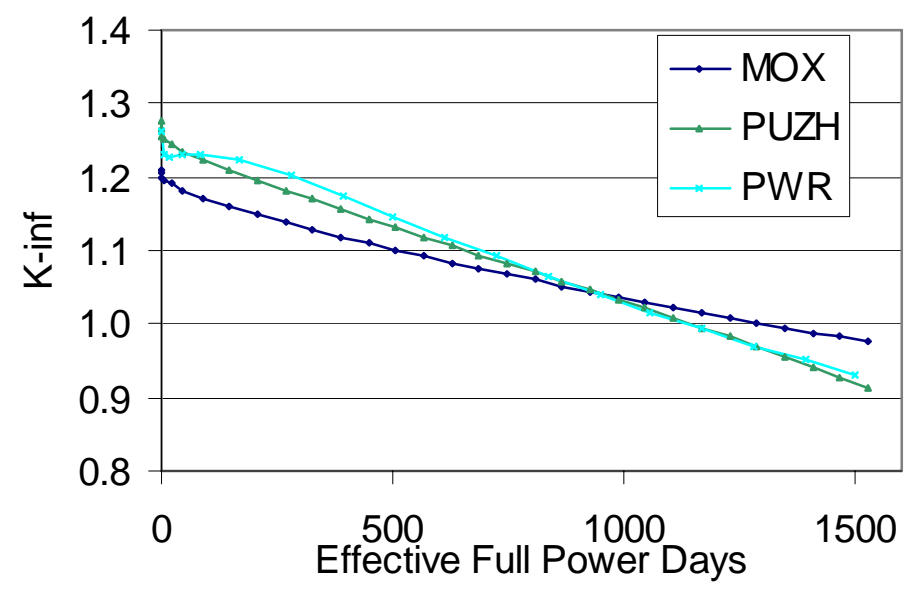

Figure 6.3: $\mathrm{k}_{\infty}$ evolution with cycle time for PUZH and MOX fuels versus $\mathrm{UO}_{2}$ (denoted as PWR) fuel in the reference PWR geometry, all giving same discharge burnup

Figure 6.4 compares the burnup dependent coolant temperature coefficient (CTC) of reactivity of the three fuels. The CTC of the PUZH fuelled lattice varies between -5 $\mathrm{pcm} / \mathrm{K}$ at $\mathrm{BOC}$ and $-30 \mathrm{pcm} / \mathrm{K}$ at $\mathrm{EOC}$; it is less negative than the CTC of the MOX fuel system that is close to those of the reference $\mathrm{UO}_{2}$ fuelled system. The $\mathrm{BOC}$ value of -5 $\mathrm{pcm} / \mathrm{K}$ is likely to become more negative when burnable poisons will be incorporated in the core thus enabling to reduce the BOL soluble boron concentration. The effect of boron loading at the beginning of each of the 3 batches is visible in the figure.

The void reactivity coefficient, presented in Figure 6.5, shows a similar behavior - it is less negative than that of $\mathrm{MOX}$ and $\mathrm{UO}_{2}$, but still negative and can be made more negative by addition of burnable poisons if needed. The results pertain to voiding $5 \%$ of the water. 


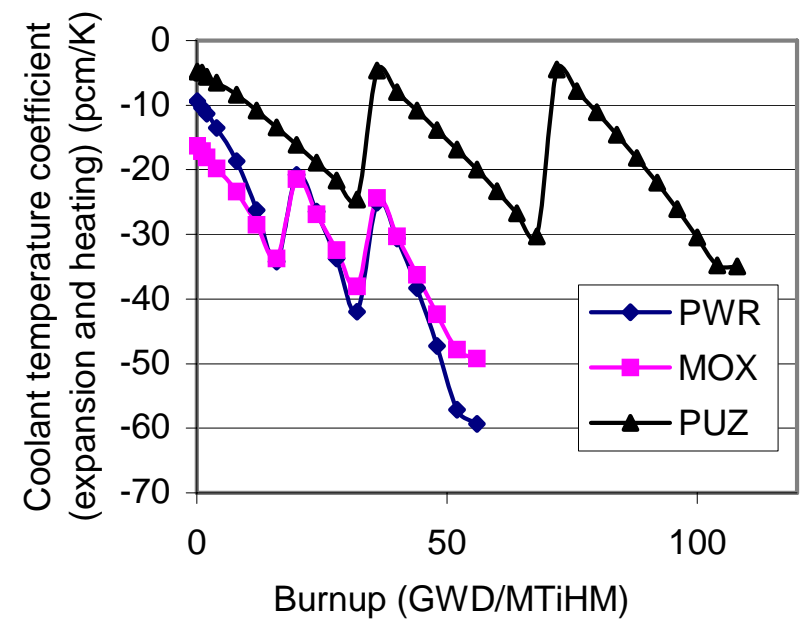

Figure 6.4 Coolant temperature coefficient of reactivity for PUZH and MOX fuels versus $\mathrm{UO}_{2}$ (denoted as PWR) fuel in the reference PWR geometry, all giving same discharge burnup

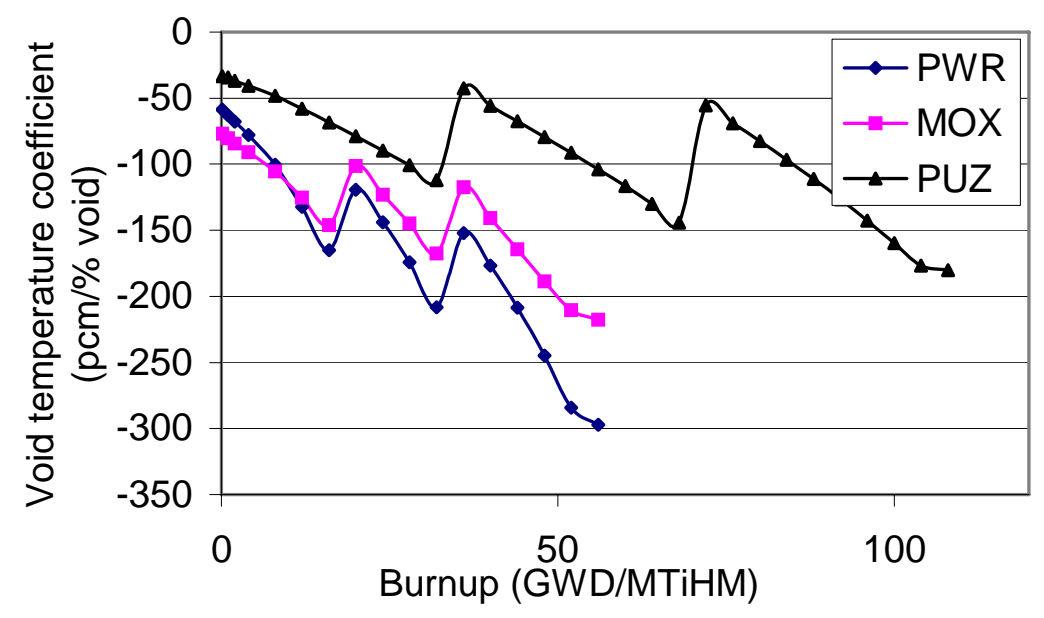

Figure 6.5 Void coefficient of reactivity for PUZH and MOX fuels versus $\mathrm{UO}_{2}$ (denoted as PWR) fuel in the reference PWR geometry, all giving same discharge burnup

Figure 6.6 compares the prompt fuel reactivity coefficients. That of the PUZH fuel lattice is negative throughout the entire life, going from $-3.6 \mathrm{pcm} / \mathrm{K}$ at $\mathrm{BOL}$ to about -2.4 $\mathrm{pcm} / \mathrm{K}$ at EOL, even in presence of soluble boron. At BOL it is noticeably more negative than that of either MOX or $\mathrm{UO}_{2}$ fuelled systems and gradually becomes less negative 
with burnup. Nevertheless, it is more negative than that of the other fuels throughout the cycle due to the combination of two effects. One is unique to hydride fuels: as the hydrogen in the fuel heats-up, the neutron spectrum hardens and a larger fraction of the neutrons get to the region where the ${ }^{239} \mathrm{Pu}$ has a deep peak in $\eta$ (around $0.3 \mathrm{eV}$ ). This in turn reduces the system reactivity. The other effect is the Doppler broadening of the resonances in the fertile component of the fuel. Based on the above analysis, both the MOX and PUZH designs considered for plutonium recycling are neutronically acceptable.

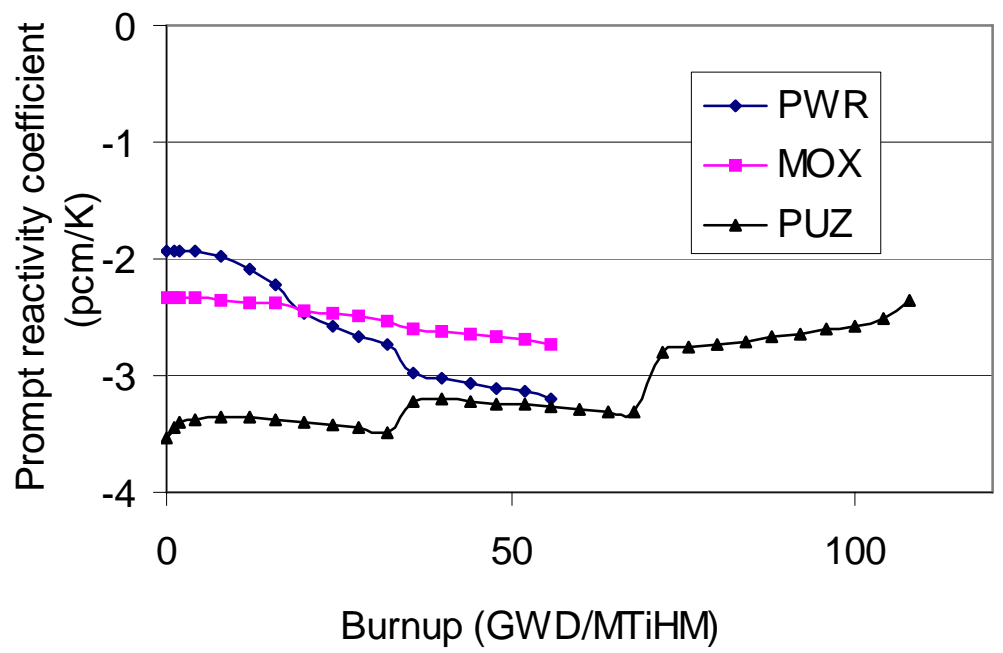

Figure 6.6 Prompt reactivity coefficients $(\mathrm{pcm} / \mathrm{K})$ for PUZH and MOX fuels versus $\mathrm{UO}_{2}$ (denoted as PWR) fuel in the reference PWR geometry, all giving same discharge burnup

The transmutation capability of PWR fueled with PUZH is compared in Table 6.3 against that of a full-MOX fuelled PWR considering the reference PWR geometry. It is found that for the same cycle length $(1350 / 3=450$ EFPD) at the same linear heat rate (174.9 W/cm), the PUZH fuel requires $25 \%$ less Pu loading and less than $50 \%$ of the depleted U loading than the MOX fuel and achieves nearly double the average discharge 
burnup - about $103 \mathrm{GWD} / \mathrm{MTiHM}$ vs. $50 \mathrm{GWD} / \mathrm{MTHM}$ of MOX. This high burnup is within the 120 GWD/MTiHM routinely achieved by TRIGA fuel (Olander et al, 2007). The net amount of $\mathrm{Pu}$ consumed per cycle is $60 \%$ higher in cores using PUZH than in cores using MOX fuel. This is due to the lower conversion ratio of the PUZH core; the ratio of neutron capture rate in ${ }^{238} \mathrm{U}$ to fission rate of the $\mathrm{Pu}$ isotopes varies from 0.339 at BOL to 0.522 at EOL whereas for MOX fuel it varies from 0.638 at BOL to 0.799 at EOL. The reduced inventory of Pu per core loading and the greatly increased discharge burnup are likely to make $\mathrm{Pu}$ recycling with hydride fuel more economical.

Table 6.3

Selected transmutation characteristics of PUZH and MOX fuels

\begin{tabular}{|l|l|l|}
\hline Characteristic & PUZH & MOX \\
\hline Burnup (GWD/MtiHM) & 103.5 & 49.6 \\
\hline Residence time (EFPD) & 1350 & 1372.5 \\
\hline Pu inventory (g/pin) & 50.3 & 115.0 \\
\hline $\mathrm{Pu}$ inventory/ initial Pu & 0.43 & 0.73 \\
\hline$\% \mathrm{Pu}$ incinerated/cycle & 57 & 27 \\
\hline Fissile $\mathrm{Pu} /$ Tot $\mathrm{Pu}(\%)$ & 44 & 63 \\
\hline $\mathrm{MA}$ inventory (g/pin) & 6.67 & 7.77 \\
\hline MA/Pu at discharge (\%) & 13.25 & 6.76 \\
\hline Neutron source (n/s/pin) & $29.7 \times 10^{6}$ & $27.4 \times 10^{6}$ \\
\hline Activity (Ci/pin) & 58700 & 72800 \\
\hline Decay heat (w/pin) & 198 & 231 \\
\hline Neutrons per g Pu (n/s) & 1250 & 796 \\
\hline Neutrons per gTRU (n/s) & $5.22 \times 10^{5}$ & $2.23 \times 10^{5}$ \\
\hline Specific heat (w/g Pu) & 0.123 & 0.045 \\
\hline Specific heat (w/g TRU) & 2.35 & 1.19 \\
\hline
\end{tabular}

Economic analysis was beyond the scope of this work. The discharged PUZH fuel contains only $43 \%$ of the amount of Pu initially loaded into it versus $73 \%$ in the MOX fuel; both fuels operating for the same amount of time and generating the same amount of energy. The amount of MA in the discharged PUZH fuel is $16 \%$ lower than in the MOX 
fuel. The quality of the Pu and TRU in the discharged PUZH fuel is worse than that in the discharged MOX fuel - the fissile Pu fraction is lower by $30 \%$. In addition, it will be more difficult to divert Pu and MA from PUZH fuel as their activity, neutron yield and decay-heat are all higher per unit mass of TRU. On the other hand, handling of the discharged and recycled PUZH fuel assemblies is likely to be easier than handling the MOX fuel assemblies as the activity and decay heat are higher for MOX even though the neutron yield is $\sim 8 \%$ higher.

All these characteristics contribute to making the PUZH fuel more efficient for Pu incineration as well as more proliferation resistant than the MOX fuel.

\subsection{Alternate hydride fuels}

Preliminary analysis was performed on the transmutation capability of a couple of alternate hydride fuels - the inert matrix fuel $\mathrm{PuH}_{2}-\mathrm{ZrH}_{1.6}$, and a thorium containing hydride fuel $\mathrm{PuH}_{2}-\mathrm{ThH}_{2}$ (Ganda and Greenspan, 2007c; 2005a; 2005b). Selected performance characteristics are summarized in Tables 6.4 and 6.5. Of the two columns of Table 6.5, one corresponds to the maximum discharge burnup accounting for the criticality constraint only, while the other is constrained by the requirement that all reactivity coefficients be negative in addition to the criticality constraint.

Soluble boron is used for excess reactivity adjustment in the case of the Th containing fuel but cannot be used as the only means to compensate for the excess reactivity in case of the inert matrix fuel. The use of burnable poisons in this latter case is necessary to obtain a negative moderator temperature coefficient. 
Table 6.4

Selected transmutation characteristics of the inert matrix $\mathrm{PuH}_{2}-\mathrm{ZrH}_{1.6}$ fuel

\begin{tabular}{|l|l|l|}
\hline Characteristic & PuZr-H & PuZr-H \\
\hline Burnup (GWD/MtiHM) & 374 & 710 \\
\hline Residence time (EFPD) & 737 & 1398 \\
\hline Pu inventory (g/pin) & 72 & 25.5 \\
\hline Pu inventory/ initial Pu & 0.57 & 0.22 \\
\hline \% Pu incinerated/cycle & 43 & 78 \\
\hline Fissile $\mathrm{Pu} / \mathrm{Tot} \mathrm{Pu}(\%)$ & 0.537 & 0.165 \\
\hline MA inventory $(\mathrm{g} /$ pin) & 3.4 & 6.7 \\
\hline MA/Pu at discharge (\%) & 4.7 & 26.2 \\
\hline Neutron source $(\mathrm{n} / \mathrm{s} /$ pin) & $10.4 \times 10^{6}$ & $37.1 \times 10^{6}$ \\
\hline Activity $(\mathrm{Ci} /$ pin) & 7950 & 20700 \\
\hline Decay heat $(\mathrm{w} /$ pin) & 40.2 & 117 \\
\hline Neutrons per g Pu (n/s) & 885 & 1897 \\
\hline Neut. per g TRU (n/s) & $0.14 \times 10^{6}$ & $1.15 \times 10^{6}$ \\
\hline Specific heat $(\mathrm{w} / \mathrm{g} \mathrm{Pu})$ & 0.0625 & 0.482 \\
\hline Specific heat $(\mathrm{w} / \mathrm{g} \mathrm{TRU)}$ & 0.53 & 3.65 \\
\hline
\end{tabular}

Table 6.5

Selected transmutation characteristics of $\mathrm{PuH}_{2}-\mathrm{ThH}_{2}$ and $\mathrm{MOX}$ fuels

\begin{tabular}{|c|c|c|}
\hline Characteristic & \begin{tabular}{|l|} 
PuTh-H \\
\end{tabular} & MOX \\
\hline Burnup (GWD/MtiHM) & 64 & 49.6 \\
\hline Residence time (EFPD) & 1814 & 1372.5 \\
\hline Pu inventory (g/pin) & 68.5 & 115.0 \\
\hline $\mathrm{Pu}$ inventory/ initial $\mathrm{Pu}$ & 0.375 & 0.73 \\
\hline$\% \mathrm{Pu}$ incinerated/cycle & 62.5 & 27 \\
\hline Fissile $\mathrm{Pu} / \mathrm{Tot} \mathrm{Pu}(\%)$ & 43 & 63 \\
\hline MA inventory (g/pin) & 8.95 & 7.77 \\
\hline MA/Pu at discharge (\%) & 13 & 6.76 \\
\hline Neutron source (n/s/pin) & $36.1 \times 10^{6}$ & $27.4 \times 10^{6}$ \\
\hline Activity (Ci/pin) & 68000 & 72800 \\
\hline Decay heat (w/pin) & 240 & 231 \\
\hline Neutrons per g Pu $(\mathrm{n} / \mathrm{s})$ & 1415 & 796 \\
\hline Neut. per g TRU (n/s) & $4.65 \times 10^{5}$ & $2.23 \times 10^{5}$ \\
\hline Specific heat (w/g Pu) & 0.088 & 0.045 \\
\hline Specific heat (w/g TRU) & 1.14 & 1.19 \\
\hline
\end{tabular}


It is found that using thorium for the fertile fuel it is possible to incinerate $62.5 \%$ of the loaded plutonium in one pass through the core of a PWR that is uniformly loaded with hydride fuel. All the reactivity coefficients remain negative throughout the core life. On the other hand, the transmutation capability of inert matrix hydride fuel is constrained by positive reactivity coefficients.

\subsection{Discussion}

For Pu loading that gives the reference PWR cycle length when using the reference PWR core geometry, $\mathrm{U}-\mathrm{PuH}_{2}-\mathrm{ZrH}_{1.6}$ fuel, referred to as $\mathrm{PUZH}$, achieves about a $40 \%$ higher peak burnup MOX fuel, when both fuels are uniformly distributed throughout the core. The reactivity coefficients of the Pu-bearing cores considered are all negative, also when soluble boron is the only means used to compensate for the core excess reactivity.

The PUZH is found superior to MOX fuel also in terms of the transmutation effectiveness and proliferation resistance. For the reference cycle duration and reference fuel rod diameter and pitch, the percentage of the Pu loaded that is incinerated in one recycle is $57 \%$ for PUZH versus $27 \%$ for MOX fuel. The net amount of $\mathrm{Pu}$ consumed per cycle is $60 \%$ higher in cores using PUZH than in cores using MOX fuel. This is due to the lower conversion ratio of the PUZH core. Relative to discharged MOX, the discharged PUZH fuel has plutonium with only $44 \%$ versus $63 \%$ of fissile isotopes, double MA concentration and higher spontaneous fission neutron source intensity and decay heat per gram of HM. Despite of the above, the radioactivity and decay heat per fuel assembly are smaller with PUZH than with MOX fuel due to the lower HM loading in the PUZH fuel. This is likely to make the PUZH fuel handling advantageous. 
Using thorium hydride instead of zirconium hydride and eliminating the uranium, it is possible to obtain an even better fractional transmutation - incinerating $62.5 \%$ of the loaded plutonium. Higher fractional transmutation may be attainable by design optimization.

The scoping study performed over a wide design space not reported in this section found (Ganda and Greenspan, 2007c) that the peak burnup of PUZH fuel is achieved in a tighter lattice $(\mathrm{P} / \mathrm{D}=1.5-1.6)$ than of MOX fuel $(\mathrm{P} / \mathrm{D}=1.7-1.9)$. This could enable PUZH cores to operate at a higher power density than possible with MOX cores. This feature, along with smaller plutonium inventory, are likely to make PUZH fuelled PWR's more economical than MOX fueled PWR's.

It is recommended to thoroughly investigate the feasibility of recycling plutonium in PWR's as well as in BWR's using U-PuH $\mathrm{PrH}_{1.6}, \mathrm{PuH}_{2}-\mathrm{ThH}_{2}$ and other types of hydride fuel. 


\section{BWR - design approaches and methodology}

\subsection{Introduction}

The objective of the work reported in this section is to assess the feasibility of improving the economics of Boiling Water Reactors (BWR) by using hydride fuel instead of oxide fuel. BWR's are expected to benefit more than PWR's from hydride fuel as the upper part of their core tends to be under-moderated as a result of the large void (steam) volume fraction. In order to compensate for the low hydrogen density of the boiling water, oxide fueled BWR fuel bundles are designed to have water rods and partial length fuel rods replacing full length fuel rods, and relatively wide water channels in-between the fuel bundles; these channels also provide space for insertion of the cruciform shaped control elements. Figure 7.1 is a horizontal cut of a typical layout of four GE designed 9x9 oxide BWR fuel bundles. As the thermal neutron flux tends to peak in the vicinity of the water rods and water channels, the enrichment of the fuel rods in the vicinity of these water bodies is lower than the enrichment of fuel rods farther away so as to flatten the pin-by-pin power distribution across the fuel bundle. Contemporary fuel bundle designs feature larger number of fuel rods of a smaller diameter than of the bundle of Figure 7.1 and are even more heterogeneous; they have on the order of ten enrichment levels.

By using hydride fuel that introduces a significant amount of the hydrogen moderator within the fuel, BWR fuel bundles can be designed without liquid water volumes such as water rods and water channels. The volume freed by the elimination of the water rods, partial length fuel rods and water channel can be used for loading more fuel rods in a given core volume; these fuel rods can be of the same, or nearly the same enrichment. 

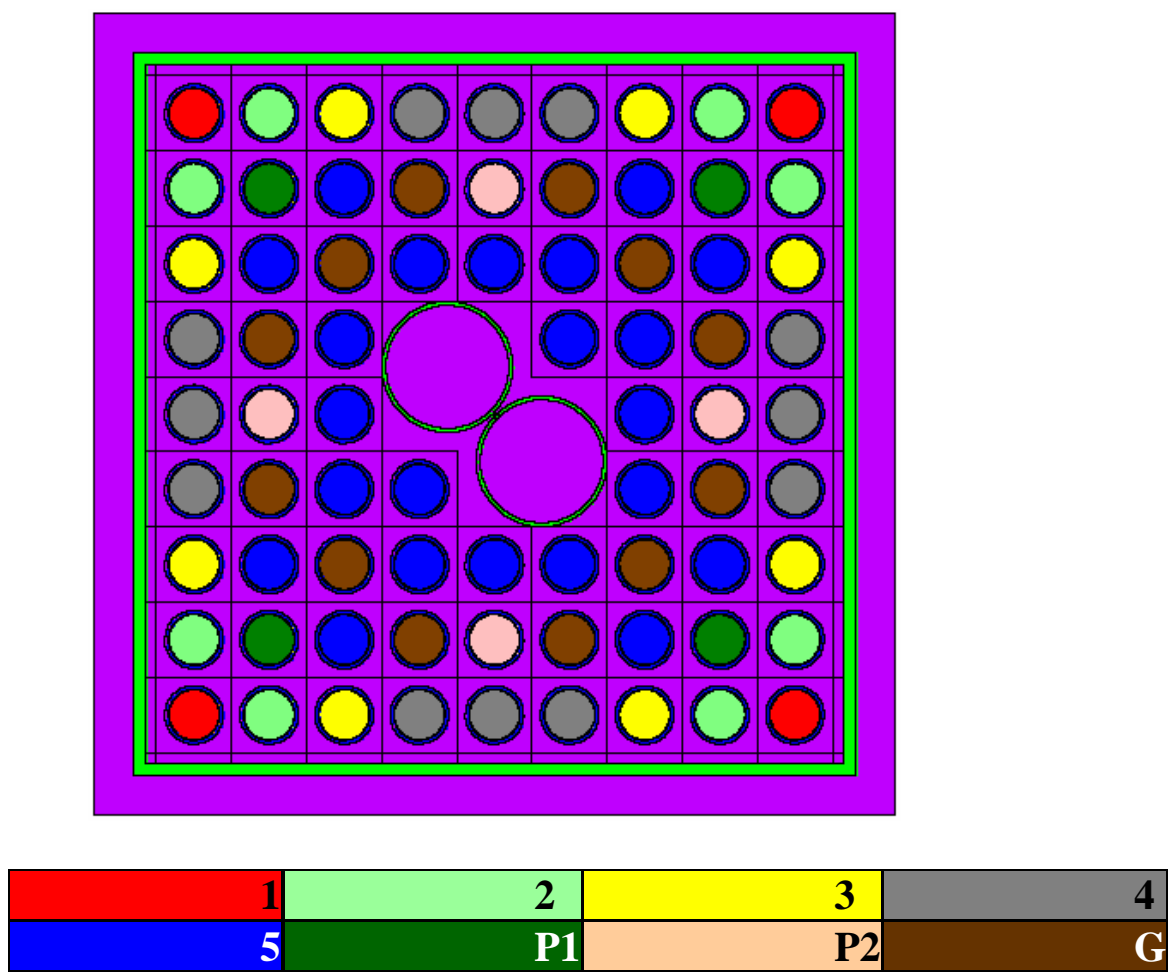

Figure 7.1 Cross sectional view of the 9x9 oxide fueled BWR fuel bundle used as the reference bundle design. Color code: 1 through 5 - full length fuel rods of 5 different enrichment levels; P1 \& P2 - partial length fuel rods; G - fuel rods containing gadolinia; water rods occupy the sites of 7 fuel rods at the bundle center.

Figure 7.2 illustrates one such possible design approach. Instead of the cruciform shaped control element there are 4 control rods per bundle. The number of hydride fuel rods in this bundle is 96 as compared with 70.67 (corresponding to 66 full length and 8 partial length fuel rods) in the reference oxide fuel bundle. The hydride fuel rods of Figure 7.2 have the same diameter as the reference oxide fuel rods and are arranged with a similar pitch.

Summarized in this section are preliminary neutronic and thermal hydraulic analyses of hydride versus oxide fueled BWR core designs (Fratoni et al., 2007; Ferroni et al., 2007). Vibration analysis is incorporated with the thermal-hydraulic analysis but no fuel performance analysis was undertaken as yet. 


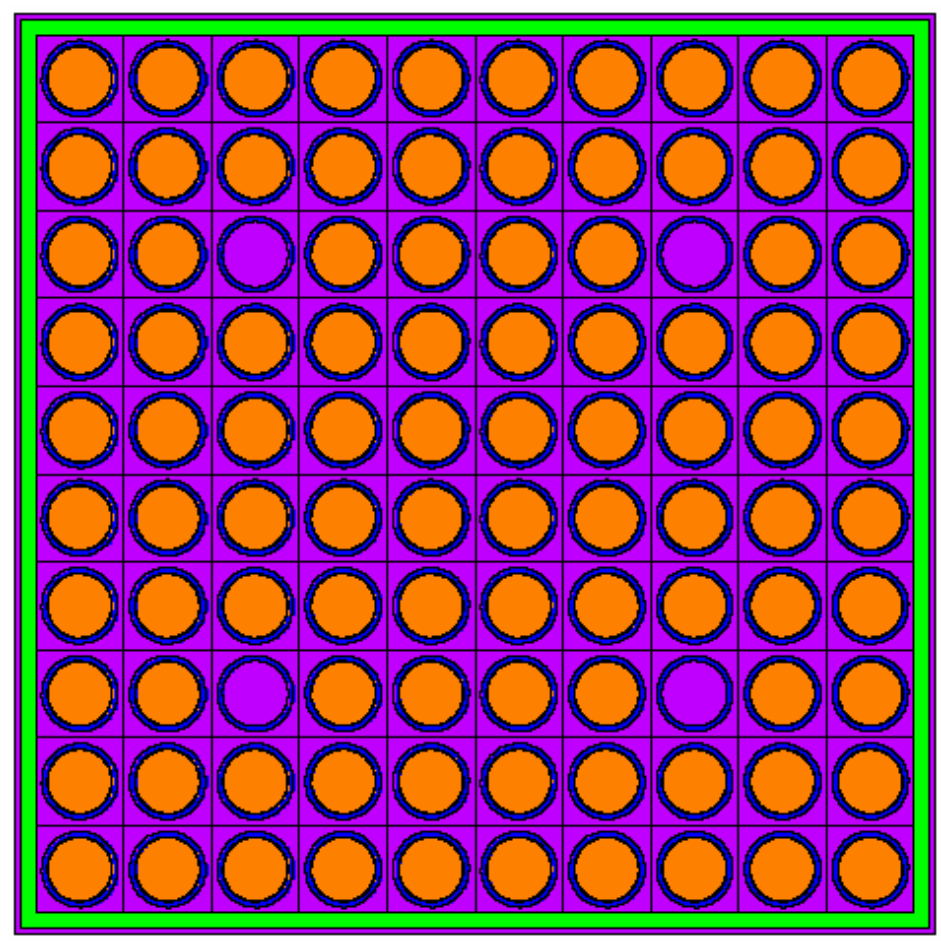

Figure 7.2 Cross sectional view of the 10x10 hydride fueled BWR fuel bundle having the same total volume as the reference oxide fueled bundle of Figure 7.1.

The objective of the neutronic analysis is to identify the acceptable combinations of fuel rod outer clad diameter, $\mathrm{D}$, and the square lattice pitch to diameter ratio, $\mathrm{P} / \mathrm{D}-$ referred to as "geometry", of hydride as well as oxide fuels and to quantify the attainable discharge burnup. To be acceptable the geometry has to have negative fuel and coolant temperature coefficients of reactivity as well as negative void reactivity feedback throughout the core life.

The objective of the thermal-hydraulic analysis is to quantify the maximum power density attainable using different geometries subjected to a number of design constraints. The results from the neutronic and thermal hydraulic analyses will eventually be combined in an economic optimization that will identify the geometry offering the lowest 
cost of electricity. The hydride fuelled core designs addressed in this work are aimed for new BWR designs; not for retrofitting existing BWR's.

\subsection{Reference reactor}

$\mathrm{ABWR} / 5$ is used for the reference BWR and the $9 \times 9$ fuel bundle of Figure 7.1 is chosen for the reference in lack of non-proprietary data on more advanced bundle and core designs. Table 7.1 summarizes key parameters of the reference reactor. The fact that the power density of the oxide fuel bundle and core selected for the reference is low relative to more advanced BWR designs does not affect the comparison between hydride and oxide fuels performed in this work, as we are searching for maximum power density oxide and hydride bundle designs using the same assumptions, constraints and methodology.

Table 7.1

Selected reference BWR design and performance parameters

\begin{tabular}{|l|l|}
\hline Parameter & Value \\
\hline Geometry & 764 \\
\hline Total number of 9x9 fuel bundles & 66 \\
\hline Number of full length fuel rods & 8 \\
\hline Number of partial length fuel rods & 71 \\
\hline Effective full length fuel rods per bundle & \\
\hline Operating Conditions & $7.136 \mathrm{MPa}$ \\
\hline Core pressure & $278.3^{\circ} \mathrm{C}$ \\
\hline Core inlet temperature & $3323 \mathrm{MW}$ \\
\hline Core thermal power & $13671 \mathrm{~kg} / \mathrm{s}$ \\
\hline Coolant flow rate & 1.45 \\
\hline Core radial peaking factor & 1.51 \\
\hline Axial peaking factor & $6567.7 \mathrm{~kW}$ \\
\hline Hot bundle thermal power & $16.98 \mathrm{~kg} / \mathrm{s}$ \\
\hline Coolant mass flow rate & $26.8 \%$ \\
\hline Exit steam quality & \\
\hline
\end{tabular}




\subsection{Neutronics}

There were two parts to the neutronic analysis. The first involved a 1-D scoping study over a wide range of the design variables - the fuel rod outer diameter $0.6 \leq \mathrm{D} \leq 1.6$ and the lattice pitch-to-diameter ratio $1.1 \leq \mathrm{P} / \mathrm{D} \leq 1.6$. Detailed 3-D fuel bundle analysis was then performed for a limited number of promising 10x10 hydride and oxide fuel bundles in addition to the reference 9x9 oxide fuel bundle. The latter analysis was done using MCNP5 Version 1.30 for calculating the power distribution, reactivity coefficients and control systems and using MOCUP for depletion analysis. The oxide fuel bundle geometry and composition were accurately simulated, accounting for water rods, partial length fuel rods, all enrichment levels, Gadolinia as well as bundle box and surrounding water gap ( Fratoni et al., 2007).

The reference oxide fuel bundle is that shown in Figure 7.1 and a typical hydride fuel bundle considered is shown in Figure 7.2. The pitch (measured, say, as the distance from the center of one bundle to the center of an adjacent bundle) of all hydride bundles considered is identical to that of the reference oxide bundle. The hydride fuel bundle box has the thickness of the oxide fuel reference bundle but a somewhat larger wall-to-wall aperture. These modifications enable to introduce a 10x10 array of rods in the same volume as of the reference 9x9 oxide fuel bundle, giving 96 full length fuel rods per hydride bundle versus $\sim 71$ effective full length fuel rods in the reference oxide fuel bundles. The remaining 4 sites house control rods guide tubes; the hydride fuelled cores do not have cruciform control rods. The fuel rod pitch of the 10x10 hydride fuel bundles is very similar to the reference oxide fuel pitch. 
The axial coolant density distribution was represented using 24 equal length axial zones. Same axial water density distribution - representing a typical core water density distribution of BWR designed by industry, was assumed for all fuel bundles. That is, in this preliminary phase of feasibility study the neutronic and thermal-hydraulic analyses were not fully coupled.

24 depletion zones were considered for the reference oxide bundle, corresponding to 8 groups of fuel rods and three average axial enrichments per group. Being of significantly more uniform design, only 9 depletion zones were considered for hydride fuel bundles -3 equal length axial and 3 radial zones. The fraction of the bundle power generated in each depletion zone was calculated at each burnup step by MOCUP. A 4 equal size batch fuel management was assumed for estimating the discharge burnup and core average $\mathrm{k}$ and reactivity coefficients. Table 7.2 gives the fraction of the core power and the average power per fuel bundle assumed for each batch based on information from actual BWR design. The corresponding core average bundle power is assumed to be 4.31 $\mathrm{MW}_{\text {th }}$, regardless of the fuel type.

Table 7.2

Core power per batch

\begin{tabular}{|c|c|c|}
\hline $\begin{array}{c}\text { Batch } \\
\text { number }\end{array}$ & $\begin{array}{c}\text { Fractional } \\
\text { power }\end{array}$ & $\begin{array}{c}\text { Power per } \\
\text { bundle [MW] }\end{array}$ \\
\hline $1^{\text {st }}$ & $31.42 \%$ & 5.40 \\
$2^{\text {nd }}$ & $27.41 \%$ & 4.73 \\
$3^{\text {rd }}$ & $24.61 \%$ & 4.17 \\
$4^{\text {th }}$ & $17.11 \%$ & 2.95 \\
\hline
\end{tabular}

The achievable burnup was taken to be that burnup for which the average core multiplication factor, $\mathrm{k}$, gets down to 1.05 - conservatively assuming $5 \%$ radial leakage 
probability. The 4-batch average core reactivity, $\rho$, and k were estimated from $\rho=\sum_{i=1}^{n} \rho_{i} f_{i}$ or $\quad \frac{1}{\mathrm{k}}=\sum_{\mathrm{i}=1}^{\mathrm{n}} \frac{\mathrm{f}_{\mathrm{i}}}{\mathrm{k}_{\mathrm{i}}} \quad$ where $\rho_{\mathrm{i}}$ is the reactivity pertaining to batch $\mathrm{i}$ and $\mathrm{f}_{\mathrm{i}}$ is the fraction of the core power generated by batch I (from Table 7.2). Likewise for the multiplication factor k. The discharge burnup thus obtained (Fratoni et al., 2007) was found to be 43.5 GWD/tHM corresponding to 1740 of EFPD of operation.

A similar averaging procedure was applied to determine the reactivity worth of the control systems and the reactivity coefficients.

Additional constraint was imposed when accounting for burnable poisons - the BOL core average multiplication factor is to equal that of the reference oxide core that uses gadolinium.

The statistical uncertainty in calculating $\mathrm{k}$ was $<5 \cdot 10^{-4}$ such that, after propagation through the $\mathrm{k}$ averaging procedure, the uncertainty in the core average $\mathrm{k}$ was $<2 \cdot 10^{-3}$.

\subsection{Thermal - hydraulics}

The thermal hydraulic analysis was also performed in two parts - a whole core analysis was first performed covering a wide range of $\mathrm{D}$ and $\mathrm{P} / \mathrm{D}$ ratios - nearly 400 geometries, altogether. Subchannel analysis was then performed in greater detail for a limited number of fuel bundles. The VIPRE-EPRI code was used for this analysis (Ferroni et al., 2007). In the following we focus on the subchannel analysis. Details about the whole core analysis can be found in Ferroni et al. (2007).

The reference 9x9 oxide bundle geometry and operating conditions are given in Figure 7.1 and Table 7.1. The axial power profile assumed is given in Figure 7.3 and pin- 
wise power distribution, as calculated for the BOL as described in Section 7.3 is given in Figure 7.4. It is assumed that of the total coolant flow rate of $16.98 \mathrm{~kg} / \mathrm{s}, 86 \%$ is active flow, $4 \%$ flows through the water rods and $10 \%$ through the bypass channel that surrounds the bundle box. For hydride fuel bundles, on the other hand, it is assumed that only $1 \%$ of the coolant flow goes through the gap between bundles and that $4 \%$ of the flow goes inside control rod thimbles. Two types of hydride fuel bundles were compared against oxide fuel bundles - one having an array of 10x10, like that shown in Figure 7.2, and a similar one having an array of $12 \times 12$; all bundles occupying the same volume, when accounting for the bundle box and surrounding water channel.

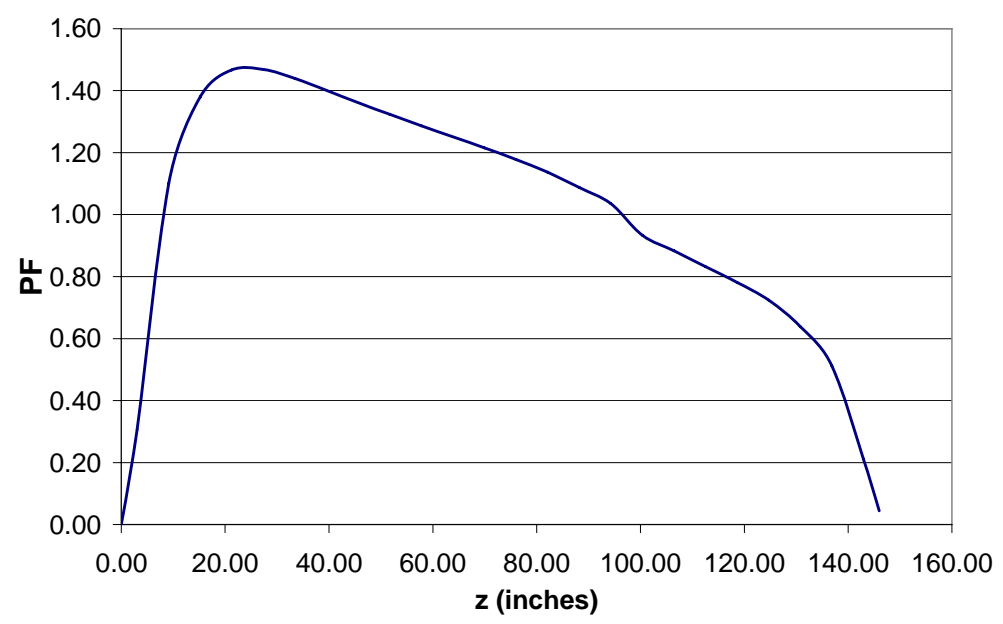

Figure 7.3 Axial power profile assumed for the thermal-hydraulic analysis

\begin{tabular}{|l|l|l|l|l|l|l|l|l|}
\hline 1.16 & 1.28 & 1.27 & 1.24 & 1.23 & 1.24 & 1.27 & 1.28 & 1.17 \\
\hline 1.28 & 0.98 & 1.03 & 0.45 & 0.76 & 0.45 & 1.03 & 1.00 & 1.28 \\
\hline 1.28 & 1.03 & 0.43 & 0.88 & 1.02 & 0.93 & 0.44 & 1.04 & 1.28 \\
\hline 1.24 & 0.45 & 0.88 & 1.15 & & & 0.94 & 0.46 & 1.24 \\
\hline 1.23 & 0.76 & 1.02 & & & & 1.01 & 0.76 & 1.22 \\
\hline 1.25 & 0.46 & 0.95 & & & 1.13 & 0.86 & 0.45 & 1.23 \\
\hline 1.29 & 1.03 & 0.44 & 0.94 & 1.02 & 0.88 & 0.44 & 1.02 & 1.26 \\
\hline 1.27 & 1.00 & 1.03 & 0.45 & 0.78 & 0.45 & 1.02 & 0.98 & 1.28 \\
\hline 1.15 & 1.27 & 1.27 & 1.25 & 1.23 & 1.24 & 1.27 & 1.26 & 1.16 \\
\hline
\end{tabular}

Figure 7.4 BOL normalized pin power distribution for the reference 9x9 oxide fuel bundle with gadolinia 
The constraints applied to the subchannel analysis are summarized in Table 7.3. Although the pressure drop of the reference design is only 22.6 psia, the analysis also considered 34 psia for the maximum allowed pressure drop assuming that within few years it will be possible to manufacture BWR recirculation pumps having $50 \%$ larger head than of the reference design. The subchannel averaged exit quality is also considered as a "soft" constraint - that is, that it could be somewhat relaxed without resulting in two-phase instability. (Ferroni et al., 2007).

Table 7.3

Constraints used in the subchannel analysis

\begin{tabular}{|l|l|l|}
\hline & Oxide bundle & $\begin{array}{l}\text { Hydride } \\
\text { bundles }\end{array}$ \\
\hline Thermal Hydraulic Constraints & \multicolumn{2}{|l|}{} \\
\hline MCPR & 1.158 & 1.158 \\
\hline Fuel centerline $\mathrm{T}^{(\mathrm{a})}\left({ }^{\circ} \mathrm{C}\right)$ & 2805 & 750 \\
\hline Fuel average $\mathrm{T}^{(\mathrm{a})}\left({ }^{\circ} \mathrm{C}\right)$ & 1400 & N.A. \\
\hline Clad surface $\mathrm{T}^{(\mathrm{a})}\left({ }^{\circ} \mathrm{C}\right)$ & 349 & 349 \\
\hline Active bundle $\Delta \mathrm{P}(\mathrm{MPa})$ & 0.234 & 0.234 \\
\hline Decay ratio & 0.5 & 0.5 \\
Subchannel avg exit quality & 0.2373 & 0.2373 \\
\hline
\end{tabular}

(a) at steady state N.A.: Not Applied

The oxide fuel rods were assumed to be filled with helium having a heat-transfer coefficient of $h_{g}^{H e}=5.6826 \mathrm{~kW} / \mathrm{K} \mathrm{m}^{2}$. Hydride fuel rods gap, on the other hand, were assumed be filled with liquid-metal having a thermal conductivity of $35 \mathrm{~W} / \mathrm{m} \mathrm{K}$ (Olander et al. 2007). As the oxide fuel temperature was not limiting the power level attainable from the oxide fuel assembly, using liquid metal bonding in the oxide fuel rods would not have any effect on the comparison between hydride and oxide fuel presented below. 


\section{BWR - results}

\subsection{Neutronics}

A detailed 3-D neutronic analysis was performed for the oxide and hydride fuel bundles to determine attainable discharge burnup, pin-by-pin power distribution, axial power distribution, reactivity coefficients, reactivity worth of control elements and burnable absorber effects. Table 8.1 compares selected characteristics of the 10x10 hydride fuel bundle offering the largest discharged BU against those of the reference 9x9 oxide fuel bundle without accounting for burnable poisons (BP).

Table 8.1

Neutronic performance characteristics of oxide and hydride fuel bundles. Not accounting for $\mathrm{BP}$

\begin{tabular}{|l|l|l|}
\hline System & Oxide 9x9 & Hydride 10x10 \\
\hline Number fuel rods & 70.67 & 96 \\
\hline Fuel rod OD [cm] & $\mathrm{PI}^{\text {(a) }}$ & 1.2413 \\
\hline P/D & “ & 1.1500 \\
\hline Control system & Control blades & 4 control rods \\
\hline Average enrichment & $3.9 \%$ & $5 \%$ \\
\hline Relative HM per bundle & 1.0 & 0.68 \\
\hline Burnup [GWD/MTHM] & 43.5 & 52.0 \\
\hline Residence time [days] & 1740 & 1412 \\
\hline BOC reactivity coefficients & & \\
\hline Fuel temperature $[\mathrm{pcm} / \mathrm{K}]$ & -4.6 & -6.7 \\
\hline Small void $(45 \%)[\Delta \mathrm{k} \%]$ & -0.43 & -0.25 \\
\hline Large void $(90 \%)[\Delta \mathrm{k} \%]$ & -4.65 & -4.75 \\
\hline
\end{tabular}

(a) Proprietary information

The neutronically optimal 10x10 hydride fuel bundle pitch is similar, but the fuel rod diameter is somewhat larger than those of the reference oxide fuel bundle. The reactivity coefficients compared in Table 8.1 are four-batch average at beginning of cycle. An average void fraction of $40 \%$ is assumed for the nominal conditions. All temperature and void coefficients considered are negative. The hydride fuel offers more negative prompt 
reactivity feedback due to fuel heat up - as a consequence of spectrum hardening caused by fuel hydrogen temperature increase, and not as negative small void reactivity coefficient - due to the fact that a relatively large fraction of the hydrogen in the core is "locked" in the fuel and does not participate in the voiding. Both trends are expected to improve reactor safety and stability.

Although the neutronic analysis revealed that P/D of 1.15 offers the maximum hydride fuel discharge burnup, the thermal-hydraulic analysis suggested that higher power could be generated with an increase in P/D. Then fixing the pitch and decreasing the fuel rod outer diameter to nearly the reference oxide fuel diameter, $\mathrm{P} / \mathrm{D}$ was increased to 1.30 while the negative reactivity coefficients were maintained. As a result the burnup dropped to $48 \mathrm{GWD} / \mathrm{MTHM}$ and the residence time to 1012 days. However, by increasing the fuel enrichment to $7.70 \%$ it is possible to obtain a cycle as long as that of the reference oxide fuel with the 10x10 high power density hydride fuel bundle. The corresponding discharge burnup is $82.5 \mathrm{GWD} / \mathrm{MTHM}$.

Four control rods interspersed between fuel rods in the 10x10 hydride fuel bundle were found to provide a shut-down reactivity margin that is comparable to that of the control blades in the reference oxide fuel design. $\mathrm{B}_{4} \mathrm{C}$ with natural boron was used as the neutron absorber. The preferred location of the 4 control rods are positions $\mathrm{C}-3, \mathrm{C}-8, \mathrm{H}-3$ and H-8.

Table 8.2 compares the penalty imposed by use of burnable poisons on the attainable discharge burnup and on the power peaking factors of a number of hydride fuel bundle designs relative to the reference oxide fuel bundle. In the reference oxide bundle Gadolinia of $\sim 5 \mathrm{wt} \%$ is mixed with the fuel in 12 out of 71 effective full length rods per 
bundle. The gadolinium is of natural composition. The use of burnable poison in hydride fuel was studied for the neutronically optimal geometry of $\mathrm{P} / \mathrm{D}=1.15$. The amount of poison loaded into each fuel bundle was that which makes the average core multiplication factor at BOL 1.07 - as in the reference oxide fuel core. This constraint was coupled with the EOL constraint of a 4-batch average multiplication factor of 1.05. The resulting BOL pin-wise power distribution is that shown in Figure 7.4. The required amount of gadolinium in hydride fuel, assumed loaded in the metallic form, was found about 2.87 wt $\%$ when added to 8 out of the 96 fuel rods. These rods were dispersed in the core similarly to the scheme of loading Gadolinia in the reference oxide fuel bundle. The resulting BOL peak-to-average pin power ratio was similar to that of the reference oxide fuel bundle. Optimization of enrichment distribution, that could possibly reduce this power peaking ratio, has not been attempted.

Table 8.2

Effect of burnable poison type on selected neutronic characteristics

\begin{tabular}{|l|c|c|c|c|}
\hline System & $\begin{array}{l}\text { Oxide }+ \\
\text { Gd }\end{array}$ & $\begin{array}{l}\text { Hydride+ } \\
\text { Gd }\end{array}$ & $\begin{array}{l}\text { Hydride+ } \\
\text { IFBA }\end{array}$ & $\begin{array}{l}\text { Hydride+ } \\
{ }^{167} \mathrm{Er}\end{array}$ \\
\hline $\begin{array}{l}\text { BU loss } \\
\text { [GWD/MTHM] }\end{array}$ & 6 & 6 & 6 & 9 \\
\hline $\begin{array}{l}\text { Burnup } \\
\text { [GWD/MTHM] }\end{array}$ & 37.5 & 46 & 46 & 43 \\
\hline $\begin{array}{l}\text { Residence time } \\
\text { [days] }\end{array}$ & 1482 & 1242 & 1162 & 1248 \\
\hline $\begin{array}{l}\text { Pin-wise power } \\
\text { peaking at BOL }\end{array}$ & 1.228 & 1.246 & 1.052 & 1.050 \\
\hline
\end{tabular}

Much flatter pin-wise power distributions were calculated when using IFBA or erbium as burnable poisons; both were uniformly distributed over all the hydride fuel rods of the bundle. For simplicity the IFBA was modeled uniformly dispersed in the fuel rather than as a thin layer on the fuel surface. A single pin depletion benchmark verified 
that this simplification is acceptable. IFBA is in the chemical form of $\mathrm{ZrB}_{2}$, uses natural boron and has an initial loading of $0.22 \mathrm{wt} \%$ of the fuel. Figure 8.1 gives the BOL pinwise power distribution for this bundle design; it is to be compared against Figure 7.4 for the reference oxide bundle.

\begin{tabular}{|l|l|l|l|l|l|l|l|l|l|}
\hline 1.04 & 1.02 & 1.02 & 1.01 & 1.01 & 1.00 & 1.01 & 1.02 & 1.02 & 1.05 \\
\hline 1.02 & 1.02 & 1.03 & 1.00 & 0.98 & 0.98 & 1.00 & 1.03 & 1.02 & 1.03 \\
\hline 1.01 & 1.03 & & 1.02 & 0.97 & 0.97 & 1.02 & & 1.03 & 1.02 \\
\hline 1.00 & 1.00 & 1.01 & 0.98 & 0.96 & 0.97 & 0.99 & 1.01 & 1.00 & 1.01 \\
\hline 1.00 & 0.98 & 0.97 & 0.96 & 0.96 & 0.95 & 0.97 & 0.97 & 0.97 & 1.01 \\
\hline 1.00 & 0.97 & 0.97 & 0.96 & 0.95 & 0.96 & 0.96 & 0.97 & 0.98 & 1.00 \\
\hline 1.00 & 0.99 & 1.01 & 0.98 & 0.96 & 0.97 & 0.98 & 1.02 & 1.00 & 1.01 \\
\hline 1.01 & 1.03 & & 1.01 & 0.97 & 0.97 & 1.02 & & 1.04 & 1.03 \\
\hline 1.01 & 1.00 & 1.02 & 0.99 & 0.98 & 0.98 & 1.00 & 1.03 & 1.01 & 1.03 \\
\hline 1.04 & 1.02 & 1.01 & 1.00 & 1.00 & 0.99 & 1.01 & 1.02 & 1.02 & 1.05 \\
\hline
\end{tabular}

Figure 8.1 BOL normalized pin power distribution for the optimal 10x10 hydride fuel bundle using IFBA

Erbium of natural composition was added to the fuel in the form of $\mathrm{ErH}_{3}$ in the amount of $0.55 \mathrm{wt} \%$. Although the pin-by-pin power distribution remains very uniform, the achievable burnup is drastically reduced by $12 \mathrm{GWD} / \mathrm{MTHM}$. The reason of this strong burnup penalty is the fact that, of the natural isotopes of erbium, only ${ }^{167} \mathrm{Er}$ is a strong neutron absorber; its abundance is $\sim 23 \%$. During operation it is kept being generated by $(\mathrm{n}, \gamma)$ reactions on ${ }^{166} \mathrm{Er}$ that makes $33.6 \%$ of the natural erbium. Had it been practical to fully enrich erbium in the isotope 167 , the achievable burnup was found limited to $43 \mathrm{GWD} / \mathrm{MTHM}$; less than with gadolinium and IFBA.

All the hydride fuel designs with burnable poisons offer negative reactivity coefficients over the entire cycle length and are, therefore, neutronically feasible. 


\subsection{Thermal hydraulics}

The power attainable from the best 10x10 hydride fuel bundle identified is compared against the performance of the reference 9x9 oxide fuel bundle as well as against a 10x10 oxide fuel bundle. The inter-comparison between the 10x10 hydride versus oxide fuel bundles performance is used to quantify the relative merits of hydride fuel, if any. The 10x10 hydride fuel bundle performance is also compared against a 12x12 hydride fuel bundle performance so as to provide an indication on the potential for farther performance improvements that may result from a more comprehensive design optimization. All fuel bundles compared have the same total volume; water gap between bundles included. Table 8.3 gives dimensional specifications of the inter-compared fuel bundles. Dimensions of the reference 9x9 oxide fuel bundle, obtained from industry, are proprietary and cannot be specified.

Table 8.3

Specifications of inter-compared bundles

\begin{tabular}{|c|c|c|c|c|}
\hline & $\begin{array}{l}\mathrm{Ox} \\
9 \times 9 \\
\end{array}$ & $\begin{array}{c}\mathrm{Ox} \\
10 \times 10 \\
\end{array}$ & $\begin{array}{l}\text { Hyd } \\
10 \times 10\end{array}$ & $\begin{array}{c}\text { Hyd } \\
12 \times 12\end{array}$ \\
\hline Fuel rod diameter $(\mathrm{cm})$ & $\mathrm{PI}^{(\mathrm{a})}$ & 1.0260 & 1.1176 & 0.9281 \\
\hline Fuel rod pitch $(\mathrm{cm})$ & “6 & 1.2950 & 1.45288 & 1.2065 \\
\hline Active flow area, bottom $\left(\times 10^{-3} \mathrm{~m}^{2}\right)$ & “ & 9.3000 & 11.38541 & 11.4859 \\
\hline Active flow area, top $\left(\times 10^{-3} \mathrm{~m}^{2}\right)$ & “" & 10.4575 & 11.38541 & 11.4859 \\
\hline $\mathrm{P} / \mathrm{D}$ & “" & 1.2622 & 1.3000 & 1.3000 \\
\hline Clad thickness $(\mathrm{cm})$ & “" & 0.0760 & 0.08164 & 0.06990 \\
\hline Fuel pellet diameter $(\mathrm{cm})$ & “" & 0.8600 & 0.91640 & 0.75709 \\
\hline Number of fuel rods per bundle & 70.67 & 86.17 & 96 & 140 \\
\hline $\begin{array}{l}\text { Control rods guide tube inner/outer } \\
\text { Diameter }(\mathrm{cm})\end{array}$ & NA & NA & $\begin{array}{l}1.3894 \\
1.2108\end{array}$ & $\begin{array}{l}1.2000 \\
1.0214\end{array}$ \\
\hline Number of Grid Spacers & 7 & 7 & 7 & 7 \\
\hline
\end{tabular}

(a) Proprietary Information

Table 8.4 compares performance characteristics of the hydride and oxide fuel bundles considered. It is found that the power attainable from the 10x10 hydride fuel bundle 
$(9917.8 \mathrm{~kW})$ is $38 \%$ higher than that of the $10 \times 10$ oxide fuel bundle $(7187.3 \mathrm{~kW})$. Part of this remarkable power gain is due to the larger number of fuel rods along with larger total cross section for coolant flow in the hydride fuel bundle achieved by eliminating water rods and minimizing the water gap width. An additional gain is due to the flatter BOL pin-wise power distribution across the hydride fuel bundle. A smaller power gain is expected from the hydride fuel in case the oxide fuel bundles could be designed to provide as flat a pin-wise power distribution. To quantify this effect consider the "Best Case" (BC) 10x10 oxide fuel bundle; it is identical in geometry and dimensions with the 10x10 oxide fuel bundle of the second column of Table 8.4 , but is fictitiously assumed to have the same pin-wise power distribution as of the 10x10 hydride fuel bundle.

Comparing the fourth and fifth columns of Table 8.4 it is seen that the hydride fuel power advantage is $29 \%$.

Table 8.4

Performance of bundles for $\chi_{\text {out }}=26.8 \%$ with none of the constraints exceeded

\begin{tabular}{|c|c|c|c|c|c|}
\hline & $\begin{array}{l}\text { Ox. } \\
9 \times 9\end{array}$ & $\begin{array}{l}\text { Ox. } \\
10 \times 10\end{array}$ & $\begin{array}{c}\mathrm{Ox} . \\
10 \times 10 \\
(\mathrm{BC})\end{array}$ & $\begin{array}{l}\text { Hyd } \\
10 \times 10\end{array}$ & $\begin{array}{l}\text { Hyd } \\
12 \times 12\end{array}$ \\
\hline Total flow rate $(\mathrm{kg} / \mathrm{s})$ & 16.975 & 18.530 & 19.845 & 22.861 & 22.385 \\
\hline Bundle active flow rate $(\mathrm{kg} / \mathrm{s})$ & 14.598 & 15.929 & 17.057 & 22.067 & 21.601 \\
\hline $\begin{array}{l}\text { Bundle pressure drop (psia) } \\
\text { (Constraint) }\end{array}$ & $\begin{array}{c}22.6 \\
(34.0)\end{array}$ & $\begin{array}{c}25.9 \\
(34.0)\end{array}$ & $\begin{array}{c}29.1 \\
(34.0)\end{array}$ & $\begin{array}{c}34.0 \\
(34.0) \\
\end{array}$ & $\begin{array}{c}34.0 \\
(34.0) \\
\end{array}$ \\
\hline $\begin{array}{l}\text { Max. peak fuel temperature }\left({ }^{\circ} \mathrm{C}\right) \\
\text { ( Constraint ) }\end{array}$ & $\begin{array}{l}2014.4 \\
(2805)\end{array}$ & $\begin{array}{l}1966.0 \\
(2805)\end{array}$ & $\begin{array}{l}1914.9 \\
(2805)\end{array}$ & $\begin{array}{l}568.1 \\
(750)\end{array}$ & $\begin{array}{l}480.9 \\
(750)\end{array}$ \\
\hline $\begin{array}{l}\text { Max. average fuel temperature }\left({ }^{\circ} \mathrm{C}\right) \\
\text { ( Constraint ) }\end{array}$ & $\begin{array}{l}1269.6 \\
(1400)\end{array}$ & $\begin{array}{l}1257.8 \\
(1400)\end{array}$ & $\begin{array}{l}1227.0 \\
(1400)\end{array}$ & NA & NA \\
\hline $\begin{array}{l}\text { Max. surface clad temperature }\left({ }^{\circ} \mathrm{C}\right) \\
\text { ( Constraint ) }\end{array}$ & $\begin{array}{l}313.3 \\
(349) \\
\end{array}$ & $\begin{array}{l}309.3 \\
(349)\end{array}$ & $\begin{array}{l}310.0 \\
(349)\end{array}$ & $\begin{array}{l}310.1 \\
(349)\end{array}$ & $\begin{array}{l}306.5 \\
(349) \\
\end{array}$ \\
\hline $\begin{array}{l}\text { MCPR } \\
\text { ( Constraint) }\end{array}$ & $\begin{array}{c}1.158 \\
(1.158)\end{array}$ & $\begin{array}{c}1.158 \\
(1.158) \\
\end{array}$ & $\begin{array}{c}1.158 \\
(1.158) \\
\end{array}$ & $\begin{array}{c}1.218 \\
(1.158)\end{array}$ & $\begin{array}{c}1.294 \\
(1.158)\end{array}$ \\
\hline Subchannel-averaged exit quality (\%) & 26.8 & 26.8 & 26.8 & 26.8 & 26.8 \\
\hline $\begin{array}{l}\text { Bundle Power }(\mathrm{kW}) \\
\% \text { difference vs. Reference }\end{array}$ & $\begin{array}{c}6567.7 \\
0\end{array}$ & $\begin{array}{c}7187.3 \\
+9.4\end{array}$ & $\begin{array}{l}7697.5 \\
+17.2 \\
\end{array}$ & $\begin{array}{r}9917.8 \\
+51.0 \\
\end{array}$ & $\begin{array}{r}9703.7 \\
+47.7 \\
\end{array}$ \\
\hline
\end{tabular}


What limits the $10 \times 10$ hydride fuel bundle power level is the pressure drop constraint whereas the 10x10 oxide fuel bundle power is limited by the MCPR constraint. Due to the pressure drop constraint the $12 \times 12$ hydride fuel bundle of Table 8.4 does not offer any power gain relative to the $10 \times 10$ hydride fuel bundle. Table 8.5 compares the attainable power from the bundles considered in case the pressure drop constraint is ignored, but all other constraints are imposed. The resulting relative gain offered by the $10 x 10$ hydride fuel bundle is significant; $53 \%$ or $43 \%$ more power than that attainable from the $10 \times 10$ oxide fuel bundle having, respectively, a contemporary or a "Best Case" pin-wise power distribution. It is also found that the power attainable from the $12 \times 12$ hydride fuel bundle is $11 \%$ larger than that attainable from the $10 \times 10$ hydride fuel bundle, provided a larger pressure drop can be accommodated.

Table 8.5

Performance of bundles for $x_{\text {out }}=26.8 \%$ and MCHFR $=1.158$. Pressure drop constraint ignored

\begin{tabular}{|c|c|c|c|c|c|}
\hline & $\begin{array}{l}\text { Oxide } \\
9 \times 9\end{array}$ & $\begin{array}{l}\text { Ox. } \\
10 \times 10\end{array}$ & $\begin{array}{c}\text { Ox. } \\
10 \times 10 \\
(\mathrm{BC}) \\
\end{array}$ & $\begin{array}{l}\text { Hyd } \\
10 \times 10\end{array}$ & $\begin{array}{l}\text { Hyd } \\
12 \times 12\end{array}$ \\
\hline Total flow rate $(\mathrm{kg} / \mathrm{s})$ & 16.975 & 18.530 & 19.845 & 25.311 & 28.178 \\
\hline Bundle active flow rate $(\mathrm{kg} / \mathrm{s})$ & 14.598 & 15.928 & 17.057 & 24.429 & 27.196 \\
\hline $\begin{array}{l}\text { Bundle pressure drop (psia) } \\
\text { (Constraint) }\end{array}$ & $\begin{array}{c}22.6 \\
(34.0)\end{array}$ & $\begin{array}{c}25.9 \\
(34.0)\end{array}$ & $\begin{array}{c}29.1 \\
(34.0)\end{array}$ & $\begin{array}{c}40.6 \\
(34.0) \\
\end{array}$ & $\begin{array}{c}50.6 \\
(34.0)\end{array}$ \\
\hline $\begin{array}{l}\text { Max. peak fuel temperature }\left({ }^{\circ} \mathrm{C}\right) \\
\text { ( Constraint ) }\end{array}$ & $\begin{array}{l}2014.4 \\
(2805)\end{array}$ & $\begin{array}{l}1966.0 \\
(2805)\end{array}$ & $\begin{array}{l}1914.9 \\
(2805)\end{array}$ & $\begin{array}{l}597.3 \\
(750)\end{array}$ & $\begin{array}{l}529.8 \\
(750)\end{array}$ \\
\hline $\begin{array}{l}\text { Max. average fuel temperature }\left({ }^{\circ} \mathrm{C}\right) \\
\text { ( Constraint ) }\end{array}$ & $\begin{array}{l}1269.6 \\
(1400)\end{array}$ & $\begin{array}{l}1257.8 \\
(1400)\end{array}$ & $\begin{array}{l}1227.0 \\
(1400)\end{array}$ & NA & NA \\
\hline $\begin{array}{l}\text { Max. surface clad temperature }\left({ }^{\circ} \mathrm{C} \text { ) }\right. \\
\text { ( Constraint ) }\end{array}$ & $\begin{array}{l}313.3 \\
(349)\end{array}$ & $\begin{array}{l}309.3 \\
(349)\end{array}$ & $\begin{array}{l}310.0 \\
(349)\end{array}$ & $\begin{array}{l}311.9 \\
(349)\end{array}$ & $\begin{array}{l}310.3 \\
(349)\end{array}$ \\
\hline $\begin{array}{l}\text { MCPR } \\
\text { ( Constraint) }\end{array}$ & $\begin{array}{c}1.158 \\
(1.158)\end{array}$ & $\begin{array}{l}1.158 \\
(1.158)\end{array}$ & $\begin{array}{l}1.158 \\
(1.158)\end{array}$ & $\begin{array}{l}1.158 \\
(1.158)\end{array}$ & $\begin{array}{c}1.158 \\
(1.158)\end{array}$ \\
\hline Subchannel-averaged exit quality (\%) & 26.8 & 26.8 & 26.8 & 26.8 & 26.8 \\
\hline $\begin{array}{l}\text { Bundle Power (kW) } \\
\% \text { difference vs. Reference }\end{array}$ & $\begin{array}{c}6568 \\
0\end{array}$ & $\begin{array}{r}7187 \\
+9.4\end{array}$ & $\begin{array}{r}7698 \\
+17.2 \\
\end{array}$ & $\begin{array}{r}10980 \\
+67.2\end{array}$ & $\begin{array}{l}12215 \\
+86.0\end{array}$ \\
\hline
\end{tabular}


Table 8.6 compares the performance expected from the considered bundles if instead of not considering the pressure drop as a constraint, the exit steam quality is not considered as a constraint; the pressure drop is set to 34 psia for all designs. Under this set of assumptions the $10 \times 10$ hydride bundle attainable power is higher than that of the 10x10 oxide fuel bundle by $28 \%$ to $33 \%$. The $12 \times 12$ hydride bundle power exceeds that of the 10x10 hydride fuel bundle by $11 \%$.

Table 8.6

Performance of bundles for $\Delta \mathrm{P}=34 \mathrm{psia}$ and $\mathrm{MCHFR}=1.158$. Exit quality constraint ignored

\begin{tabular}{|c|c|c|c|c|c|}
\hline & $\begin{array}{l}\text { Oxide } \\
9 \times 9\end{array}$ & $\begin{array}{l}\text { Oxide } \\
10 \times 10\end{array}$ & $\begin{array}{c}\text { Oxide } \\
10 \times 10 \\
(\mathrm{BC})\end{array}$ & $\begin{array}{l}\text { Hyd } \\
10 \times 10\end{array}$ & $\begin{array}{l}\text { Hyd } \\
12 \times 12\end{array}$ \\
\hline Bundle active flow rate $(\mathrm{kg} / \mathrm{s})$ & 19.410 & 19.176 & 18.975 & 21.690 & 20.749 \\
\hline $\begin{array}{l}\text { Bundle pressure drop (psia) } \\
\text { (Constraint) }\end{array}$ & $\begin{array}{c}34.0 \\
(34.0) \\
\end{array}$ & $\begin{array}{c}34.0 \\
(34.0) \\
\end{array}$ & $\begin{array}{c}34.0 \\
(34.0) \\
\end{array}$ & $\begin{array}{c}34.0 \\
(34.0) \\
\end{array}$ & $\begin{array}{c}34.0 \\
(34.0) \\
\end{array}$ \\
\hline $\begin{array}{l}\text { Max. peak fuel temperature }\left({ }^{\circ} \mathrm{C}\right) \\
\text { ( Constraint ) }\end{array}$ & $\begin{array}{l}2215.7 \\
(2805)\end{array}$ & $\begin{array}{l}2126.4 \\
(2805)\end{array}$ & $\begin{array}{l}2004.4 \\
(2805)\end{array}$ & $\begin{array}{l}579.7 \\
(750)\end{array}$ & $\begin{array}{l}498.2 \\
(750)\end{array}$ \\
\hline $\begin{array}{l}\text { Max. average fuel temperature }\left({ }^{\circ} \mathrm{C}\right) \\
\text { ( Constraint ) }\end{array}$ & $\begin{array}{l}1399.3 \\
(1400)\end{array}$ & $\begin{array}{l}1359.7 \\
(1400)\end{array}$ & $\begin{array}{l}1281.6 \\
(1400)\end{array}$ & NA & NA \\
\hline $\begin{array}{l}\text { Max. surface clad temperature }\left({ }^{\circ} \mathrm{C}\right) \\
\text { ( Constraint ) }\end{array}$ & $\begin{array}{l}313.0 \\
(349)\end{array}$ & $\begin{array}{l}310.8 \\
(349)\end{array}$ & $\begin{array}{l}310.8 \\
(349)\end{array}$ & $\begin{array}{l}310.7 \\
(349)\end{array}$ & $\begin{array}{l}307.7 \\
(349)\end{array}$ \\
\hline $\begin{array}{l}\text { MCPR } \\
\text { ( Constraint ) }\end{array}$ & $\begin{array}{c}1.179 \\
(1.158)\end{array}$ & $\begin{array}{c}1.158 \\
(1.158)\end{array}$ & $\begin{array}{c}1.158 \\
(1.158)\end{array}$ & $\begin{array}{c}1.158 \\
(1.158)\end{array}$ & $\begin{array}{c}1.158 \\
(1.158)\end{array}$ \\
\hline Subchannel-averaged exit quality (\%) & 21.8 & 23.8 & 25.0 & 28.6 & 30.9 \\
\hline Bundle Power $(\mathrm{kW})$ & 7259 & 7788 & 8050 & 10344 & 10605 \\
\hline$\%$ difference vs. Reference & +10.5 & +18.5 & +22.6 & +57.5 & +61.5 \\
\hline$\%$ difference vs. $9 \times 9$ oxide " 34 psia" & 0.0 & +7.3 & +10.9 & +42.5 & +46.1 \\
\hline
\end{tabular}

\subsection{Discussion}

It is found possible to design hydride fuel bundles for the BWR's that are significantly less heterogeneous than present day oxide fuel bundles and that can operate at a remarkably higher power density without violating any of the steady-state design constraints used for BWR's, provided the core coolant pressure drop could be increased from the reference BWR design value. Three factors contribute to the advantageous 
thermal-hydraulic performance of the hydride fuel: (a) larger total clad surface area per core volume - either larger number of fuel rods of comparable diameter or same number of fuel rods of larger diameter; (b) larger coolant flow area per fuel bundle; and (c) flatter pin-wise power distribution.

The higher power density of hydride fuel cores could be used either to increase the total power attainable from a given core volume or a given reactor vessel volume, or to reduce the length (or volume) of the core. The former approach may be of interest for a new generation of ABWR whereas the latter approach may become of interest to the ESBWR .

The hydride fuel bundles have greater discharge burnup but reduced HM inventory per bundle. Consequently, the hydride fuel need have higher uranium enrichment to provide the reference cycle length. A potentially promising approach for obtaining long cycles is to use thorium-containing hydride fuels ${ }^{6}$ not examined in the present work; the HM contents of thorium-based hydride fuel is more than double that of the $\mathrm{U}-\mathrm{ThH}_{1.6}$ fuel considered in this work; it is even larger than that of oxide fuel.

The fuel temperature coefficient of reactivity of the hydride fuel bundle designs considered is more negative than that of the reference oxide fuel bundle whereas the void coefficient of reactivity of the hydride fuel bundle is less negative. These trends are expected to enhance the safety and improve the stability of hydride fueled BWR's. Adequate shutdown margin can be provided by incorporating four $\mathrm{B}_{4} \mathrm{C}$ control rods per 10x10 hydride fuel bundle.

The feasibility study need be refined and extended before sound conclusions could be withdrawn on the possible benefits from using hydride fueled BWR cores. 
Future undertakings should include coupled neutronic - thermal hydraulic analysis, transients and accidents analysis, as well as economic analysis. A number of important feasibility issues need to be assessed including (1) elimination of large water gaps around the fuel bundles and the replacement of cruciform control blades by clusters of control rods. (2) Compatibility of hydride fuel with BWR water and clad. 


\section{Summary and recommendations}

The feasibility study reported in this overview paper and detailed in the set of 10 accompanying topical papers has established that hydride fuel can safely operate in PWR's and BWR's without restricting the linear heat generation rate of these reactors relative to that attainable with oxide fuel. However, the study performed addressed design performance feasibility issues but could not consider important material compatibility issues, including the compatibility of hydride fuel with PWR and BWR coolants and clad. These material compatibility issues need be experimentally addressed before a sound conclusion could be drawn on the desirability of developing hydride fuel for commercial LWR's.

The study identified a couple of promising applications of hydride fuel in both PWR's and BWR's:

(1) Eliminating dedicated water moderator volumes in BWR cores thus enabling to significantly increase the cooled fuel rods surface area as well as the coolant flow cross section area in a given volume fuel bundle while significantly reducing the heterogeneity of BWR fuel bundles thus achieving flatter pin-by-pin power distribution. The net result is a possibility to significantly increase the core power density - on the order of $30 \%$ and, possibly, more, while greatly simplifying the fuel bundle design. Implementation of the above modifications is, though, not straightforward; it requires a design of completely different control system that could probably be implemented only in newly designed plants. It also requires increasing the coolant pressure drop across the core. 
(2) Recycling plutonium in PWR's more effectively than is possible with oxide fuel by virtue of a couple of unique features of hydride fuel - reduced inventory of ${ }^{238} \mathrm{U}$ and increased inventory of hydrogen. As a result of these features, the amount of Pu that needs to be loaded into the hydride core to provide the reference cycle length is only $75 \%$ that is needed for MOX cores, and the hydride core neutron spectrum is softer. Due to these characteristics, the hydride fuelled core achieves nearly double the average discharge burnup - about 103 vs. 50 GWD/MTHM of MOX. The total Pu inventory in the discharged PUZH fuel is only $43 \%$ of the initially loaded inventory versus $73 \%$ in the discharged MOX fuel. The net amount of Pu consumed per cycle is $60 \%$ larger with PUZH versus MOX fuel. The corresponding fissile Pu to total Pu ratio is $44 \%$ versus $63 \%$. The corresponding ratio of minor actinides (MA) to Pu concentration at discharge is $13.25 \%$ versus $6.76 \%$. The total neutron source strength at discharge of PUZH fuel is $1250 \mathrm{n} / \mathrm{s}$ per gram of $\mathrm{Pu}$ and $5.25 \times 10^{5} \mathrm{n} / \mathrm{s}$ per gram of TRU versus, respectively, $796 \mathrm{n} / \mathrm{s}$ and $2.23 \times 10^{5} \mathrm{n} / \mathrm{s}$ for MOX fuel. The decay heat levels are $2.35 \mathrm{w} / \mathrm{gTRU}$ for PUZH and $1.19 \mathrm{w} / \mathrm{gTRU}$ for MOX fuel. Nevertheless, the decay heat and radiation levels per PUZH fuel assembly discharged are smaller than for MOX fuel assembly.

Even though not studied in this project, we expect that use of hydride fuel will also significantly improve the capability of BWR's to recycle plutonium. Likewise, even though not considered in this project, we expect that hydride fuel will also significantly improve the MA recycling capability of PWR's and BWR's. 
Possible new reactor design concepts were arrived at during the project based on the results generated in this study and the insight provided by these results:

(1) Inverted core design in which the hydride fuel is made of hexagonal fuel prisms through which penetrate cylindrical water coolant channels arranged in a hexagonal array. Hydride fuel makes such a geometry feasible by virtue of its fabrication process - it is first cast as a metal alloy in the desirable shape, and then turned into hydride by diffusion of hydrogen it is exposed to. The inverted geometry features reduced coolant friction losses for a given fuel-to-coolant volume ratio relative to conventional core designs featuring cylindrical fuel rods held in place by grid spacers. This latter feature enables designing the inverted core to have a larger fuel volume fraction, a feature of particular benefit for hydride fuel. However, for the core coolant pressure drop considered, the attainable power density of the inverted geometry was found to be lower than desirable.

(2) Hexagonally shaped fuel assemblies housing hexagonal lattice of fuel rods with wire wrap support as considered for many liquid metal cooled fast reactor designs. This is similar to the Russian PWR (VVER) design approach except that wire wraps are used instead of grid spacers. This design approach features significantly lower pressure drop than the conventional grid spacer design at, especially, the high fuel volume fraction design range - a range that was expected to be preferred for hydride fuel. Unfortunately, it was found that at the coolant pressure range considered in this study, hydride fuel was not advantageous to oxide fuel. 
(3) BWR having hydride fuel made of deuterium at the lower part of the core, and made of regular hydrogen at the upper part of the core. This design approach is expected to enable designing BWR cores to have more uniform axial distribution of $\mathrm{H}$ and, therefore, more uniform moderation and more symmetric axial power distribution. This design approach has not been analyzed, as yet.

(4) HWR in which the oxide fuel is replaced by hydride fuel, thereby enabling to significantly reduce the heavy water moderator inventory and the reactor capital cost. Alternatively, it may be possible to replace the $\mathrm{D}_{2} \mathrm{O}$ moderator by graphite without having to increase the pitch between the pressure tubes, that is, the reactor volume while providing sufficient distance between the pressure tubes to provide convenient access for the on-line refueling machines. In case that graphite is used for the moderator, no calandria tubes may be required, further simplifying the design. This reactor concept has not been studied, as yet.

(5) PWR that uses $\mathrm{U}-\mathrm{ZrH}_{1.6}$ or, even better, $\mathrm{U}-\mathrm{ZrH}_{1.6}-\mathrm{ThH}_{2}$ as "driver fuel" in part of the core, and $\mathrm{TRuH}_{2}-\mathrm{ZrH}_{2}$ as "incinerating fuel" in another part of the core. The driver fuel will use $20 \%$ enriched uranium while the incinerating fuel is a hydride version of an "inert-matrix" fuel. The TRu to be loaded in this incinerating fuel include all the plutonium and minor actinides to be generated in the driver fuel. Alternatively, $\mathrm{PuH}_{2}-\mathrm{U}-\mathrm{ZrH}_{1.6}-\mathrm{ThH}_{2}$ could be used for the driver fuel for enhanced incineration of the $\mathrm{Pu}$.

Additional contributions of this work include the following:

(6) The optimal oxide fueled PWR core design features smaller fuel rod diameter of $6.5 \mathrm{~mm}$ and a larger $\mathrm{P} / \mathrm{D}$ ratio of 1.39 than presently practiced by industry - 
typically $9.5 \mathrm{~mm}$ and 1.326 . This optimal design can provide a $30 \%$ increase in the power density and a $24 \%$ reduction in the cost of electricity $(\mathrm{COE})$ provided the PWR could be designed to have the coolant pressure drop across the core increased from the reference 29 psia to 60 psia.

(7) Using wire wrapped oxide fuel rods in hexagonal fuel assemblies it is possible to design PWR cores to operate at 54\% higher power density than the reference PWR design that uses grid spacers and a square lattice, provided 60 psia coolant pressure drop across the core could be accommodated. Uprating existing PWR's to use such cores could result in $40 \%$ reduction in the COE. The optimal lattice geometry is $\mathrm{D}=8.08 \mathrm{~mm}$ and $\mathrm{P} / \mathrm{D}=1.41$. The most notable advantages of wire wraps over grid spacers are their significant lower pressure drop, higher critical heat flux and improved vibrations characteristics.

(8) U- $\mathrm{ZrH}_{1.6}$ fueled PWR cores have positive coolant temperature coefficient of reactivity in the $\mathrm{D}-\mathrm{P}$ design range offering peak power. Three approaches that can turn over the CTC to be negative were identified:

a. Use of erbium burnable poison.

b. Replacement of some of the $\mathrm{ZrH}_{1.6}$ by $\mathrm{ThH}_{2}$

c. Using plutonium rather than enriched uranium as the primary fissile material Of the three, use of erbium is the least desirable as it penalizes the attainable discharge burnup, even if the erbium is enriched with the isotope ${ }^{167} \mathrm{Er}$. Replacement of some of the Zr hydride by Th hydride can, actually, somewhat 
increase the attainable discharge burnup. The use of plutonium is also effective but is practical only when Pu recycling is desirable.

(9) The BOL prompt reactivity feedback due to fuel temperature increase is more negative when using $\mathrm{U}-\mathrm{ZrH}_{1.6}$ fuel than when using $\mathrm{UO}_{2}$ fuel due to a unique feature of hydride fuel - spectrum hardening due to fuel hydrogen temperature increase. This prompt spectrum hardening effect is superimposed on and enhances the Doppler effect.

(10) However, the EOL prompt reactivity feedback is not as negative as is the BOL feedback because of the buildup of ${ }^{239} \mathrm{Pu}$.

(11) The void reactivity feedback of hydride fueled BWR fuel assemblies is not as negative with hydride fuel as it is with oxide fuel. This is expected to have stability and safety benefits but the quantification of these benefits was out of the scope of this work.

(12) The transmutation capability of inert matrix hydride fuel $\mathrm{PuH}_{2}-\mathrm{ZrH}_{1.6}$ is constrained by positive reactivity coefficients. However, using $\mathrm{PuH}_{2}-\mathrm{ThH}_{2}$ fuel (with some depleted uranium added for denaturing the ${ }^{233} \mathrm{U}$ ) it is possible to transmute at least $62.5 \%$ of the loaded plutonium in one recycle in PWR, using uniform composition fuel assemblies. Further optimization is required to identify maximum fractional transmutation using hydride fuel. 


\section{REFERENCES}

Diller, P., Todreas, N. and Hejzlar, P., 2007. Thermal hydraulic analysis for wire wrapped PWR cores. Nucl. Eng. Des. To be published.

Ferroni, P., Handwerk, C. and Todreas, N., 2007. Thermal hydraulic for grid supported BWR cores. Nucl. Eng. Des. To be published.

Fratoni, M., Ginex, F., Ganda, F. and Greenspan E., 2007. Reactor Physics Analysis for BWR Cores. Nucl. Eng. Des. To be published.

Ganda, F., Greenspan, E. and Petrovic, B., 2007a. Reactor physics analysis for PWR cores. Nucl. Eng. Des. To be published.

Ganda, F., Shuffler, C. and Greenspan, E., 2007b. Economic analysis for BWRs. Nucl. Eng. Des. To be published.

Ganda, F. and Greenspan, E., 2007c. Plutonium recycling in hydride fueled PWR cores. Nucl. Eng. Des. To be published.

Ganda, F. and Greenspan, E., 2005a. Incineration of Pu in PWR using hydride fuel. Proc. International Conference on Advances in Nuclear Power Plants; ICAPP-2005, Seoul, Korea.

Ganda, F. and Greenspan, E., 2005b. Plutonium incineration capability of hydride versus MOX fuel in PWR. Proceedings of GLOBAL'05, Tsukuba, Japan, October 9-13, 2005.

Ganda, F. and Greenspan, E., 2005c. a simplified method for multi-batch PWR core analysis based on SAS2H unit cell calculations, Proc. Int. Mtg. Mathematics and Computation - MC2005, Avignon, France.

Ganda, F., Barnes D. and Greenspan, E., 2005d. OECD benchmark A \& B of MOX fueled PWR unit cells using SAS2H, Proc. Int. Mtg. Mathematics and Computation MC2005, Avignon, France.

Greenspan, E., Todreas, N. and Petrovic, B. 2002. Use of solid hydride for improved long-life LWR core designs, NERI Project Number 02-189.

Greenspan, E., Garkisch, H., Malen, J., Moalem, M., Olander, D., Petrovic, B., Shayer, Z. and Todreas, N., 2003. Preliminary assessment of possibilities for improving the performance of LWRs using hydride fuel. Transactions American Nuclear Society, 89, 381-382.

Greenspan, E., Ganda, F., Garkisch, H., Malen, J., Petrovic, B., Romano, A., Shayer, Z., Shuffler, C., Todreas, N. and Trant, J., 2005. Optimization of $\mathrm{UO}_{2}$ fueled PWR core design. Proc. International Conference on Advances in Nuclear Power Plants; ICAPP- 
2005, Seoul, Korea.

Greenspan, E., Todreas, N., Petrovic, B., Diller, P., Ferroni, P., Fratoni, M., Ganda, F., Garkisch, H., Ginex, F., Malen, J., Olander, D., Romano, A., Shuffler, C. and Trant, J., Hydride fuel for LWR's - project overview, Nucl. Eng. Des. To be published.

Iorgulis, C., Ciocanescu, M., Preda, M. and Mladin, M., October 1998. Neutronic calculations regarding the new LEU $6 \times 6$ fuel bundle for 14 MW TRIGA-SSR, in order to increase the reactor power up to $21 \mathrm{MW}$. Int. Mtg. on Reduced Enrichment for Research and Test Reactors, Sao Paulo, Brazil.

Malen, J. A., Todreas, N. E. and Romano, A., 2004a. Thermal hydraulic design of hydride fueled PWR cores. Proc. $6^{\text {th }}$ Int. Conf. on Nuclear Thermal Hydraulics,NUTHOS-6, Nara, Japan.

Malen, J. A., Todreas, N. E. and Romano, A., March 2004b. Thermal hydraulic design of hydride fueled PWR cores. MIT Department of Nuclear Science and Engineering Report MIT-NFC-TR-062.

Nine Mile Point Unit 2, Updated Safety Analysis Report (USAR), Rev.16, October 2004.

OECD/NEA, 1994. The Economics of the Nuclear Fuel Cycle," OECD Publications, Paris.

Olander, D., Garkisch, H., Petrovic, B. and Greenspan, E., 2007. Hydride fuel materials performance and design constraints. Nucl. Eng. Des. To be published.

Romano, A., Shuffler, C., Garkisch, H., Olander, D. and Todreas, N., 2007. Fuel performance analysis for PWR cores. Nucl. Eng. Des. To be published.

Saccheri, J., August 2003. A tight lattice epithermal core design for the integral PWR, Ph.D. Dissertation, Department of Nuclear Engineering, MIT.

Simnad, M. T., August 1981. The U-ZrH $\mathrm{Zn}_{\mathrm{x}}$ alloy: its properties and use in TRIGA fuel, Nucl. Eng. Design, 64, 403-422. Also General Atomic Report GA-A16029, 1980.

M.T. Simnad, 1986b. An Assessment of Thorium Hydride or Deutride as a Reactor Fuel Matrix, Reprint from the archives of Prof. Mike Driscoll of MIT Nuclear Engineering Department.

Shayer, Z. and Greenspan, E., 2004. Physics of U-ZrH $\mathrm{Zr}_{1.6}$ fuel in PWR. Proc. of the Reactor Physics Topical Meeting, PHYSOR-2004, Chicago, IL.

Shuffler, C.A., August 2004. Optimization of hydride fueled pressurized water reactor cores" M.Sc. Dissertation, MIT Department of Nuclear Engineering. 
Shuffler, C., Malen, J., Trant, J. and Todreas, N., 2007a. Thermal hydraulic analysis for grid supported and inverted fueled PWR cores. Nucl. Eng. Des. To be published.

Shuffler, C., Malen, J., Diller, P., Ganda, F., Todreas, N. Greenspan E. and Petrovic, B., 2007b. Economic analysis for PWRs. Nucl. Eng. Des. To be published.

Shwageraus, E., Hejzlar P. and Kazimi, M.S., 2003. Feasibility of multirecycling of $\mathrm{Pu}$ and MA in PWRs using combined non-fertile and $\mathrm{UO}_{2}$ (CONFU) fuel, Proc. GLOBAL'03, New Orleans, LA.

Taiwo, T.A., Kim, T.K., Stillman, J.A., Hill, R.N., Salvatores, M. and Finck, P.J., 2003. Assessment of a heterogeneous PWR assembly for plutonium and minor actinides recycle, Proc. GLOBAL'03, New Orleans, LA.

Todreas, N., Greenspan, E., Petrovic, B., Diller, P. Ferroni, P., Fratoni, M., Ganda, F., Garkisch, H., Ginex, F., Malen, J., Olander, D., Romano, A., Shuffler, C. and Trant, J., 2007. Optimal Oxide Fueled PWR and BWR Core Designs. Nucl. Eng. Des. To be published.

Trant, J. M., August 2004. Transient analysis of hydride fueled pressurized water reactor cores, M.Sc. Dissertation, MIT Department of Nuclear Engineering.

Trellue, H. R., 2004. Neutronic and logistic proposal for transmutation of plutonium from spent nuclear fuel as mixed-oxide fuel in existing light-water reactors, Nucl. Tech. 147.

Tsuchiya, B., Huang, J., Konashi, K., Saiki, W., Onoue, T. and Yamawaki, M., 2000. Thermal diffusivity measurement of uranium-thorium-zirconium hydride, J. Alloys Comps. 312, 104-110.

Yamawaki, M., Suwarno, H., Yamamoto, T., Ono F., Yamaguchi K. and Kayano, H., 1997. Development of MA-containing hydride fuel as MA burning target material, Proc. Int. Conf. on Future Nuclear Systems, GLOBAL'97, Yokohama, Japan.

Yamamoto, T., Suwarno, H., Ono, F., Kayano, H. and Yamawaki, M., 1998. Preparation, analysis and irradiation of hydrided U-Th-Zr alloy samples for a new fuel, J. Alloys Compds. 271-273, 702-726.

Yamawaki, M. et al., 1999. Development of U-Th-Zr alloy hydrides as alternative thorium-base fuel and MA burning target fuel, Proc. Int. Conf. on Future Nuclear Systems, GLOBAL'99, Jackson Hole, Wy.

Youinou, G., Zaetta, A., Vasile, A., Delpech, M., Rohart, M. and Guillet, J.L., 2001. Heterogeneous assembly for plutonium multirecycling in PWRs: The CORAIL concept, Proc. Global' 01, Paris, France. 


\section{APPENDIX I}

Papers to be Submitted to the Journal Nuclear Engineering and Design

1. Hydride Fuel for LWR's - Project Overview

E. Greenspan, N. Todreas, Petrovic, P. Diller, P. Ferroni, M. Fratoni, F. Ganda, H.

Garkisch, F. Ginex, J. Malen, D. Olander, A. Romano, C. Shuffler, J. Trant

2. Hydride Fuel Materials Performance and Design Constraints

D. Olander, H. Garkisch, B. Petrovic and E. Greenspan

3. Reactor Physics Analysis for PWR Cores

F. Ganda, E. Greenspan and B. Petrovic

4. Thermal Hydraulic Analysis for Grid Supported and Inverted Fueled PWR

Cores

C. Shuffler, J. Malen, J. Trant and N. Todreas

5. Thermal Hydraulic Analysis for Wire Wrapped PWR Cores

P. Diller, N. Todreas and P. Hejzlar

6. Fuel Performance Analysis for PWR Cores

A. Romano, C. Shuffler, H. Garkisch, D. Olander and N. Todreas

7. Economic Analysis for PWR's

C. Shuffler, J. Malen, P. Diller, F. Ganda, N. Todreas, E. Greenspan and B. Petrovic

8. Reactor Physics Analysis for BWR Cores

M. Fratoni, F. Ginex, F. Ganda and E. Greenspan

9. Thermal Hydraulic for Grid Supported BWR Cores

P. Ferroni, C. Handwerk and N. Todreas

10. Economic Analysis for BWR's

F. Ganda, C. Shuffler and E. Greenspan

11. Plutonium Recycling in Hydride Fueled PWR Cores

F. Ganda and E. Greenspan

12. Optimal Oxide Fueled PWR and BWR Core Designs

N. Todreas, E. Greenspan, B. Petrovic, P. Diller, P. Ferroni, M. Fratoni, F. Ganda, H. Garkisch, F. Ginex, J. Malen, D. Olander, A. Romano, C. Shuffler, J. Trant 


\section{APPENDIX II}

\section{Papers Published or to be Published in Conference Proceedings}

E. Greenspan, H. Garkisch, J. Malen, M. Moalem, D. Olander, B. Petrovic, Z. Shayer and

N. Todreas, "Preliminary Assessment of Possibilities for Improving the Performance of LWR's Using Hydride Fuel," American Nuclear Society, 89, 381-382, November 2003.

J. A. Malen, N. E. Todreas and A. Romano, "Thermal Hydraulic Design of Hydride Fueled Pressurized Water Reactor Cores", MIT Nuclear Fuel Cycle Technology and Policy Program Report MIT-NFC-TR-062, March 2004.

Z. Shayer and E. Greenspan, "Physics of U-Z $\mathrm{ZrH}_{1.6}$ Fuel in PWR," Proc. Reactor Physics Topical Meeting, PHYSOR-2004, Chicago, IL, April 2004.

C. A. Shuffler, "Optimization of Hydride Fueled Pressurized Water Reactor Cores" M.Sc. Dissertation, MIT Department of Nuclear Engineering, August 2004.

J. M. Trant, "Transient Analysis of Hydride Fueled Pressurized Water Reactor Cores," M.Sc. Dissertation, MIT Department of Nuclear Engineering, August 2004.

J. A. Malen, N. E. Todreas, A. Romano, "Thermal Hydraulic Design of Hydride Fueled PWR Cores," Proc. $6^{\text {th }}$ Int. Conf. on Nuclear Thermal Hydraulics,NUTHOS-6, Nara, Japan, October 4-8, 2004. Paper ID: N6P216.

E. Greenspan, F. Ganda, H. Garkisch, J. Malen, B. Petrovic, A. Romano, Z. Shayer, C. Shuffler, N. Todreas and J. Trant, "Optimization of $\mathrm{UO}_{2}$ Fueled PWR Core Design", Proc. 2005 International Conference on Advances in Nuclear Power Plants; ICAPP2005, Seoul, Korea, May 15-19, 2005.

F. Ganda, E. Greenspan, "Incineration of Pu in PWR Using Hydride Fuel," Proc. 2005 International Conference on Advances in Nuclear Power Plants; ICAPP-2005, Seoul, Korea, May 15-19, 2005.

F. Ganda and E. Greenspan, "A Simplified Method for Multi-Batch PWR Core Analysis Based on SAS2H Unit Cell Calculations," Submitted for the Int. Mtg. Mathematics and Computation - MC2005, Avignon, France, September 12-15, 2005.

F. Ganda, D. Barnes and E. Greenspan, "OECD Benchmark A \& B of MOX Fueled PWR Unit Cells Using SAS2H," Submitted for the Int. Mtg. Mathematics and Computation MC2005, Avignon, France, September 12-15, 2005.

F. Ganda and E. Greenspan, "Plutonium Incineration Capability of Hydride Versus MOX Fuel in PWR" Proceedings of GLOBAL'05, Tsukuba, Japan, October 9-13, 2005.

C.A. Shuffler, A. Romano, N.E. Todreas, and J.M. Trant, "Thermal Hydraulic and Economic Analysis of Grid Supported Hydride Fueled PWR's", MIT-NFC-TR-077, MIT, Department of Nuclear Science and Engineering, (January 2006). 